\title{
Sexually dimorphic placental responses to maternal SARS-CoV-2 infection
}

Evan A Bordt ${ }^{1 *}$, Lydia L Shook ${ }^{2,3 *}$, Caroline Atyeo $^{4,5 *}$, Krista M Pullen $^{6 *}$, Rose M De Guzman $^{2,3}$, MarieCharlotte Meinsohn ${ }^{7}$, Maeva Chauvin ${ }^{7}$, Stephanie Fischinger ${ }^{4}$, Laura J. Yockey ${ }^{2,8}$, Kaitlyn James ${ }^{2}$, Rosiane Lima $^{9}$, Lael M Yonker ${ }^{9}$, Alessio Fasano ${ }^{9,10}$, Sara Brigida ${ }^{2,3}$, Lisa M Bebell ${ }^{11}$, Drucilla J Roberts ${ }^{12}$, David Pépin ${ }^{7}$, Jun R Huh ${ }^{13,14}$, Staci D Bilbo ${ }^{1,15}$, Jonathan Z Li ${ }^{16}$, Anjali Kaimal ${ }^{2}$, Danny Schust ${ }^{17}$, Kathryn J Gray ${ }^{18}$, Douglas Lauffenburger $^{6}$, Galit Alter ${ }^{4}$, Andrea G Edlow ${ }^{2,3}$

${ }^{1}$ Department of Pediatrics, Lurie Center for Autism, Massachusetts General Hospital, Harvard Medical School, Boston, MA, USA.

${ }^{2}$ Department of Obstetrics and Gynecology, Massachusetts General Hospital, Harvard Medical School, Boston, MA, USA

${ }^{3}$ Vincent Center for Reproductive Biology, Massachusetts General Hospital, Boston, MA, USA

${ }^{4}$ Ragon Institute of MGH, MIT, and Harvard, Cambridge, MA, USA

${ }^{5} \mathrm{PhD}$ Program in Virology, Division of Medical Sciences, Harvard University, Boston, MA, USA

${ }^{6}$ Department of Biological Engineering, Massachusetts Institute of Technology, Cambridge, MA, USA

${ }^{7}$ Pediatric Surgical Research Laboratories, Department of Surgery, Massachusetts General Hospital, Harvard Medical School, Boston, MA 02114, USA

${ }^{8}$ Department of Medicine, Massachusetts General Hospital, Harvard Medical School, Boston, MA, USA

${ }^{9}$ Mucosal Immunology and Biology Research Center, Massachusetts General Hospital, Boston, MA; Department of Pediatrics, Massachusetts General Hospital, Boston, MA; Harvard Medical School, Boston, MA, USA.

${ }^{10}$ European Biomedical Research Institute of Salerno (EBRIS), Salerno, Italy.

${ }^{11}$ Department of Medicine, Massachusetts General Hospital and Harvard Medical School, Boston, MA USA

${ }^{12}$ Department of Pathology, Massachusetts General Hospital, Harvard Medical School, Boston, MA, USA

${ }^{13}$ Department of Immunology, Blavatnik Institute, Harvard Medical School, Boston, MA, USA

${ }^{14}$ Evergrande Center for Immunologic Diseases, Harvard Medical School and Brigham and Women's Hospital, Boston, MA, USA

${ }^{15}$ Duke University, Department of Psychology and Neuroscience, Durham, NC, USA

${ }^{16}$ Department of Medicine, Brigham and Women's Hospital, Boston, MA, USA

${ }^{17}$ Department of Obstetrics, Gynecology, and Women's Health, University of Missouri, Columbia, MO, USA

${ }^{18}$ Department of Obstetrics and Gynecology, Brigham and Women's Hospital, Harvard Medical School, Boston, MA, USA

*These authors contributed equally to this work

\section{Address correspondence to:}

Andrea G. Edlow

Vincent Center for Reproductive Biology 
bioRxiv preprint doi: https://doi.org/10.1101/2021.03.29.437516; this version posted March 29, 2021. The copyright holder for this preprint (which was not certified by peer review) is the author/funder. All rights reserved. No reuse allowed without permission.

Massachusetts General Hospital

55 Fruit Street, Thier Research Building, 903b

Ph: 617-724-0654

Email: aedlow@mgh.harvard.edu 


\section{ABSTRACT}

There is a persistent male bias in the prevalence and severity of COVID-19 disease. Underlying mechanisms accounting for this sex difference remain incompletely understood. Interferon responses have been implicated as a modulator of disease in adults, and play a key role in the placental anti-viral response. Moreover, the interferon response has been shown to alter Fc-receptor expression, and therefore may impact placental antibody transfer. Here we examined the intersection of viral-induced placental interferon responses, maternalfetal antibody transfer, and fetal sex. Placental interferon stimulated genes (ISGs), Fc-receptor expression, and SARS-CoV-2 antibody transfer were interrogated in 68 pregnancies. Sexually dimorphic placental expression of ISGs, interleukin-10, and Fc receptors was observed following maternal SARS-CoV-2 infection, with upregulation in males. Reduced maternal SARS-CoV-2-specific antibody titers and impaired placental antibody transfer were noted in pregnancies with a male fetus. These results demonstrate fetal sex-specific maternal and placental adaptive and innate immune responses to SARS-CoV-2.

\section{INTRODUCTION}

Mortality and morbidity risk during the perinatal period and infancy is significantly higher in males than in females (1-4). The underlying susceptibility of males may relate to evolutionary differences that occur throughout pregnancy and in the perinatal period, but the precise mechanistic differences that lead to this differential female survival benefit is not completely understood. Consistent with perinatal male vulnerability in general, male infants and children fare significantly worse in the setting of SARS-CoV-2 infection, with higher rates of severe disease in infants and multisystem inflammatory syndrome in children (MIS-C), a SARS-CoV-2 inflammatory syndrome associated with shock, cardiac involvement, and significantly elevated markers of inflammation (5-10). The biological basis for the observed relative vulnerability of the male immune system to SARS-CoV-2 in pediatric populations is likely multifactorial $(11,12)$. Emerging data point to a retrograde impact of infant sex on maternal immunity $(13,14)$, with specific differences in innate immune signaling across fetal sex, which may contribute to a differential dialogue between female and male fetuses with their mothers. 
This differential dialogue may critically impact immunity across the dyad, leading to an alternative hypothesis underlying sex-based differences in perinatal life, including the possibility of differential transfer of immunity from the mother that may empower female and male infants with differential levels of immunity.

Type I and Type III interferons (IFN) are induced after innate recognition of viruses. Upon binding to their receptors, they induce expression of downstream effectors, interferon stimulated genes (ISGs), which inhibit viral infection by a number of different mechanisms (15). However, viruses have evolved to evade these IFN responses, and IFN responses can also be drivers of inflammatory pathology. Type I IFN signaling correlates strongly with pathogenicity and fatality in both SARS-CoV-1 and MERS-CoV infections (16-18). Dysregulated Type I IFN signaling is also associated with severe disease and drives pathogenicity in SARSCoV-2 infection, in both humans and murine models $(17,19-25)$. Notably, sex differences in adult peripheral blood and pulmonary IFN signaling have been observed in both SARS-CoV-1 and SARS-CoV-2 infection (2628), but there is a dearth of information about sex differences in fetal and pediatric populations. Type I and Type III IFN responses at the maternal-fetal interface play a crucial role in limiting viral infection but may also be drivers of abnormal development (29-31). Sex differences have been noted in the placental immune response to bacterial infection $(32,33)$ and to other prenatal alterations such as maternal stress and maternal high-fat diet $(12,34,35)$. However, placental expression of interferon-stimulated genes (ISGs) in maternal SARS-CoV-2 infection, the role of sex differences, and potential impact on placental function have not yet been examined. Newborn anti-viral immunity relies heavily on the placental transfer of maternal immunoglobulin-G (IgG) to the fetal circulation (36-38). Public health strategies to protect newborns from potentially devastating respiratory infections such as pertussis and influenza capitalize on the ability of the placenta to transfer vaccineinduced maternal IgG to the fetal circulation $(39,40)$. Fragment crystallizable (Fc) receptors in the placenta play an active role in antibody transfer from mother to fetus $(36,37,41-43)$. FC $\gamma \mathrm{R} 1$ expression relies on IFN, and emerging data have clearly demonstrated perturbed placental transfer in the setting of other coinfections including HIV (44) and malaria (45). Whether differences in inflammatory responses to SARS-CoV-2 infection could influence placental antibody transfer is unknown. In addition, little is known regarding sex differences in 
neonatal immune profiles and in maternal-fetal antibody transfer. Recent work has demonstrated reduced transplacental transfer of SARS-CoV-2-specific antibodies relative to influenza and pertussis antibodies (46, 47), and associated alterations in expression and localization of specific Fc receptors in the placenta (47), but sex differences in neonatal antibody-mediated immunity to SARS-CoV-2 and in placental receptors involved in antibody transfer have not yet been characterized.

Given known sex differences in immune responses to SARS-CoV-2 infection (26), the observed sex differences in disease prevalence and severity in the pediatric population including infants (6-9), and the placenta's critical role as an immune organ mediating anti-viral responses and antibody transfer at the maternalfetal interface (31), we sought to examine sex differences in the placental immune response to SARS-CoV-2 and how this may impact placental expression of receptors associated with antibody transfer. In a cohort of 38 participants infected with SARS-CoV-2 during pregnancy (19 male and 19 female fetuses) and a comparator group of 30 contemporaneously-enrolled pregnant women testing negative for SARS-CoV-2 (15 male and 15 female fetuses), striking differences were noted in placental transfer of antibodies to male and female infants linked to different ISG-driven Fc-receptor expression profiles in the placenta. These data point to unexpected sex-driven bilateral communication across the maternal:fetal interface associated with differences in rates of antibody transfer to SARS-CoV-2 that may help explain a major unaddressed sex-based difference across infectious diseases in male infants globally.

\section{RESULTS}

\section{Demographic and clinical characteristics of study participants}

Maternal demographic and clinical characteristics of study participants for placental analyses grouped by offspring sex are depicted in Table 1, while those providing maternal and umbilical cord blood are depicted in Supplementary Table 1. Of the 68 participants, 34 were pregnant with females and 34 with males. There were no significant differences between groups with respect to maternal age, parity, obesity, diabetes, hypertension, or gestational age at delivery, among other characteristics examined. Women with SARS-CoV-2 infection 
during pregnancy were more likely to be Hispanic compared to negative controls, concordant with our prior report of ethnic disparities in COVID-19 vulnerability in our hospital catchment area (48). Of the 38 women with SARS-CoV-2 infection during pregnancy, there were no significant differences between male and female fetuses with respect to gestational age at diagnosis of SARS-CoV-2 infection, days from positive SARS-CoV-2 test to delivery, or severity of COVID-19 illness. Although both male and female fetuses of mothers with SARS-CoV-2 had lower birthweights than their sex-matched control counterparts, clinically this difference was not meaningful as all neonatal birthweights were in the normal range. No neonates born to mothers with SARSCoV-2 infection during pregnancy were infected with SARS-CoV-2. 


\begin{tabular}{|c|c|c|c|c|c|c|}
\hline & \multirow[t]{2}{*}{ All (68) } & \multicolumn{2}{|c|}{ Female } & \multicolumn{2}{|c|}{ Male } & \multirow{2}{*}{$\begin{array}{c}\text { P- } \\
\text { value }^{\text {b }}\end{array}$} \\
\hline & & $\begin{array}{c}\text { SARS-CoV-2 } \\
\text { negative } \\
\text { (15) }\end{array}$ & $\begin{array}{c}\text { SARS-CoV-2 } \\
\text { positive } \\
(19)^{\mathrm{a}}\end{array}$ & $\begin{array}{c}\text { SARS-CoV-2 } \\
\text { negative } \\
\text { (15) }\end{array}$ & $\begin{array}{l}\text { SARS-CoV-2 } \\
\text { positive } \\
(19)^{\mathrm{a}}\end{array}$ & \\
\hline Maternal Age, years & $\begin{array}{c}33 \\
{[28-38]}\end{array}$ & $\begin{array}{c}33 \\
{[30-36]}\end{array}$ & $\begin{array}{c}34 \\
{[30-40]}\end{array}$ & $\begin{array}{c}30 \\
{[27-37]}\end{array}$ & $\begin{array}{c}31 \\
{[26-36]}\end{array}$ & 0.34 \\
\hline Parity, $n$ & $\begin{array}{c}1 \\
{[0-2]}\end{array}$ & $\begin{array}{c}1 \\
{[0-2]}\end{array}$ & $\begin{array}{c}1 \\
{[0-2]}\end{array}$ & $\begin{array}{c}1 \\
{[0-2]}\end{array}$ & $\begin{array}{c}1 \\
{[0-2]}\end{array}$ & 0.34 \\
\hline Race, $n(\%)$ & & & & & & 0.19 \\
\hline White & $40(59)$ & $11(73)$ & $8(42)$ & $12(80)$ & $9(59)$ & \\
\hline Black & $5(7)$ & $1(7)$ & $3(16)$ & $0(0)$ & $1(7)$ & \\
\hline Asian & $1(1)$ & $0(0)$ & $0(0)$ & $1(7)$ & $0(0)$ & \\
\hline Other & $12(18)$ & $3(20)$ & $4(21)$ & $1(7)$ & $4(8)$ & \\
\hline Not Reported & $10(15)$ & $0(0)$ & $4(21)$ & $1(7)$ & $5(15)$ & \\
\hline Ethnicity, $n(\%)$ & & & & & & 0.01 \\
\hline Hispanic & $32(47)$ & $4(27)$ & $11(58)$ & $2(13)$ & $15(79)$ & \\
\hline Non-Hispanic & $33(48)$ & $10(67)$ & $7(37)$ & $12(80)$ & $4(21)$ & \\
\hline Not Reported & $3(4)$ & $1(7)$ & $1(5)$ & $1(7)$ & $0(0)$ & \\
\hline $\begin{array}{l}\text { Chronic } \\
\text { hypertension, } n(\%)\end{array}$ & $0(0)$ & $0(0)$ & $0(0)$ & $0(0)$ & $0(0)$ & $\mathrm{N} / \mathrm{A}$ \\
\hline DM/GDM, $n(\%)$ & $6(9)$ & $1(7)$ & $3(16)$ & $1(7)$ & $1(5)$ & 0.67 \\
\hline $\begin{array}{l}\mathrm{BMI} \geq 30 \mathrm{~kg} / \mathrm{m}^{2}, n \\
(\%)\end{array}$ & $20(29)$ & $2(13)$ & $7(37)$ & $3(20)$ & $8(42)$ & 0.21 \\
\hline $\begin{array}{l}\text { Pre-pregnancy BMI, } \\
\mathrm{kg} / \mathrm{m}^{2}\end{array}$ & $\begin{array}{c}27.4 \\
{[21.5-30.8]}\end{array}$ & $\begin{array}{c}25.8 \\
{[21.6-29.4]}\end{array}$ & $\begin{array}{c}28.5 \\
{[26.5-32.7]}\end{array}$ & $\begin{array}{c}21.5 \\
{[20.3-29.8]}\end{array}$ & $\begin{array}{c}29.5 \\
{[22.3-32.0]}\end{array}$ & 0.06 \\
\hline $\begin{array}{l}\text { GA at delivery, } \\
\text { weeks }\end{array}$ & $\begin{array}{c}39.2 \\
{[38.6-40.3]}\end{array}$ & $\begin{array}{c}39.3 \\
{[39.0-39.4]}\end{array}$ & $\begin{array}{c}39.3 \\
{[38.4-40.1]}\end{array}$ & $\begin{array}{c}39.1 \\
{[39.0-41.1]}\end{array}$ & $\begin{array}{c}39.0 \\
{[35.3-40.3]}\end{array}$ & 0.09 \\
\hline Any labor, $n(\%)$ & $52(76)$ & $8(53)$ & $16(84)$ & $11(73)$ & $17(89)$ & 0.07 \\
\hline $\begin{array}{l}\text { Neonatal } \\
\text { birthweight, } g\end{array}$ & $\begin{array}{c}3283 \\
{[3005-3590]}\end{array}$ & $\begin{array}{c}3400 \\
{[3060-3590]}\end{array}$ & $\begin{array}{c}3255 \\
{[2920-3340]}\end{array}$ & $\begin{array}{c}3435 \\
{[3260-3730]} \\
\end{array}$ & $\begin{array}{c}3115 \\
{[2615-3590]}\end{array}$ & 0.06 \\
\hline $\begin{array}{l}\text { GA at positive } \\
\text { SARS-CoV-2 test, } \\
\text { weeks }\end{array}$ & $\begin{array}{c}38.7 \\
{[35.6-39.6]}\end{array}$ & $\mathrm{N} / \mathrm{A}$ & $\begin{array}{c}36.3 \\
{[32.4-39.4]}\end{array}$ & $\mathrm{N} / \mathrm{A}$ & $\begin{array}{c}36.3 \\
{[32.4-39.5]}\end{array}$ & 0.90 \\
\hline $\begin{array}{l}\text { COVID-19 disease } \\
\text { severity at } \\
\text { diagnosis }{ }^{\mathrm{c}}, n\end{array}$ & & & & & & 0.82 \\
\hline Asymptomatic & $16(42)$ & $\mathrm{N} / \mathrm{A}$ & $8(42)$ & $\mathrm{N} / \mathrm{A}$ & $8(42)$ & \\
\hline Mild/Moderate & $19(50)$ & $\mathrm{N} / \mathrm{A}$ & $9(47)$ & $\mathrm{N} / \mathrm{A}$ & $10(53)$ & \\
\hline Severe/Critical & $3(8)$ & $\mathrm{N} / \mathrm{A}$ & $2(11)$ & $\mathrm{N} / \mathrm{A}$ & $1(5)$ & \\
\hline $\begin{array}{l}\text { Time between } \\
\text { SARS-CoV-2 } \\
\text { symptom onset and } \\
\text { delivery, days }\end{array}$ & 36.5 [18-57] & $N / A$ & 44 [28-64] & $\mathrm{N} / \mathrm{A}$ & 32 [8-51] & 0.18 \\
\hline
\end{tabular}

Table 1. Demographic and clinical characteristics of study cohort by fetal sex and maternal SARS-CoV2 status. Abbreviations: DM/GDM, diabetes mellitus/gestational diabetes mellitus; BMI, body mass index; GA, gestational age; N/A, not applicable. a SARS-CoV-2 positive and negative status determined by nasopharyngeal RT PCR at time of sample collection. If a participant was SARS-CoV-2 positive at any time in pregnancy, she was included in "SARS-CoV-2 positive" category. ${ }^{b}$ Significant differences between groups were determined using chi-square test for categorical variables, and Kruskal-Wallis test for continuous variables presented as median [IQR]. ' Severity determinations were made based on published criteria from the Society for Maternal-Fetal Medicine and the National Institutes of Health. 


\section{Sexually dimorphic placental expression of interferon stimulated genes (ISGs) in response to maternal}

\section{SARS-CoV-2 infection}

Dysregulation of placental type I IFN responses has been noted in response to other viral infections (30, 31, 49). Placental type III IFN responses play an essential barrier function in maternal viral infection (50). Given the key role ISGs are known to play in the placental anti-viral response and previous reports of sex differences in expression of ISGs in the plasma of patients with COVID-19 (26), we examined whether maternal SARS-CoV-2 infection was associated with sex-specific alterations in placental ISG response (Fig. 1A). There was a sexually dimorphic expression pattern of the classical ISGs IFI6, CXCL10, and OAS1 driven by increased expression in male SARS-CoV-2-exposed placentas compared to SARS-CoV-2-negative controls (Fig. 1B-D; Supplementary Table 2). We next examined expression of CCL2/MCP-1, a type I IFN-stimulated cytokine implicated in monocyte chemotaxis (51) and upregulated in lung samples from patients with COVID$19(23,24)$, as well as $M X 1$, an anti-viral response gene induced by type I/III IFNs and upregulated during SARS-CoV-2 infection (52). Maternal SARS-CoV-2 exposure was associated with increased expression of $C C L 2$ and $M X 1$ in the placenta, with these differences primarily driven by increases in male placentas (Fig. 1EF; Supplementary Table 2). Although maternal SARS-CoV-2 infection did not affect expression of placental $T N F, I L 6$, or $C C L 7$ compared to expression in placentas from women negative for SARS-CoV-2

(Supplementary Fig. 1A-C; Supplementary Table 2), there was a sexually dimorphic effect of maternal SARSCoV-2 infection on the expression of anti-inflammatory factor ILIO (53), driven by significantly increased expression in SARS-CoV-2-exposed male placentas (Fig. 1G; Supplementary Table 2). We also observed a male-specific increase in density of CD163+ Hofbauer cells, placental resident fetal macrophages (54), in response to maternal SARS-CoV-2 exposure (Figure 1H-I; Supplementary Table 2). While placental Hofbauer cell hyperplasia has been described in maternal SARS-CoV-2 infection $(86,87)$, sex differences have not yet been examined. Together, these results suggest a sex-specific, and in some cases, sexually dimorphic response of placental ISGs to maternal SARS-CoV-2 infection, with significant upregulation of ISGs in male placentas exposed to maternal SARS-CoV-2 infection. 
A
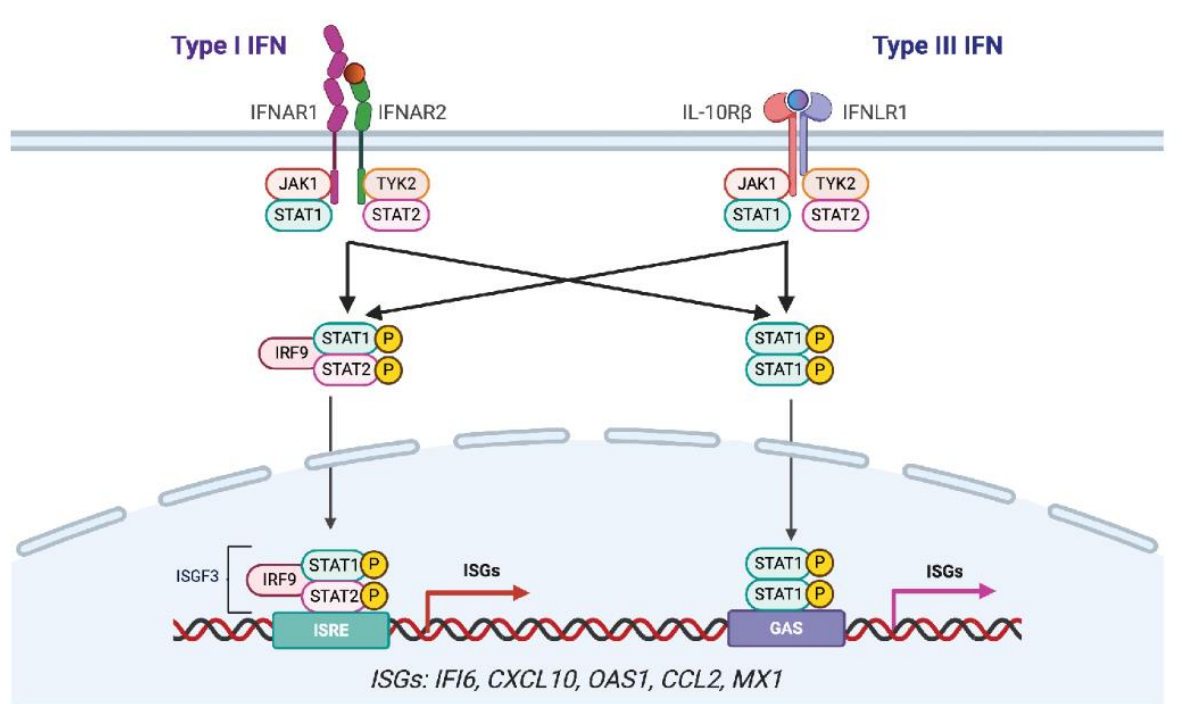

SARS-CoV-2 -

SARS-CoV-2 +
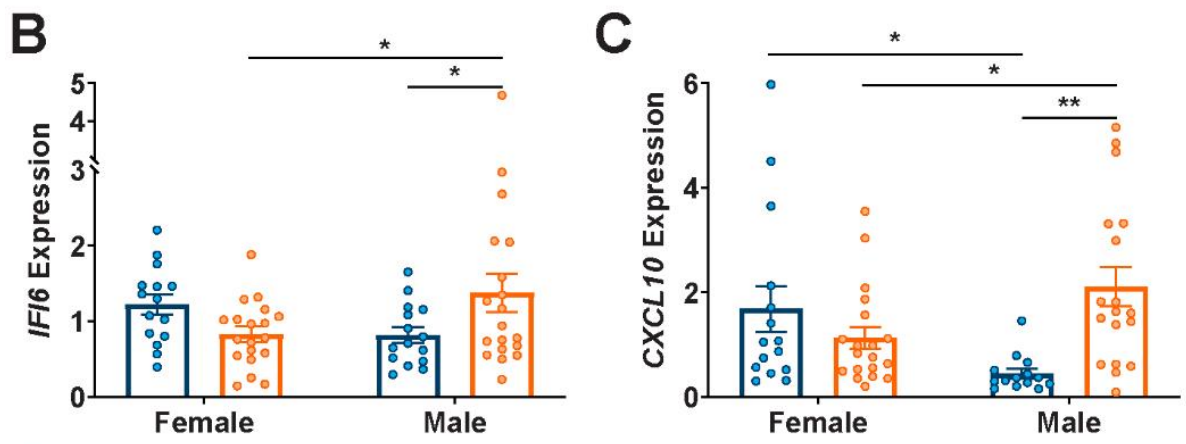

D

E

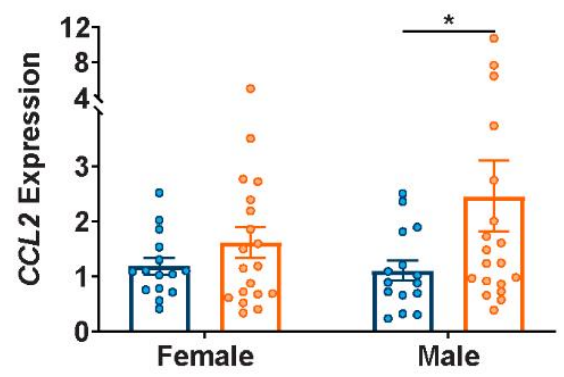

$\mathbf{F}$

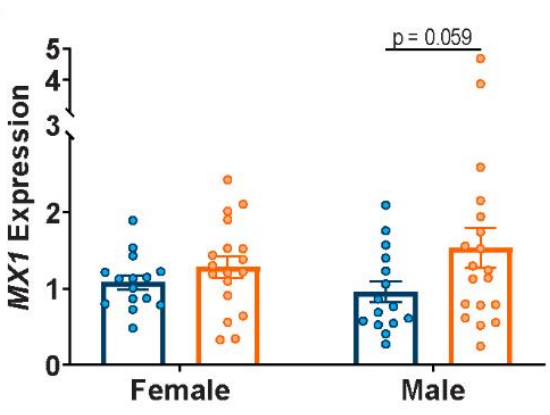

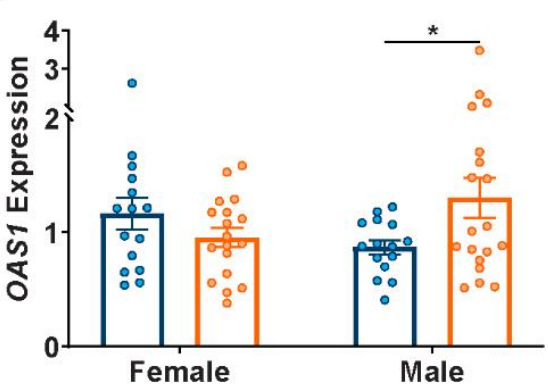

G

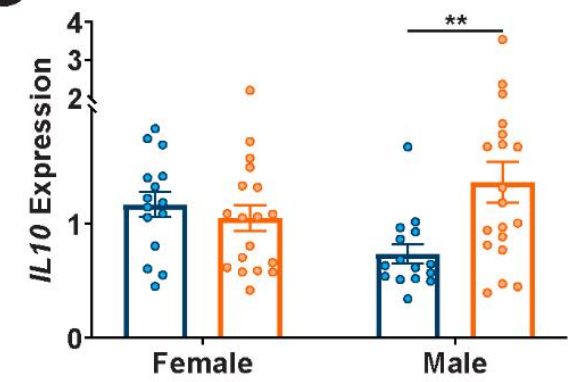

H SARS-CoV-2 -

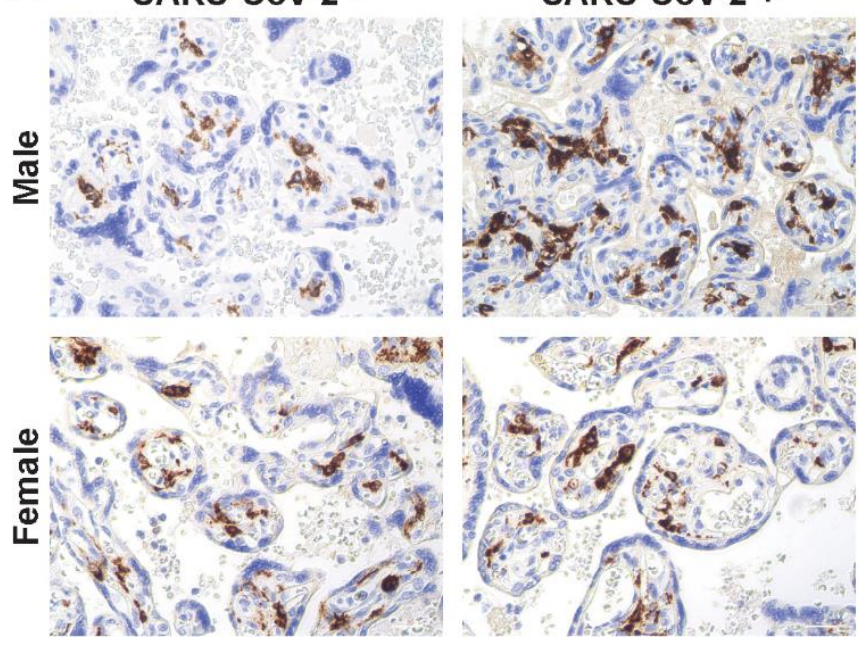

I

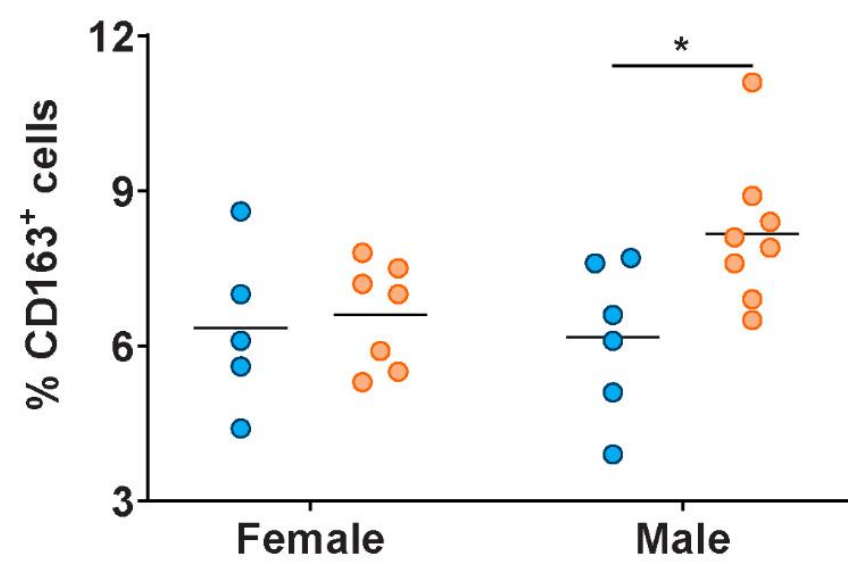


Figure 1. Male-specific upregulation of interferon stimulated genes in placentas exposed to maternal SARS-CoV-2 infection.

(A) Interferon stimulated gene pathway diagram. Production of interferon stimulated genes (ISGs) of interest can occur through activation of Type I IFN (left) or Type III IFN (right). Image created using Biorender. (B-G) RTqPCR analyses of male or female placental expression of (B) IFI6, (C) CXCL10, (D) OAS1, (E) CCL2, (F) $M X 1$, and (G) IL10 in placental biopsies from SARS-CoV-2 negative (blue) or SARS-CoV-2 positive (orange) pregnancies. Expression levels shown are relative to reference gene YWHAZ. (H-I) Representative immunohistochemistry images and quantification of CD163-positive cells in placental slices from SARS-CoV-2 negative (blue) or SARS-CoV-2 positive (orange) pregnancies. Two-way ANOVA followed by Bonferroni's post-hoc analyses were performed to determine significance. $* \mathrm{p}<0.05, * * \mathrm{p}<0.01$

\section{Sex differences in placental transfer of SARS-CoV-2-specific antibodies and antibody function}

Placental inflammation is associated with impaired antibody transfer $(45,55)$, and reduced

transplacental antibody transfer has been shown in the context of maternal infections such as HIV (44) and malaria (45). Given the known vulnerability of male infants to more severe respiratory disease (11), we sought to determine whether the sex of the fetus would impact transplacental transfer of maternal SARS-CoV-2specific antibodies. We comprehensively profiled SARS-CoV-2 antibodies spike (S), receptor binding domain (RBD), spike S1 subunit (S1), spike S2 subunit (S2), and nucleocapsid (N) including titer, function, and placental receptor interactions in maternal:cord plasma pairs of SARS-CoV-2 exposed and unexposed (SARSCoV-2 negative) pregnancies, using a previously-described Systems Serology approach (47). Rather than the expected transplacental transfer observed for other pathogens (cord-to-maternal ratio of 1.1-1.5 or greater (42, 56, 57)), IgG titers against all examined SARS-CoV-2 antigens were significantly reduced in cord relative to maternal plasma across IgG subtypes in pregnancies with a male fetus compared to those with a female fetus

(Fig. 2A, Supplementary Fig. 2). In contrast, significant reduction in cord versus maternal titers was only observed in the case of N-specific IgG2 in pregnancies with a female fetus (Supplementary Fig. 2). There were significantly reduced cord:maternal transfer ratios for SARS-CoV-2-specific antibodies in male versus female fetuses (Fig. 2B), and significantly reduced transfer of SARS-CoV-2-specific antibodies capable of binding to FcRn, FCGR2A/B and FCGR3A/B predominantly in males (Fig. 2C and Supplementary Fig. 2). Although transfer ratios for SARS-CoV-2-specific antibodies were significantly higher for female fetuses than those of males, they were still lower than the expected 1.1-1.5 ratios often observed for other pathogens $(47,56,57)$. 
SARS-CoV-2-specific functional antibodies were also transferred less efficiently, with a marked male-specific decrease in antibody-dependent complement deposition (ADCD)-inducing antibodies and antibodies that induce natural killer (NK) cell chemokine secretion (macrophage inflammatory protein-1b/MIP-1b)(Fig. 2E-F).

In contrast to SARS-CoV-2-specific antibodies, efficient transfer of pertussis antigen pertactin (PTN) and the influenza hemagglutinin (HA) glycoprotein-specific titers (Fig. 2C-D, Supplementary Fig. 3) and functions (Fig. 2E-F) was observed across pregnancies with both female and male fetuses.

As transplacental passive humoral immune transfer from maternal to cord blood is dependent in part on maternal antibody titers (58), we assessed the influence of fetal sex on maternal anti-SARS-CoV-2 antibody titers. Maternal levels of SARS-CoV-2-specific IgG1 were significantly lower in mothers with a male fetus compared to a female fetus (Fig. 2G). This effect was specific to anti-SARS-CoV-2 antibodies, with no significant impact of fetal sex on maternal anti-HA and PTN titers (Fig. 2H). Similar results were observed for maternal IgG2, IgG3, and IgM (Supplementary Fig. 4). Overall, these results suggest a reduced maternal SARSCoV-2-specific humoral immune response in pregnancies with male fetuses. The reduced maternal antibody titers in mothers with male fetuses are consistent with prior studies demonstrating suppressed maternal proinflammatory responses in mothers with a male fetus relative to female fetus $(13,14)$ and the known direct correlation between pro-inflammatory response and increased antibody production in COVID-19 infection (59, 60). 


\section{SARS-CoV-2 +}

SARS-CoV-2 -

A
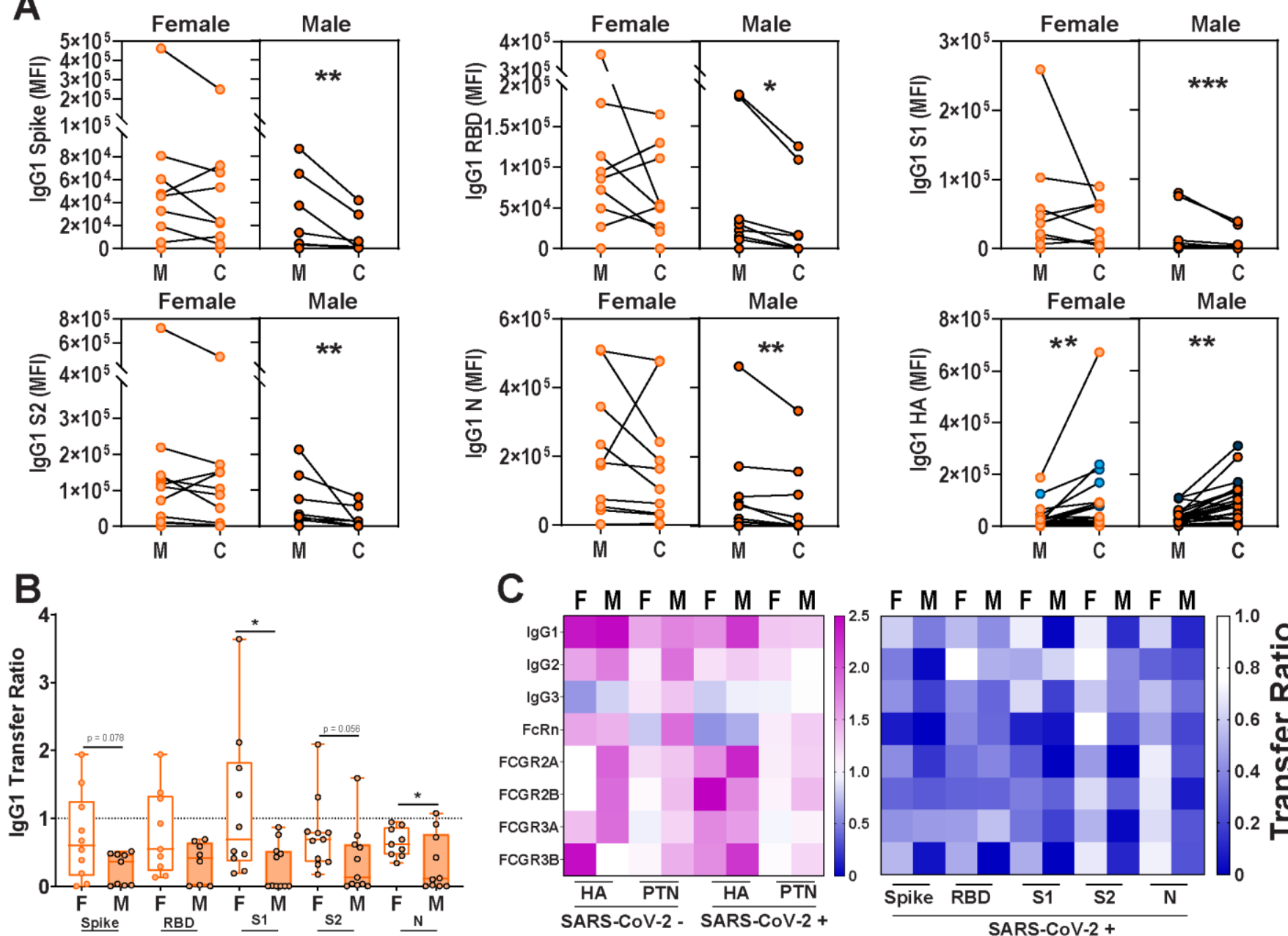

F M F M M F M F

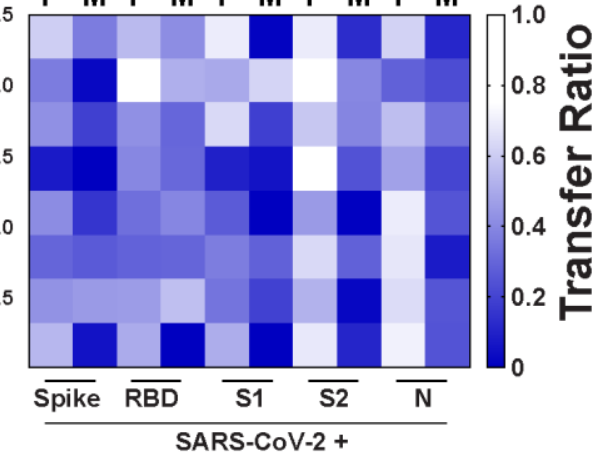

D

E
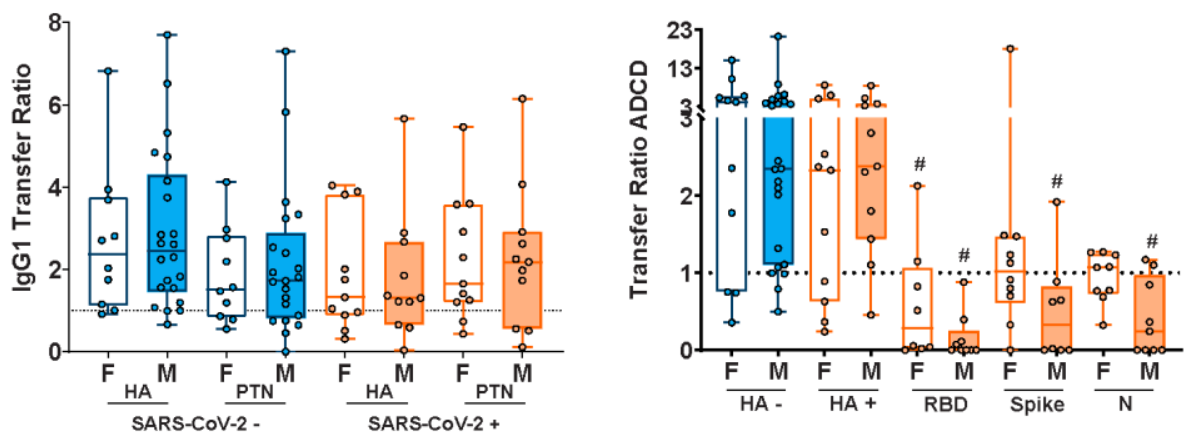

$\mathbf{F}$

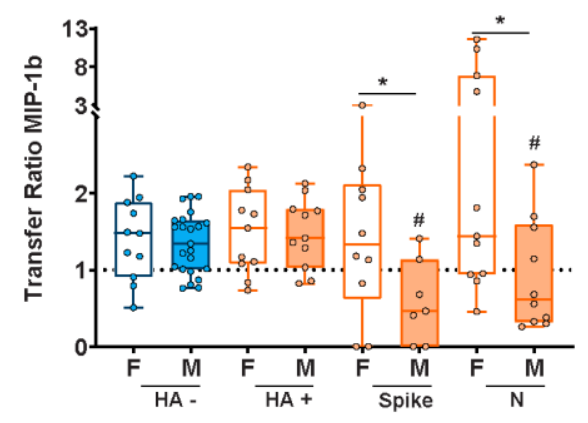

G

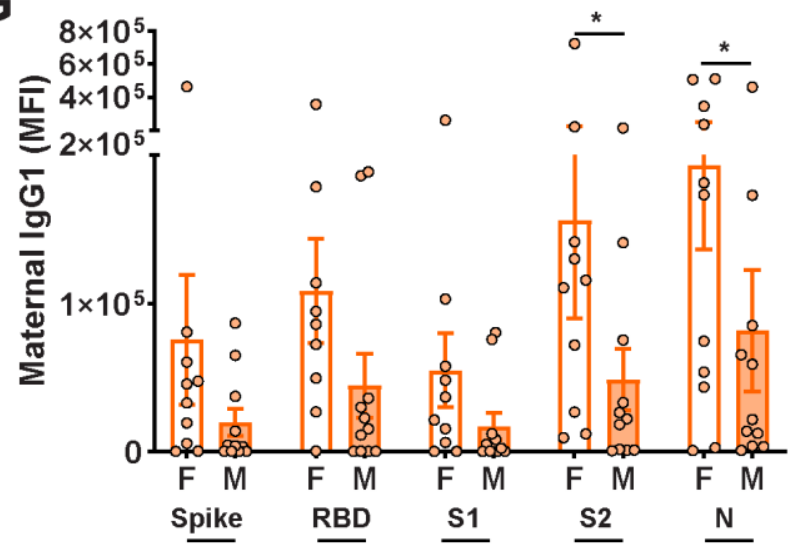

$\mathrm{H}$

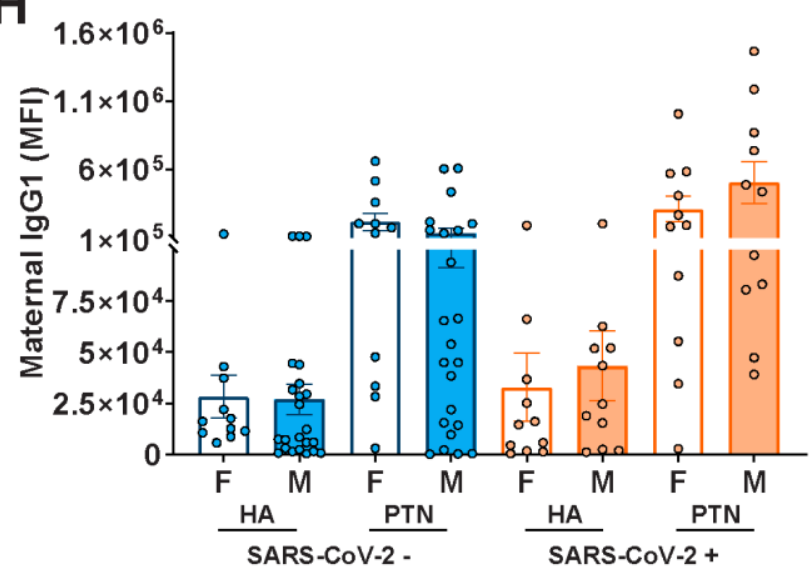


Figure 2. SARS-CoV-2 infected mothers with male fetuses demonstrate reduced placental transfer of SARS-CoV-2 antibodies compared to those with female fetuses.

A. Dot plots showing relative Spike-, RBD-, S1-, S2-, N-, and influenza (HA)-specific maternal blood (M) and cord blood (C) titers of IgG1. Female neonates of SARS-CoV-2 negative mothers are shown in light blue, female neonates of SARS-CoV-2 positive mothers are shown in light orange. Males born to SARS-CoV-2 negative mothers are shown in dark blue, and males born to SARS-CoV-2 positive mothers are shown in dark orange. Units are Mean Fluorescence Intensity or MFI. All values reflect PBS background correction. Wilcoxon matched-pairs signed rank test was performed to determine significance.

$* \mathrm{p}<0.05, * * \mathrm{p}<0.01, * * * \mathrm{p}<0.001$.

B. Box-and-whisker plots show the transfer ratios (cord:maternal ratios) for IgG1 against the SARS-CoV-2 antigens Spike, RBD, S1, S2, and N. SARS-CoV-2 negative maternal status is shown in blue (female: open bars; male: shaded bars) and SARS-CoV-2 positive maternal status is shown in orange (female: open bars; male: shaded bars). All values are PBS background corrected. Kruskal-Wallis test followed by Dunn's post-hoc analyses were performed to determine significance. In panels B-H, F indicates female and M indicates male fetus. Dotted line denotes a transfer ratio of 1 or $100 \% . * \mathrm{p}<0.05$.

C. Heatmap depicting the median PBS background-corrected cord:maternal transfer ratio of HA, PTN, Spike, RBD, S1, S2, and N across all antibody subclasses and Fc receptor binding profiles in both SARS-CoV-2 negative and positive maternal:neonate dyads.

D. The box-and-whisker plots show the transfer ratios (cord:maternal ratio) for IgG1 against HA and PTN in maternal:neonate dyads from either SARS-CoV-2 negative or SARS-CoV-2 positive pregnancies. SARS-CoV2 negative are shown in blue (female: open bars; male: shaded bars) and SARS-CoV-2 positive are shown in orange (female: open bars; male: shaded bars). Kruskal-Wallis test followed by Dunn's post-hoc analyses were performed to determine significance. In panels D-F, dotted line denotes transfer ratio of 1 or $100 \%$. $*$ p $<0.05$. E-F. Box-and-whisker plots depicting transfer ratios (cord:maternal) for (E) antibody-dependent complement deposition (ADCD) and (F) MIP-1b NK activation against HA, RBD, Spike, and N. SARS-CoV-2 negative maternal status is shown in blue (female: open bars; male: shaded bars) and SARS-CoV-2 positive maternal status is shown in orange (female: open bars; male: shaded bars). For each SARS-CoV-2 antigen, significance was determined against the HA-specific activity using the matched SARS-CoV-2 + dyad. Kruskal-Wallis test followed by post-hoc analyses was performed to determine significance. \# $\mathrm{p}<0.01$ compared to HA SARS$\mathrm{CoV}-2+$ of that sex, $* \mathrm{p}<0.01$ compared to indicated group.

G. Bar graphs depicting Spike-, RBD-, S1-, S2-, and N-specific maternal blood IgG1 levels. Two-way ANOVA followed by post-hoc analyses was used to determine significance. There was a main effect of fetal sex on maternal IgG1 levels. Units are MFI: Mean Fluorescence Intensity. ${ }^{*} \mathrm{p}<0.05$.

H. Bar graphs depicting HA- and PTN-specific maternal blood IgG1 levels. SARS-CoV-2 negative maternal status is shown in blue (female: open bars; male: shaded bars) and SARS-CoV-2 positive maternal status is shown in orange (female: open bars; male: shaded bars). Two-way ANOVA revealed no effect of fetal sex or maternal SARS-CoV-2 infection status. Units are MFI: Mean Fluorescence Intensity.

\section{Sexually dimorphic placental Fc receptor expression in response to maternal SARS-CoV-2 infection}

The transfer of maternal antibodies across the placenta is mediated by Fc receptors $(36,37)$. The neonatal Fc receptor (FcRn) was considered the classical receptor mediating transplacental transfer of $\operatorname{IgG}(61)(62)$,

although other Fc receptors (Fc $\gamma \mathrm{I}, \mathrm{II}, \mathrm{III})$ are increasingly recognized as being expressed in the placenta and

likely to play a role in transfer $(36,37)$. Given the lower maternal antibody levels in pregnancies with a male

fetus, we next aimed to probe the potential contribution of Fc-receptor expression to antibody-transfer 
differences across fetal sex. We observed sexually dimorphic expression of FCGRT, FCGR1, FCGR3A and FCGR3B in the setting of maternal SARS-CoV-2 infection (Fig 3A-C, Supplementary Fig.5 Supplementary Table 3), driven by increased expression in male SARS-CoV-2-exposed placentas. There were no fetal sex or maternal SARS-CoV-2 infection-mediated differences in placental expression of $F C G R 2 A / B$ (Supplementary Fig. 5; Supplementary Table 3). These findings point to sexual dimorphism in Fc-receptor expression specifically in male infants, potentially in an effort to increase the transfer of antibodies to infants to empower them with enhanced immunity. To distinguish whether increased transcript expression of Fc receptors was compensatory in the setting of diminished protein expression, or whether protein expression mirrored gene expression, we performed immunoblot analyses of FcRn, FC $\gamma \mathrm{R} 3, \mathrm{FC} \gamma \mathrm{R} 2$, and $\mathrm{FC} \gamma \mathrm{R} 1$. Protein expression was consistent with gene expression for FcRn, FC $\gamma$ R2 and FC $\gamma$ R3 (Fig. 3D-F, Supplementary Fig. 5 and Supplementary Table 3). There was no statistically significant impact of maternal SARS-CoV-2 infection nor fetal sex on protein expression of FC $\gamma$ R1 (Fig. 3E; Supplementary Table 3). In addition to Fc receptor quantity, it has been demonstrated that co-localization of other Fc $\gamma$ receptors with FcRn augments efficiency of placental antibody transfer $(37,47)$. Immunohistochemical analyses of placental villi revealed significant sexual dimorphism in placental Fc receptor co-localization, with a significant increase in co-localization of FC $\gamma \mathrm{R} 3$ and FcRn in male placentas only (Fig. 3G, 3J; Supplementary Table 3). No fetal sex or maternal SARS-CoV-2 exposure differences in co-localization with FcRn were observed for FC $\gamma$ R1 (Fig. 3H, 3K; Supplementary Table 3) or FC $\gamma$ R2 (Supplementary Fig. 5E-F; Supplementary Table 3). The gene and protein expression results suggest that maternal SARS-CoV-2 infection has a sexually dimorphic impact on placental Fc $\gamma$ receptor expression, driven by an increase in overall expression and in $\mathrm{FC} \gamma \mathrm{R} 3 / \mathrm{FcRn}$ co-localization in male placentas. Such increases may be compensatory for lower maternal titers of IgG in the setting of a male fetus, but still were not able to restore normal placental transfer of humoral immunity to male fetuses. 


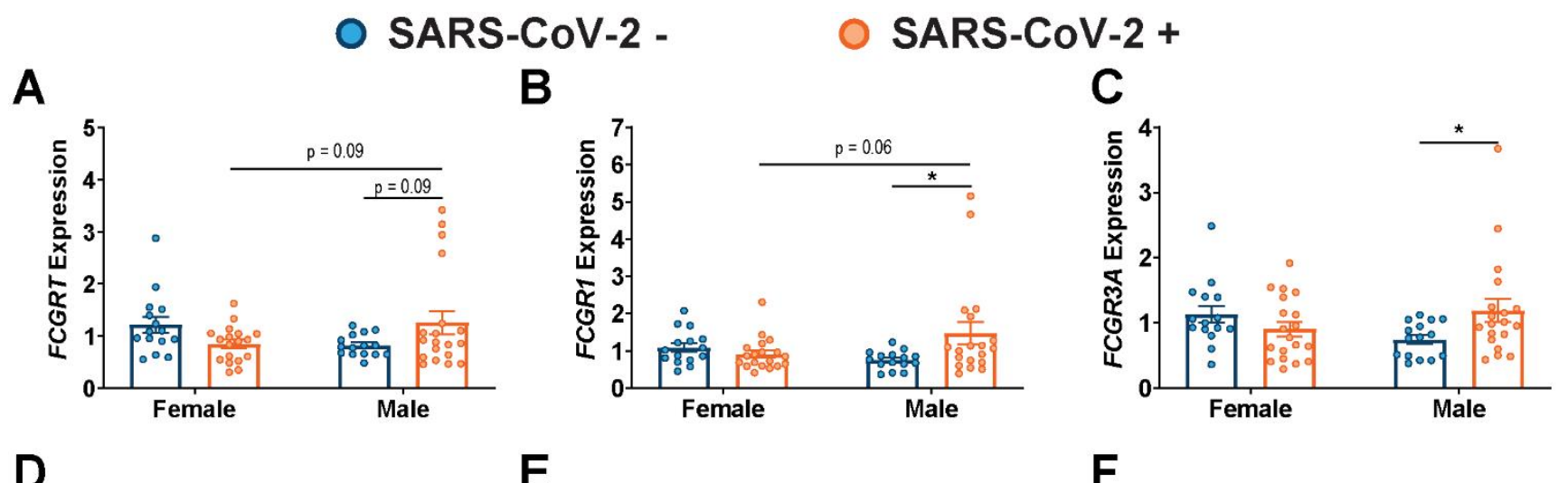

\section{FcRn}

Tubulin _ - - - - -
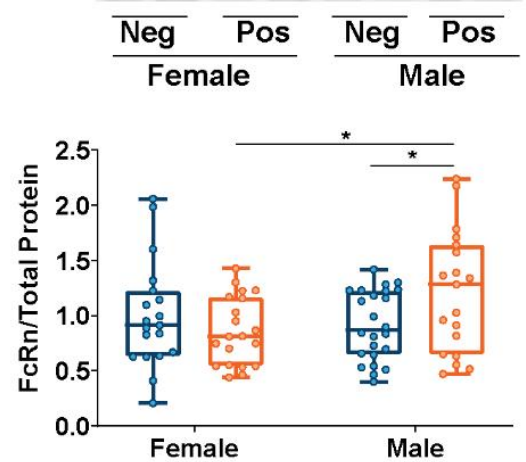

$\mathbf{G}$
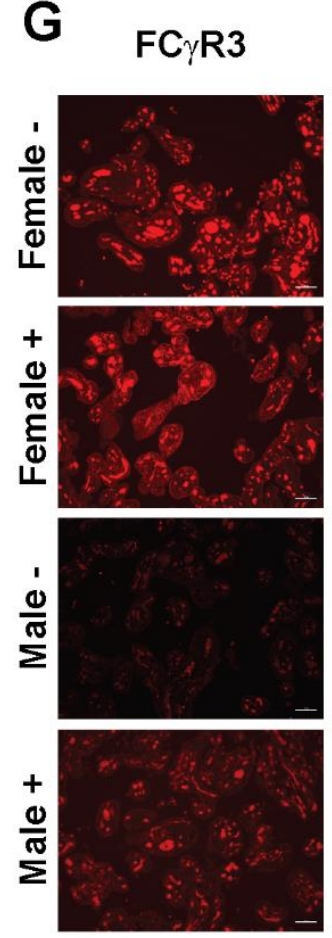

FcRn
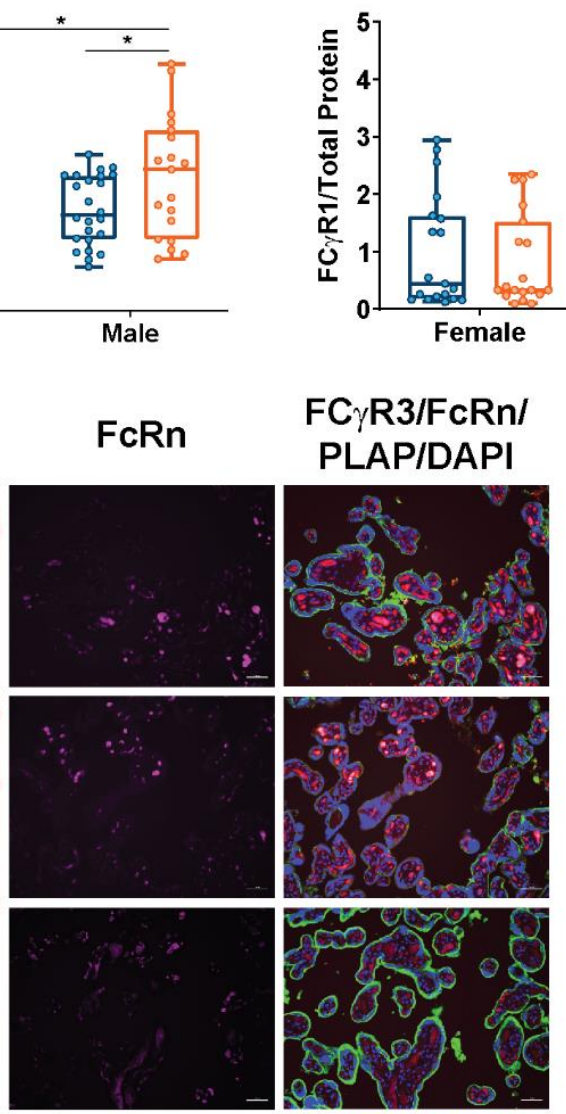

FC $\gamma$ R3/FcRn/
PLAP/DAPI
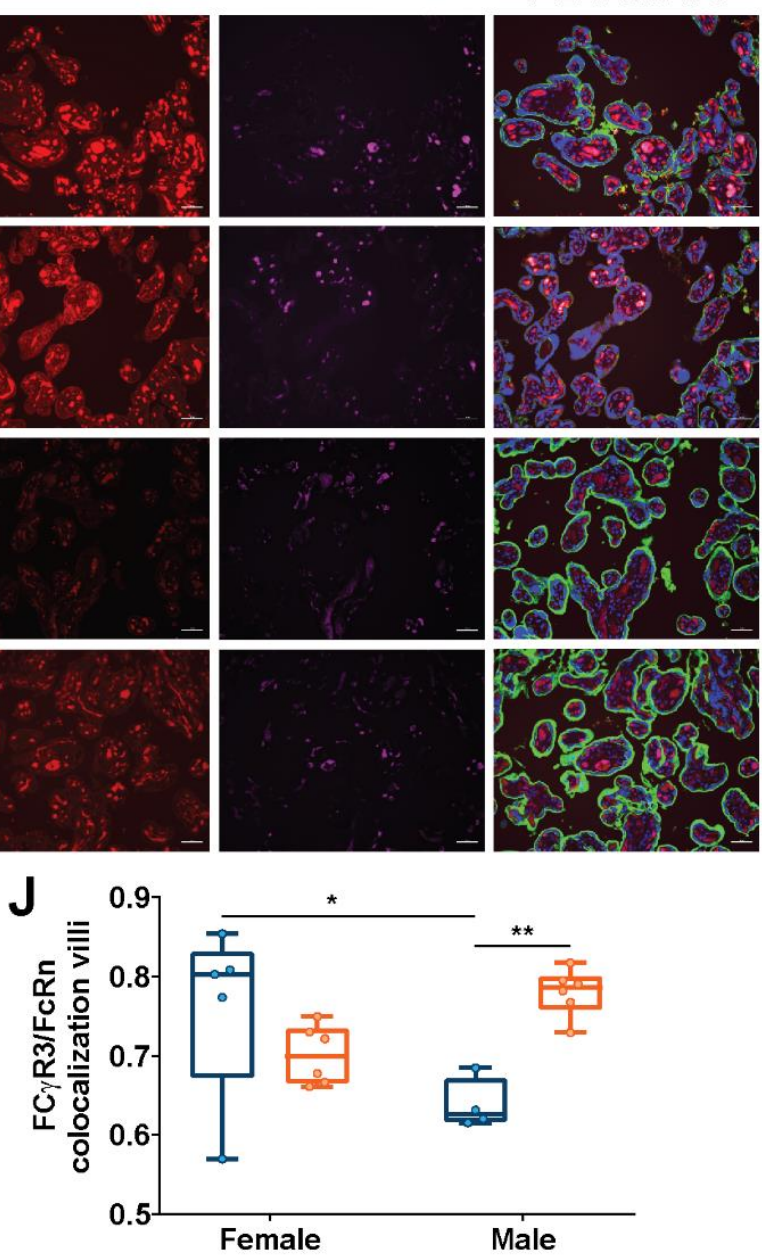
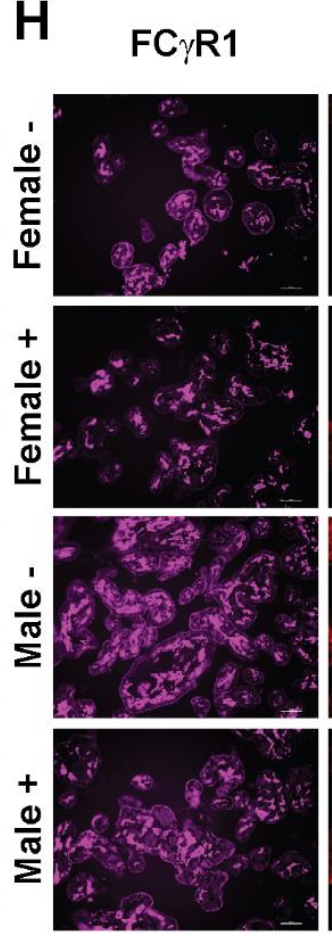

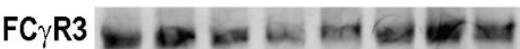

Tubulin - $-\ldots-\cdots$
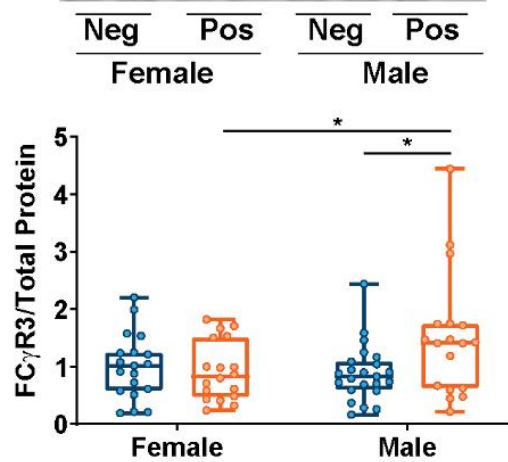

FcRn

FC $\gamma$ R1/FcRn/

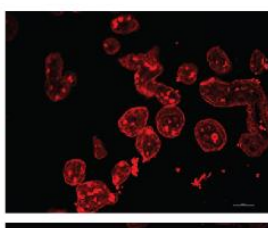

PLAP/DAPI
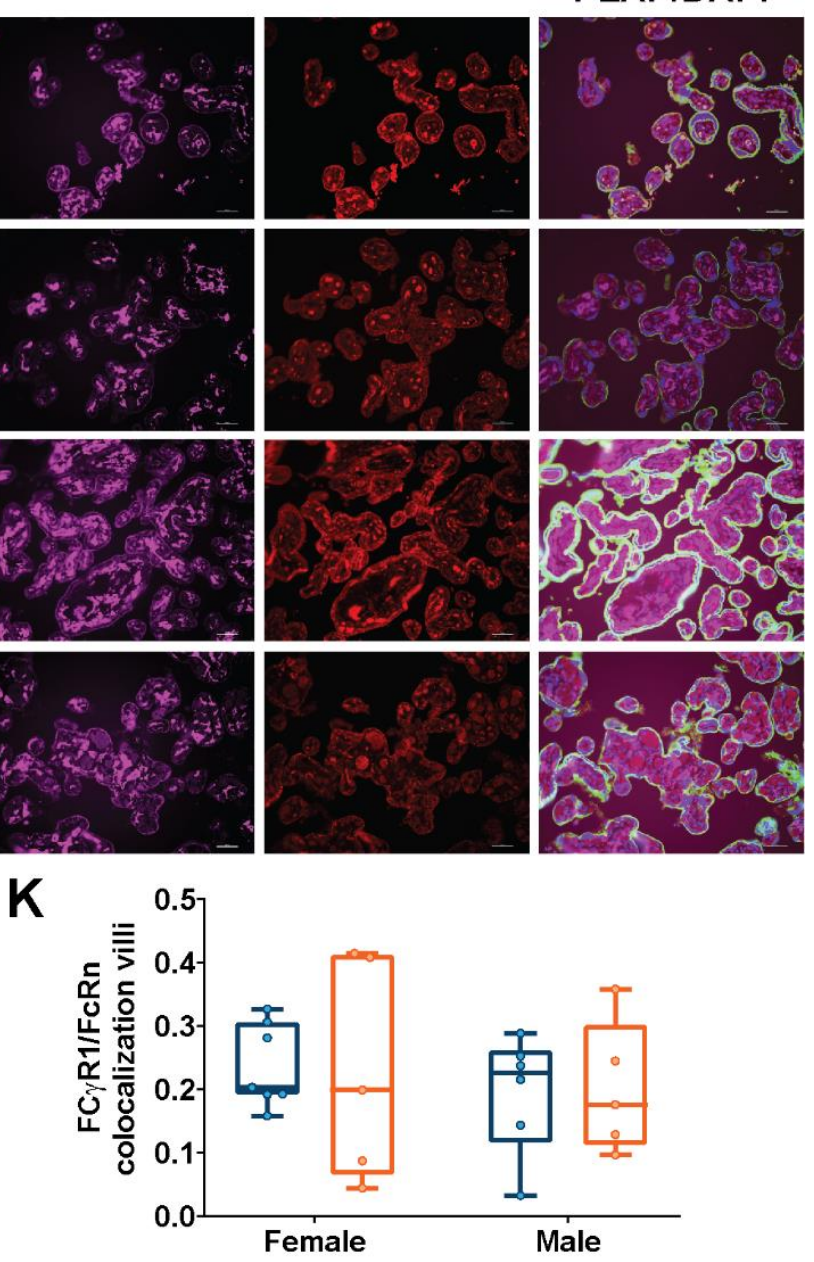
Figure 3. Sexually dimorphic regulation of Fc receptor gene expression, protein expression, and colocalization.

(A-C) RTqPCR analyses of male or female placental expression of $F C G R T$ (A), FCGR1 (B), and FCGR3A (C) in placental biopsies from SARS-CoV-2 negative (blue) or SARS-CoV-2 positive (orange) pregnancies. Expression levels shown are relative to reference gene YWHAZ. (D-F) Representative immunoblots and

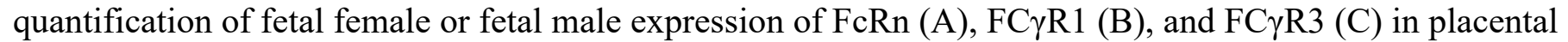
biopsies from SARS-CoV-2 negative (blue) or SARS-CoV-2 positive (orange) pregnancies. Neg and Pos on western blot designates SARS-CoV-2 negative and positive pregnancies. (G) Placental tissue sections from SARS-CoV-2 + and SARS-CoV-2 - mothers were stained for FC $\gamma$ R3 (red), FcRn (purple), and placental alkaline phosphatase (PLAP, green), a trophoblast marker, and DAPI (blue). (H) Box-and-whisker plots showing FC $\gamma$ R3/FcRn co-localization in placental villi. (I) Placental tissue sections from SARS-CoV-2 + and SARS-CoV-2 - mothers were stained for FC $\gamma$ R1 (purple), FcRn (red), and placental alkaline phosphatase (PLAP, green), a trophoblast marker, and DAPI (blue). (J) Box-and-whisker plots showing (J) FC $\gamma \mathrm{R} 1 / \mathrm{FcRn}$ or (K) FC $\gamma$ R2/FcRn co-localization in placental villi. Two-way ANOVA followed by Bonferroni's post-hoc analyses were performed to determine significance. $* \mathrm{p}<0.05, * * \mathrm{p}<0.01$.

\section{Modeling the relative impact of placental gene expression, antibody features, and disease timing and}

\section{severity}

While we observed sexually dimorphic expression of individual placental genes and sex-biased transplacental antibody transfer in response to maternal SARS-CoV-2 infection, it was still unclear whether placental gene expression influenced the transfer of humoral immunity in a sex-specific manner. To investigate the relationship between fetal sex, placental gene expression, and antibody transfer, we examined whether S1specific IgG1 transplacental transfer could be predicted by differential inflammatory, ISG, and Fc receptor placental gene expression in male and female orthogonal partial least squares discriminant analysis (O-PLSDA) models. S1-specific IgG1 transfer was modeled because the most significant sex difference was noted in the transfer of this antibody (Fig. 2B). Given that transfer of SARS-CoV-2 specific antibodies in fetuses of both sexes was less than the expected cord:maternal ratio of $\geq 1.1-1.5$, there was no truly high or efficient transfer. Ratio thresholds for distinguishing higher and lower transfer were therefore determined based on the natural distribution of the data. For female neonates, this ratio was 0.8 , and for males, this ratio was 0.4 (reflective of more impaired transfer in males). To investigate whether multivariate analysis could identify gene signatures specific to relatively high or low transfer, we performed O-PLSDA separately on the female and male neonates (Fig. 4A-D). To avoid overfitting the O-PLSDA model, features were reduced to the 'optimal' set of nonredundant features using LASSO feature selection (63). In both male and female pregnancies, high placental 
expression of $F C G R 3 B$ was associated with lower IgG1 S1 transfer efficiency (Fig. 4). Interestingly, higher placental IL10 expression was associated with higher IgG1 S1 transfer in female pregnancies, but lower transfer efficiency in male pregnancies (Fig. 4B,4D). In male pregnancies, high expression of OAS1 was associated with higher transfer (Fig. 4D). Overall, these O-PLSDA models support a systemic sexually dimorphic response that triggers distinct inflammatory cascades likely critical for driving different levels of antibody production in mothers, as well as Fc-receptor expression alterations aimed at compensating for these differences.

We also examined the sex-specific impacts of other disease and birth-related factors on placental ISG and Fc-receptor expression, and placental antibody transfer. Using linear regression we did not observe significant impact of time since infection or disease severity on male or female placental expression of any ISGs, pro-inflammatory cytokines, Fc receptors, or IgG transfer (Supplementary Fig. 6). Additionally, though both male and female neonates born to SARS-CoV-2 positive mothers had statistically significantly lower birthweight compared to sex-matched controls, birthweights were in the normal range for both groups (Table 1) and birthweight did not significantly impact IgG antibody transfer in linear regression models (Supplementary Fig 6). Similarly, we did not observe significant associations between antibody transfer and days from infection or gestational age at delivery for either male or female neonates (Supplementary Fig. 6). In summary, disease severity, time since infection, neonatal birthweight, and gestational age at delivery do not appear to confound our earlier findings related to sexually dimorphic gene expression and antibody transfer. 

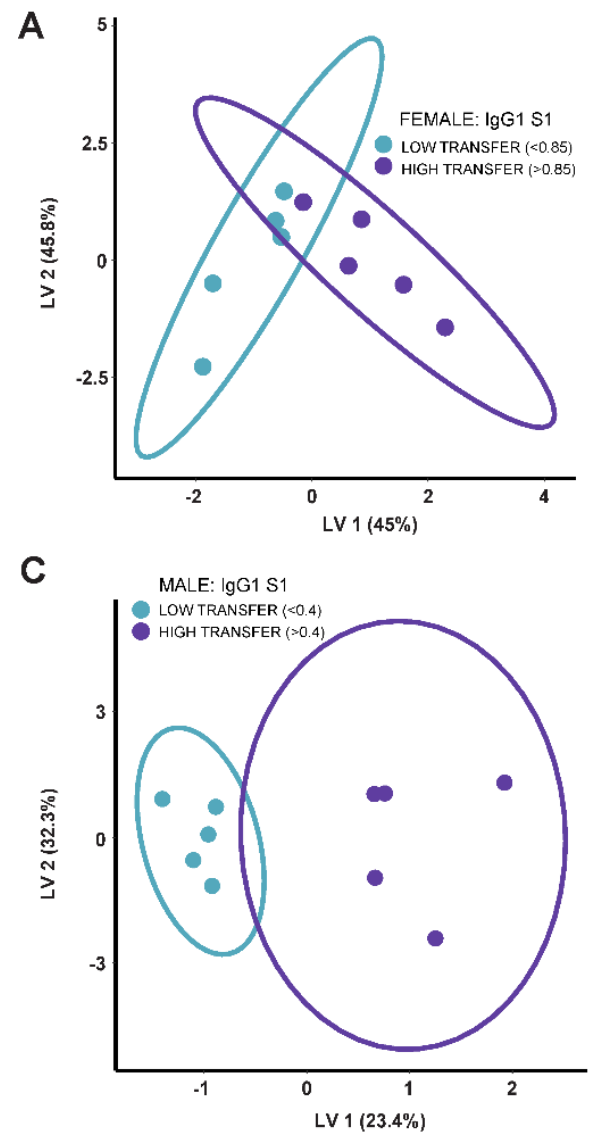

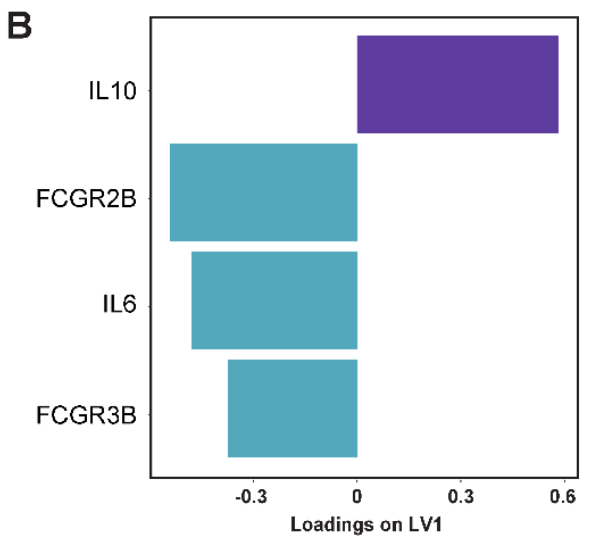

D

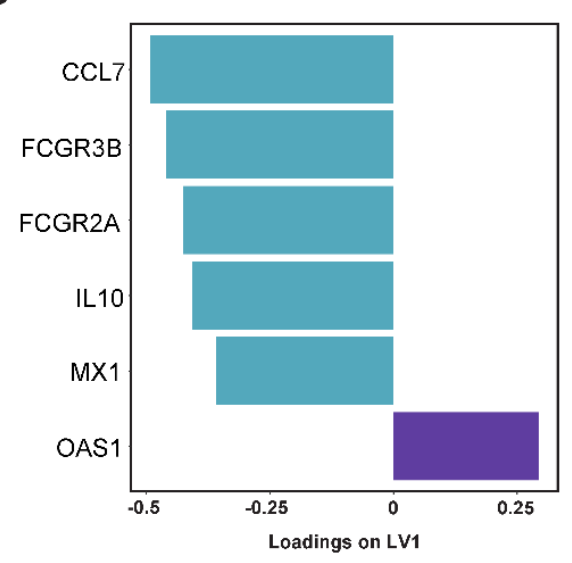

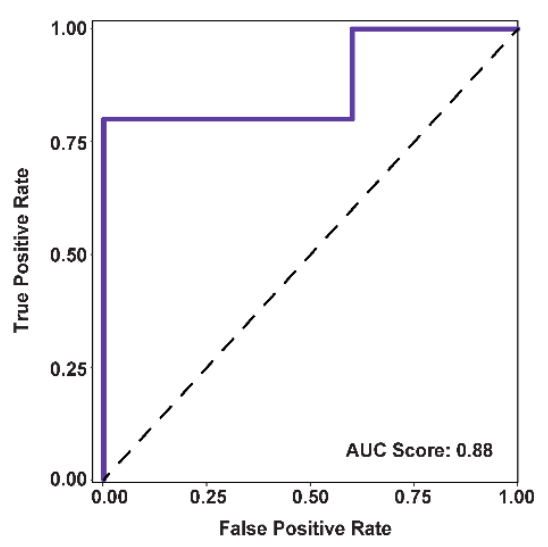

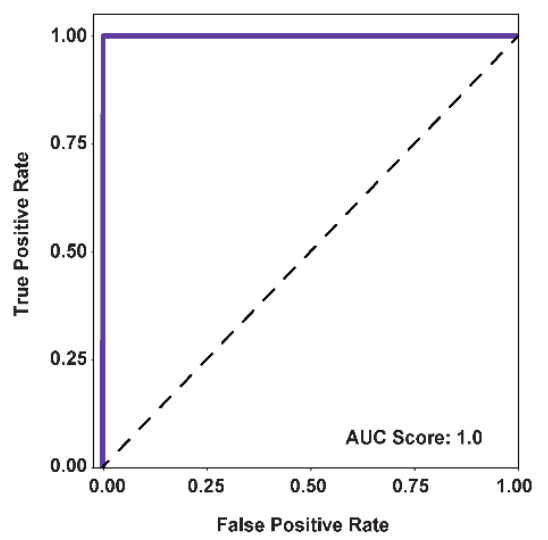

Figure 4. Transplacental antibody transfer characterized by gene expression.

(A) OPLSDA model classifying relatively low (ratio < 0.8) vs. high (ratio > 0.8) IgG1 S1 transfer to female neonates based on placental gene expression. The model was built on gene expression features after LASSO feature selection. Each dot represents one mother-cord pair.

(B) Gene expression feature loadings on the first latent variable (LV1) for the female model in (A). Bar color corresponds with which transfer classification (low vs. high) is characterized by enriched expression of that gene, with blue bars enriched in low transfer and purple bars enriched in high transfer. The receiver operating characteristic curve (solid purple line) for this model quantifies the accuracy in classifying IgG1 S1 transfer to female neonates after leave-one-out cross validation. The area under the curve (AUC) score is reported. The black dashed line represents the expected performance of a random model (AUC Score $=0.5$ ).

(C) OPLSDA model classifying relatively low (ratio < 0.4) vs. high (ratio > 0.4) IgG1 S1 transfer to male neonates based on placental gene expression. The model was built on gene expression features after LASSO feature selection.

(D) Gene expression feature loadings on the first latent variable (LV1) for the male model in (C). Bar color corresponds with which transfer classification (low vs. high) is characterized by enriched expression of that gene, with blue bars enriched in low transfer and purple bars enriched in high transfer, respectively. The receiver operating characteristic curve (solid purple line) for this model quantifies the accuracy in classifying IgG1 S1 transfer to male neonates after leave-one-out cross validation. The AUC score is reported with black dashed line representing the expected performance of a random model (AUC Score $=0.5$ ). 


\section{DISCUSSION}

Our results demonstrate the impact of fetal sex on the maternal and placental immune response to SARS-CoV-2, and the potential consequences for neonatal antibody-mediated immunity. We show that maternal SARS-CoV-2 infection is associated with sexually dimorphic expression of interferon stimulated genes and Fc receptors involved in placental transfer of maternal antibodies, with significant upregulation of ISGs and Fc receptors in SARS-CoV-2-exposed males. Male fetal sex was associated with reduced maternal SARS-CoV-2-specific IgG titers, and despite significant compensatory upregulation of placental Fc receptors, SARS-CoV-2-specific placental antibody transfer to the male fetus was reduced. Crosstalk between innate immunity (ISGs) and antibody adapters (FcRn/Fc $\gamma$ ) has been demonstrated to play a key role in optimizing tissue-specific immune responses against unfamiliar pathogens $(64,65)$. While Type I and III interferon responses may help protect the placenta from SARS-CoV-2 infection, the associated male-specific upregulation of placental Fc receptors was unable to overcome the deficit in SARS-CoV-2-specific antibody transfer from mother to fetus.

Epidemiologic data point to a persistent male bias in the development and severity of COVID-19 disease in adults, children, and infants $(6,8,9,68,69)$. Male COVID-19 patients are three times as likely to require admission to intensive care units and have higher odds of death than females (70). This male-biased vulnerability to maternal SARS-CoV-2 infection is consistent with a male-biased risk of mortality and morbidity across the perinatal period in general (1-3). Our findings of sexually dimorphic placental innate immune responses to infection, coupled with sex differences in transfer of maternal humoral immunity, may reveal broader vulnerabilities contributing to higher morbidity and mortality in male infants.

Although the impact of fetal sex is not consistently evaluated in studies of placental function (71), sexspecific alterations in the placental transcriptome have been described in both normal and pathologic pregnancies (72-75). Sex differences in the placental immune response to prenatal infections and other immune stressors have been described in human and animal models (32, 76-79), but have not been examined in SARSCoV-2 infection. Here we report that maternal SARS-CoV-2 infection induces a sexually dimorphic placental 
anti-viral innate immune response, with significant upregulation of ISGs in male, but not female, placentas. Male-specific stimulation of placental ISGs following SARS-CoV-2 exposure is consistent with the heightened male immune responses reported in SARS-CoV-2-infected adult and pediatric cohorts $(5,6,8-10,26,80)$. Interestingly, although we do not see evidence of placental, maternal blood, or cord blood SARS-CoV-2 infection (46), and the majority of maternal infections represent mild or moderate disease, there is still evidence of altered placental gene expression and an anti-viral response in the placentas of male pregnancies. This indicates that even a mild maternal infection has the potential to affect the placenta and fetus.

Innate immune sensing of SARS-CoV-2 involves the activation of type I and type III interferons and upregulation of ISGs in target cells (81). Given the relative paucity of SARS-CoV-2 placental infection (46) in comparison to other pandemic infections such as Zika (82), the increased ISG production and upregulated IL10 expression in exposed male placentas may be a protective mechanism to prevent direct placental infection and pathology. Indeed, high IFN levels during pregnancy have proven protective against placental HSV infection (83) and type III IFNs impair ZIKV transplacental transmission (84). Induction of ISGs is likely not universally protective, however. While type III IFNs primarily serve a barrier defense role, type I IFNs can serve a more classical immune activating/inflammatory role $(15,29)$. Animal models of viral infection in pregnancy implicate type I interferons and ISGs in impaired placental development and fetal growth restriction (30, 85), conditions which can have both short- and long-term impact on fetal and offspring health. Thus, it remains unclear if the male-specific upregulation of ISGs described here is potentially beneficial (e.g. protection from viral infection) or harmful, and what the long-term consequences may be for fetal development and in utero programming of later life metabolic and neurodevelopmental outcomes.

Due to their immature immune system, newborns rely on the passive transplacental transfer of maternal antibodies for initial protection against infectious pathogens $(36,39,86)$. While previous reports in adults have noted sex differences in production of SARS-CoV-2-specific antibodies $(26,87)$, this is the first report of sexbiased maternal production and transplacental transfer of SARS-CoV-2-specific antibodies. We previously reported impaired placental transfer of maternal SARS-CoV-2-specific antibodies in the setting of maternal 
SARS-CoV-2 infection $(46,47)$, consistent with the reduced transplacental transfer of maternal antibodies in other maternal infections such as malaria and HIV (38, 88-91). While there are known sex differences in adult antibody production in response to SARS-CoV-2 infection $(26,80)$, little is known about sex differences in maternal titers or transplacental antibody transfer $(92,93)$, particularly in the setting of maternal SARS-CoV-2 infection. Our finding of impaired placental transfer of SARS-CoV-2-specific antibodies, more pronounced in males, is consistent with the male-specific reduction of placental transfer of maternal IgG reported in a nonhuman primate model of maternal stress (92). We observed decreased maternal antibody titers against all measured SARS-CoV-2-specific antigens (S, S1, S2, RBD, N) when the fetus was male compared to female, a difference not noted for influenza or pertussis antigens. The reduced maternal antibody titers in the setting of a male fetus are likely attributable to suppressed maternal pro-inflammatory responses in the setting of a male fetus, possibly to improve tolerance of the fetal allograft $(13,14)$, and the direct correlation between proinflammatory response and increased antibody production noted in COVID-19 infection (59, 60). Reduced maternal SARS-CoV-2-specific IgG titer in male pregnancies is undoubtedly a driver of reduced transplacental transfer noted in male fetuses, as maternal titer is a key aspect of passive antibody transfer (94). Whether the male-biased impairment in placental SARS-CoV-2-specific antibody transfer renders male infants more vulnerable to early-life SARS-CoV-2 infection remains unclear, as the amount of antibody necessary for protection against SARS-CoV-2 infection is unknown.

Differential induction of placental ISGs in males versus females may impact placental antibody transfer via alteration in Fc receptor expression (95-97) and function (98). FC $\gamma$ receptor expression is upregulated on monocytes in the setting of Type I IFN signaling (99). The significant upregulation of FCGRT, FCGRI, and $F C G R 3 A / B$ we observed in male SARS-CoV-2-exposed placentas may therefore be a response to significantly increased IFN signaling in exposed male placentas. Hofbauer cells, tissue-resident macrophages of the placenta, express Fc $\gamma$ RI, II and III (41). The male-specific Hofbauer cell hyperplasia in placentas exposed to maternal SARS-CoV-2 infection could contribute to increased placental FCGR1/FCGR3 expression in males. Importantly, given the known role of placental Fc receptors in facilitating transplacental antibody transfer to the 
fetus, the male-specific upregulation of these receptors could be a compensatory response for the lower maternal SARS-CoV-2-specific antibody titers we describe in pregnancies with a male fetus.

A limitation of our study is the infection of participants primarily in the third trimester, because these samples were collected during the initial wave of the SARS-CoV-2 pandemic in Boston. Whether maternal SARS-CoV-2 infection in the first and second trimester alters ISG and Fc receptor expression, and how such altered expression might durably impact placental immune function, is a question that remains to be answered in future studies. In addition, although we found no significant association between disease severity and placental gene expression or antibody transfer, such examinations were limited by the relatively small number of women with severe or critical illness. Finally, while our regression models did not find time from infection to delivery to be a significant contributor to the antibody transfer ratios, we cannot entirely rule out any contribution of timing of maternal infection to the reduced antibody transfer noted in males. However, our robust sexually dimorphic gene and protein expression results, with significant upregulation of both placental ISGs and Fc receptors in males, demonstrate placental factors are a stronger driver of antibody transfer than any time-from-infection effect.

In conclusion, our comprehensive evaluation of the impact of fetal sex on placental gene expression and transplacental antibody transfer in maternal SARS-CoV-2 infection provides insight into sexually dimorphic or sex-specific placental innate and adaptive immune responses to maternal SARS-CoV-2 infection. The significantly increased impact of maternal SARS-CoV-2 infection on male placental and neonatal immunity highlights the importance of evaluating fetal sex in future studies of placental pathology and infant outcomes in SARS-CoV-2, as well as the critical importance of disaggregating sex data in follow-up studies of offspring neurodevelopmental and metabolic outcomes. These findings may have broader implications for understanding placental immune response, male vulnerability, and passive transfer of maternal antibody in other viral infections. Studies investigating SARS-CoV-2 vaccine safety and efficacy in pregnant women should also study placental immune response and antibody-transfer effects in addition to neonatal infection rates, and report these data in a sex-disaggregated fashion (100). 


\section{METHODS}

\section{Study design and participant recruitment}

Pregnant women at two tertiary care centers in Boston, Massachusetts were approached for enrollment in a COVID-19 pregnancy biorepository study starting April 2, 2020 (Massachusetts General Hospital and Brigham and Women's Hospital; Mass General Brigham IRB approval \#2020P000804). All participants provided written informed consent (virtual). Pregnant women were eligible for inclusion if they were: (1) 18 years of age or older, (2) able to provide informed consent or had a healthcare proxy to do so, (3) diagnosed with, or at risk for, SARS-CoV-2 infection. Due to wide community spread in Massachusetts during the study period (101), all pregnant women presenting for hospital care were deemed "at risk" for SARS-CoV-2 infection. Enrollment coincided with universal COVID-19 screening of all patients admitted to the Labor and Delivery units by nasopharyngeal RT-PCR testing (initiated April 16, 2020). Maternal SARS-CoV-2 positivity was defined by a positive clinical nasopharyngeal RT-PCR test result.

\section{Maternal and cord blood collection and processing}

Sample collection protocols have been described in a previous publication (102) and are described in detail in the Supplementary Materials and Methods.

\section{Systems Serology}

A multiplexed Luminex assay was used to determine relative titer of antigen-specific isotypes, subclasses, and FcR binding, as previously described (45). Detailed methodology is available in the Supplementary Materials and Methods.

\section{Placental sampling and processing}

Fetal side biopsies ( 0.5 cubic centimeter per biopsy) were collected immediately after delivery. Biopsies were taken from two separate locations at least $4 \mathrm{~cm}$ from the cord insertion avoiding surface vasculature, edges, and areas of gross pathology. Fetal membranes were dissected from the fetal and maternal surfaces, respectively. Biopsies were serially washed in DPBS, submerged in 5 volumes of RNAlater ${ }^{\circledR}$ (Invitrogen), and stored at least 24 hours at $4^{\circ} \mathrm{C}$. Excess RNAlater ${ }^{\circledR}$ was removed by blotting on Kimwipes, and biopsies were subdivided 
into $50 \mathrm{mg}$ segments, placed into cryovials, flash frozen in liquid nitrogen and stored at $-80^{\circ} \mathrm{C}$. For

histopathological examination, placentas were fixed in formalin, weighed, examined grossly, and sectioned/stained as described below.

\section{RNA extraction, cDNA synthesis, and qPCR}

Placental tissue was placed in Trizol $(100 \mathrm{uL} / 10 \mathrm{mg})$ and homogenized using a TissueTearor. Chloroform extraction was performed using an Rneasy Mini Kit (Qiagen), and cDNA synthesis was performed using iScript $^{\mathrm{TM}}$ cDNA Synthesis Kit (Bio-Rad) according to manufacturer instructions, as detailed in the

Supplemental materials and methods.

\section{Protein extraction and quantification}

Placental tissue was placed in RIPA Lysis and Extraction Buffer (ThermoFisher Scientific \#89901) containing Halt Protease and Phosphatase Inhibitor Cocktail (ThermoFisher Scientific \#78443) and homogenized using a TissueTearor. Resulting mixture was centrifuged at $10,000 \mathrm{rpm}$ for $10 \mathrm{~min}$ at $4{ }^{\circ} \mathrm{C}$ and supernatant was kept for protein quantification. Protein was quantified using Pierce BCA Protein Assay Kit (ThermoFisher Scientific \#23225).

\section{Immunoblotting}

50 ug of protein was prepared in Protein Sample Loading Buffer (Li-Cor Biosciences) and loaded on MiniPROTEAN 4-20\% TGX Stain-Free Precast Gels (Bio-Rad). Immunoblotting was performed as detailed in the Supplementary Materials and Methods. Fluorescence was then imaged with a ChemiDoc MP System (Bio-Rad) and quantified using Image Lab Software (Bio-Rad). Data is presented as volume of bands for protein of interest relative to the volume of bands contained in the total protein stain-free image.

\section{Immunofluorescence}

For co-labeling immunofluoresence (IF) experiments, placenta tissue sections were prepared as previously described (47). Detailed methodology is available in the Supplementary Materials and Methods.

\section{Multivariate Analyses}


All multivariate analyses were performed using R (version 4.0.0) and are detailed in the Supplementary

Materials and Methods.

\section{Statistical Analyses}

Statistical analyses were performed using GraphPad Prism 9 and using the 'stats' package in R (Version 4.0.0). Details of the specific statistical tests performed and statistical significance are described in figure legends and in the Supplementary Material.

\section{SUPPLEMENTARY MATERIALS}

\section{Methods}

Fig. S1. Maternal SARS-CoV-2 infection does not impact placental expression of TNF, IL6, or CCL7.

Fig. S2. SARS-CoV-2 infected mothers with male fetuses demonstrate reduced placental transfer of SARSCoV-2 antibodies compared to those with female fetuses.

Fig. S3. Maternal and cord blood titers of HA and PTN in SARS-CoV-2-infected and non-infected mothers.

Fig. S4. SARS-CoV-2 infected mothers with male fetuses have lower plasma levels of SARS-CoV-2-specific antibodies.

Fig. S5. No effect of maternal SARS-CoV-2 infection on expression or localization of FC $\gamma$ R2.

Fig. S6. Effect of disease severity, time since infection, neonatal birthweight, and gestational age on gene expression and antibody transfer.

Table S1. Demographic and clinical characteristics of participants providing maternal and cord blood by fetal sex and maternal SARS-CoV-2 status.

Table S2. 2-way ANOVA analysis of inflammatory cytokine and interferon stimulated gene expression.

Table S3. 2-way ANOVA analysis of Fc receptor gene expression, immunoblots, and immunohistochemistry.

Table S4. Taqman gene expression assays used for qPCR. 


\section{REFERENCES}

1. Z. H. Aghai, S. S. Goudar, A. Patel, S. Saleem, S. M. Dhaded, A. Kavi, P. Lalakia, F. Naqvi, P. L. Hibberd, E. M. McClure, T. L. Nolen, P. Iyer, R. L. Goldenberg, R. J. Derman, Gender variations in neonatal and early infant mortality in India and Pakistan: a secondary analysis from the Global Network Maternal Newborn Health Registry, Reprod. Health 17, 178 (2020).

2. N. Turner, K. Danesh, K. Moran, The evolution of infant mortality inequality in the United States, 19602016, Sci Adv 6, eaba5908 (2020).

3. R. Pongou, Why is infant mortality higher in boys than in girls? A new hypothesis based on preconception environment and evidence from a large sample of twins, Demography 50, 421-444 (2013).

4. J. E. Tyson, N. A. Parikh, J. Langer, C. Green, R. D. Higgins, National Institute of Child Health and Human Development Neonatal Research Network, Intensive care for extreme prematurity--moving beyond gestational age, N. Engl. J. Med. 358, 1672-1681 (2008).

5. L. R. Feldstein, E. B. Rose, A. G. Randolph, Multisystem Inflammatory Syndrome in Children in the United States. ReplyN. Engl. J. Med. 383 (2020), doi:10.1056/NEJMc2026136.

6. S. Godfred-Cato, B. Bryant, J. Leung, M. E. Oster, L. Conklin, J. Abrams, K. Roguski, B. Wallace, E. Prezzato, E. H. Koumans, E. H. Lee, A. Geevarughese, M. K. Lash, K. H. Reilly, W. P. Pulver, D. Thomas, K. A. Feder, K. K. Hsu, N. Plipat, G. Richardson, H. Reid, S. Lim, A. Schmitz, T. Pierce, S. Hrapcak, D. Datta, S. B. Morris, K. Clarke, E. Belay, California MIS-C Response Team, COVID-19-Associated Multisystem Inflammatory Syndrome in Children - United States, March-July 2020, MMWR Morb. Mortal. Wkly. Rep. 69, 1074-1080 (2020).

7. F. Götzinger, B. Santiago-García, A. Noguera-Julián, M. Lanaspa, L. Lancella, F. I. Calò Carducci, N. Gabrovska, S. Velizarova, P. Prunk, V. Osterman, U. Krivec, A. Lo Vecchio, D. Shingadia, A. SorianoArandes, S. Melendo, M. Lanari, L. Pierantoni, N. Wagner, A. G. L'Huillier, U. Heininger, N. Ritz, S. Bandi, N. Krajcar, S. Roglić, M. Santos, C. Christiaens, M. Creuven, D. Buonsenso, S. B. Welch, M. Bogyi, F. Brinkmann, M. Tebruegge, J. Pfefferle, A. Zacharasiewicz, A. Berger, R. Berger, V. Strenger, D. S. Kohlfürst, A. Zschocke, B. Bernar, B. Simma, E. Haberlandt, C. Thir, A. Biebl, K. Vanden Driessche, T. Boiy, D. Van Brusselen, A. Bael, S. Debulpaep, P. Schelstraete, I. Pavic, U. Nygaard, J. P. Glenthoej, L. Heilmann Jensen, I. Lind, M. Tistsenko, Ü. Uustalu, L. Buchtala, S. Thee, R. Kobbe, C. Rau, N. Schwerk, M. Barker, M. Tsolia, I. Eleftheriou, P. Gavin, O. Kozdoba, B. Zsigmond, P. Valentini, I. Ivaškeviciene, R. Ivaškevicius, V. Vilc, E. Schölvinck, A. Rojahn, A. Smyrnaios, C. Klingenberg, I. Carvalho, A. Ribeiro, A. Starshinova, I. Solovic, L. Falcón, O. Neth, L. Minguell, M. Bustillo, A. M. Gutiérrez-Sánchez, B. Guarch Ibáñez, F. Ripoll, B. Soto, K. Kötz, P. Zimmermann, H. Schmid, F. Zucol, A. Niederer, M. Buettcher, B. S. Cetin, O. Bilogortseva, V. Chechenyeva, A. Demirjian, F. Shackley, L. McFetridge, L. Speirs, C. Doherty, L. Jones, P. McMaster, C. Murray, F. Child, Y. Beuvink, N. Makwana, E. Whittaker, A. Williams, K. Fidler, J. Bernatoniene, R. Song, Z. Oliver, A. Riordan, COVID-19 in children and adolescents in Europe: a multinational, multicentre cohort study, The Lancet Child \& Adolescent Health 4, 653-661 (2020).

8. L. Kim, M. Whitaker, A. O’Halloran, A. Kambhampati, S. J. Chai, A. Reingold, I. Armistead, B. Kawasaki, J. Meek, K. Yousey-Hindes, E. J. Anderson, K. P. Openo, A. Weigel, P. Ryan, M. L. Monroe, K. Fox, S. Kim, R. Lynfield, E. Bye, S. Shrum Davis, C. Smelser, G. Barney, N. L. Spina, N. M. Bennett, C. B. Felsen, L. M. Billing, J. Shiltz, M. Sutton, N. West, H. K. Talbot, W. Schaffner, I. Risk, A. Price, L. Brammer, A. M. Fry, A. J. Hall, G. E. Langley, S. Garg, COVID-NET Surveillance Team, Hospitalization Rates and Characteristics of Children Aged <18 Years Hospitalized with Laboratory-Confirmed COVID-19 - COVID-NET, 14 States, March 1-July 25, 2020, MMWR Morb. Mortal. Wkly. Rep. 69, 1081-1088 (2020). 
9. L. M. Yonker, A. M. Neilan, Y. Bartsch, A. B. Patel, J. Regan, P. Arya, E. Gootkind, G. Park, M. Hardcastle, A. St John, L. Appleman, M. L. Chiu, A. Fialkowski, D. De la Flor, R. Lima, E. A. Bordt, L. J. Yockey, P. D’Avino, S. Fischinger, J. E. Shui, P. H. Lerou, J. V. Bonventre, X. G. Yu, E. T. Ryan, I. V. Bassett, D. Irimia, A. G. Edlow, G. Alter, J. Z. Li, A. Fasano, Pediatric Severe Acute Respiratory Syndrome Coronavirus 2 (SARS-CoV-2): Clinical Presentation, Infectivity, and Immune Responses, J. Pediatr. (2020), doi:10.1016/j.jpeds.2020.08.037.

10. X. Ma, S. Liu, L. Chen, L. Zhuang, J. Zhang, Y. Xin, The clinical characteristics of pediatric inpatients with SARS-CoV-2 infection: A meta-analysis and systematic review, J. Med. Virol. (2020), doi:10.1002/jmv.26208.

11. M. Muenchhoff, P. J. R. Goulder, Sex differences in pediatric infectious diseases, J. Infect. Dis. 209 Suppl 3, S120-6 (2014).

12. S. L. Klein, K. L. Flanagan, Sex differences in immune responses, Nat. Rev. Immunol. 16, 626-638 (2016).

13. B. D. Taylor, R. B. Ness, M. A. Klebanoff, G. Tang, J. M. Roberts, D. M. Hougaard, K. Skogstrand, C. L. Haggerty, The impact of female fetal sex on preeclampsia and the maternal immune milieu, Pregnancy Hypertens. 12, 53-57 (2018).

14. A. M. Mitchell, M. Palettas, L. M. Christian, Fetal sex is associated with maternal stimulated cytokine production, but not serum cytokine levels, in human pregnancy, Brain Behav. Immun. 60, 32-37 (2017).

15. H. M. Lazear, J. W. Schoggins, M. S. Diamond, Shared and Distinct Functions of Type I and Type III Interferons, Immunity 50, 907-923 (2019).

16. M. J. Cameron, L. Ran, L. Xu, A. Danesh, J. F. Bermejo-Martin, C. M. Cameron, M. P. Muller, W. L. Gold, S. E. Richardson, S. M. Poutanen, B. M. Willey, M. E. DeVries, Y. Fang, C. Seneviratne, S. E. Bosinger, D. Persad, P. Wilkinson, L. D. Greller, R. Somogyi, A. Humar, S. Keshavjee, M. Louie, M. B. Loeb, J. Brunton, A. J. McGeer, Canadian SARS Research Network, D. J. Kelvin, Interferon-mediated immunopathological events are associated with atypical innate and adaptive immune responses in patients with severe acute respiratory syndrome, J. Virol. 81, 8692-8706 (2007).

17. R. Channappanavar, A. R. Fehr, R. Vijay, M. Mack, J. Zhao, D. K. Meyerholz, S. Perlman, Dysregulated Type I Interferon and Inflammatory Monocyte-Macrophage Responses Cause Lethal Pneumonia in SARSCoV-Infected Mice, Cell Host Microbe 19, 181-193 (2016).

18. J. Zhao, K. Li, C. Wohlford-Lenane, S. S. Agnihothram, C. Fett, J. Zhao, M. J. Gale Jr, R. S. Baric, L. Enjuanes, T. Gallagher, P. B. McCray Jr, S. Perlman, Rapid generation of a mouse model for Middle East respiratory syndrome, Proc. Natl. Acad. Sci. U. S. A. 111, 4970-4975 (2014).

19. D. Blanco-Melo, B. E. Nilsson-Payant, W.-C. Liu, S. Uhl, D. Hoagland, R. Møller, T. X. Jordan, K. Oishi, M. Panis, D. Sachs, T. T. Wang, R. E. Schwartz, J. K. Lim, R. A. Albrecht, B. R. tenOever, Imbalanced Host Response to SARS-CoV-2 Drives Development of COVID-19, Cell 181, 1036-1045.e9 (2020).

20. B. Israelow, E. Song, T. Mao, P. Lu, A. Meir, F. Liu, M. M. Alfajaro, J. Wei, H. Dong, R. J. Homer, A. Ring, C. B. Wilen, A. Iwasaki, Mouse model of SARS-CoV-2 reveals inflammatory role of type I interferon signaling, J. Exp. Med. 217 (2020), doi:10.1084/jem.20201241.

21. J. S. Lee, S. Park, H. W. Jeong, J. Y. Ahn, S. J. Choi, H. Lee, B. Choi, S. K. Nam, M. Sa, J.-S. Kwon, S. J. Jeong, H. K. Lee, S. H. Park, S.-H. Park, J. Y. Choi, S.-H. Kim, I. Jung, E.-C. Shin, Immunophenotyping of COVID-19 and influenza highlights the role of type I interferons in development of severe COVID-19, Sci Immunol 5 (2020), doi:10.1126/sciimmunol.abd1554. 
22. C. Lucas, P. Wong, J. Klein, T. B. R. Castro, J. Silva, M. Sundaram, M. K. Ellingson, T. Mao, J. E. Oh, B. Israelow, T. Takahashi, M. Tokuyama, P. Lu, A. Venkataraman, A. Park, S. Mohanty, H. Wang, A. L. Wyllie, C. B. F. Vogels, R. Earnest, S. Lapidus, I. M. Ott, A. J. Moore, M. C. Muenker, J. B. Fournier, M. Campbell, C. D. Odio, A. Casanovas-Massana, Yale IMPACT Team, R. Herbst, A. C. Shaw, R. Medzhitov, W. L. Schulz, N. D. Grubaugh, C. Dela Cruz, S. Farhadian, A. I. Ko, S. B. Omer, A. Iwasaki, Longitudinal analyses reveal immunological misfiring in severe COVID-19, Nature 584, 463-469 (2020).

23. C. Qin, L. Zhou, Z. Hu, S. Zhang, S. Yang, Y. Tao, C. Xie, K. Ma, K. Shang, W. Wang, D.-S. Tian, Dysregulation of immune response in patients with COVID-19 in Wuhan, China, Clin. Infect. Dis. (2020), doi:10.1093/cid/ciaa248.

24. Y. Xiong, Y. Liu, L. Cao, D. Wang, M. Guo, A. Jiang, D. Guo, W. Hu, J. Yang, Z. Tang, H. Wu, Y. Lin, M. Zhang, Q. Zhang, M. Shi, Y. Liu, Y. Zhou, K. Lan, Y. Chen, Transcriptomic characteristics of bronchoalveolar lavage fluid and peripheral blood mononuclear cells in COVID-19 patients, Emerg. Microbes Infect. 9, 761-770 (2020).

25. Z. Zhou, L. Ren, L. Zhang, J. Zhong, Y. Xiao, Z. Jia, L. Guo, J. Yang, C. Wang, S. Jiang, D. Yang, G. Zhang, H. Li, F. Chen, Y. Xu, M. Chen, Z. Gao, J. Yang, J. Dong, B. Liu, X. Zhang, W. Wang, K. He, Q. Jin, M. Li, J. Wang, Heightened Innate Immune Responses in the Respiratory Tract of COVID-19 Patients, Cell Host Microbe 27, 883-890.e2 (2020).

26. T. Takahashi, M. K. Ellingson, P. Wong, B. Israelow, C. Lucas, J. Klein, J. Silva, T. Mao, J. E. Oh, M. Tokuyama, P. Lu, A. Venkataraman, A. Park, F. Liu, A. Meir, J. Sun, E. Y. Wang, A. Casanovas-Massana, A. L. Wyllie, C. B. F. Vogels, R. Earnest, S. Lapidus, I. M. Ott, A. J. Moore, Yale IMPACT Research Team, A. Shaw, J. B. Fournier, C. D. Odio, S. Farhadian, C. Dela Cruz, N. D. Grubaugh, W. L. Schulz, A. M. Ring, A. I. Ko, S. B. Omer, A. Iwasaki, Sex differences in immune responses that underlie COVID-19 disease outcomes, Nature (2020), doi:10.1038/s41586-020-2700-3.

27. R. Channappanavar, C. Fett, M. Mack, P. P. Ten Eyck, D. K. Meyerholz, S. Perlman, Sex-Based Differences in Susceptibility to Severe Acute Respiratory Syndrome Coronavirus Infection, J. Immunol. 198, 4046-4053 (2017).

28. N. Gadi, S. C. Wu, A. P. Spihlman, V. R. Moulton, What's Sex Got to Do With COVID-19? Gender-Based Differences in the Host Immune Response to Coronaviruses, Front. Immunol. 11, 2147 (2020).

29. A. I. Wells, C. B. Coyne, Type III Interferons in Antiviral Defenses at Barrier Surfaces, Trends Immunol. 39, 848-858 (2018).

30. L. J. Yockey, K. A. Jurado, N. Arora, A. Millet, T. Rakib, K. M. Milano, A. K. Hastings, E. Fikrig, Y. Kong, T. L. Horvath, S. Weatherbee, H. J. Kliman, C. B. Coyne, A. Iwasaki, Type I interferons instigate fetal demise after Zika virus infection, Sci Immunol 3 (2018), doi:10.1126/sciimmunol.aao1680.

31. L. J. Yockey, C. Lucas, A. Iwasaki, Contributions of maternal and fetal antiviral immunity in congenital disease, Science 368, 608-612 (2020).

32. A. E. Braun, P. A. Carpentier, B. A. Babineau, A. R. Narayan, M. L. Kielhold, H. M. Moon, A. Shankar, J. $\mathrm{Su}$, V. Saravanapandian, U. Haditsch, T. D. Palmer, "Females Are Not Just 'Protected' Males": Sex-Specific Vulnerabilities in Placenta and Brain after Prenatal Immune Disruption, eNeuro 6 (2019), doi:10.1523/ENEURO.0358-19.2019.

33. I. Trus, D. Udenze, B. Cox, N. Berube, R. E. Nordquist, F. J. van der Staay, Y. Huang, G. Kobinger, D. Safronetz, V. Gerdts, U. Karniychuk, Subclinical in utero Zika virus infection is associated with interferon 
alpha sequelae and sex-specific molecular brain pathology in asymptomatic porcine offspring, PLoS Pathog. 15, e1008038 (2019).

34. V. L. Clifton, Review: Sex and the human placenta: mediating differential strategies of fetal growth and survival, Placenta 31 Suppl, S33-9 (2010).

35. S. M. Leon-Garcia, H. A. Roeder, K. K. Nelson, X. Liao, D. P. Pizzo, L. C. Laurent, M. M. Parast, D. Y. LaCoursiere, Maternal obesity and sex-specific differences in placental pathology, Placenta 38, 33-40 (2016).

36. M. F. Jennewein, B. Abu-Raya, Y. Jiang, G. Alter, A. Marchant, Transfer of maternal immunity and programming of the newborn immune system, Semin. Immunopathol. 39, 605-613 (2017).

37. M. F. Jennewein, I. Goldfarb, S. Dolatshahi, C. Cosgrove, F. J. Noelette, M. Krykbaeva, J. Das, A. Sarkar, M. J. Gorman, S. Fischinger, C. M. Boudreau, J. Brown, J. H. Cooperrider, J. Aneja, T. J. Suscovich, B. S. Graham, G. M. Lauer, T. Goetghebuer, A. Marchant, D. Lauffenburger, A. Y. Kim, L. E. Riley, G. Alter, Fc Glycan-Mediated Regulation of Placental Antibody Transfer, Cell 178, 202-215.e14 (2019).

38. M. I. de Moraes-Pinto, F. Verhoeff, L. Chimsuku, P. J. Milligan, L. Wesumperuma, R. L. Broadhead, B. J. Brabin, P. M. Johnson, C. A. Hart, Placental antibody transfer: influence of maternal HIV infection and placental malaria, Arch. Dis. Child. Fetal Neonatal Ed. 79, F202-5 (1998).

39. M. Albrecht, P. C. Arck, Vertically Transferred Immunity in Neonates: Mothers, Mechanisms and Mediators, Front. Immunol. 11, 555 (2020).

40. CDC, Vaccinating Pregnant Women (2019) (available at https://www.cdc.gov/vitalsigns/maternalvaccines/index.html).

41. D. R. Martinez, G. G. Fouda, X. Peng, M. E. Ackerman, S. R. Permar, Noncanonical placental Fc receptors: What is their role in modulating transplacental transfer of maternal IgG?, PLoS Pathog. 14, e1007161 (2018).

42. D. R. Martinez, Y. Fong, S. H. Li, F. Yang, M. F. Jennewein, J. A. Weiner, E. A. Harrell, J. F. Mangold, R. Goswami, G. R. Seage 3rd, G. Alter, M. E. Ackerman, X. Peng, G. G. Fouda, S. R. Permar, Fc Characteristics Mediate Selective Placental Transfer of IgG in HIV-Infected Women, Cell 178, 190-201.e11 (2019).

43. N. E. Simister, C. M. Story, Human placental Fc receptors and the transmission of antibodies from mother to fetus, J. Reprod. Immunol. 37, 1-23 (1997).

44. P. Cumberland, C. E. Shulman, P. A. C. Maple, J. N. Bulmer, E. K. Dorman, K. Kawuondo, K. Marsh, F. T. Cutts, Maternal HIV infection and placental malaria reduce transplacental antibody transfer and tetanus antibody levels in newborns in Kenya, J. Infect. Dis. 196, 550-557 (2007).

45. A. R. D. McLean, D. Stanisic, R. McGready, K. Chotivanich, C. Clapham, F. Baiwog, M. Pimanpanarak, P. Siba, I. Mueller, C. L. King, F. Nosten, J. G. Beeson, S. Rogerson, J. A. Simpson, F. J. I. Fowkes, P. falciparum infection and maternofetal antibody transfer in malaria-endemic settings of varying transmission, PLoS One 12, e0186577 (2017).

46. A. G. Edlow, J. Z. Li, A.-R. Y. Collier, C. Atyeo, K. E. James, A. A. Boatin, K. J. Gray, E. A. Bordt, L. L. Shook, L. M. Yonker, A. Fasano, K. Diouf, N. Croul, S. Devane, L. J. Yockey, R. Lima, J. Shui, J. D. Matute, P. H. Lerou, B. O. Akinwunmi, A. Schmidt, J. Feldman, B. M. Hauser, T. M. Caradonna, D. De la Flor, P. D’Avino, J. Regan, H. Corry, K. Coxen, J. Fajnzylber, D. Pepin, M. S. Seaman, D. H. Barouch, B. D. Walker, X. G. Yu, A. J. Kaimal, D. J. Roberts, G. Alter, Assessment of Maternal and Neonatal SARS-CoV-2 Viral Load, Transplacental Antibody Transfer, and Placental Pathology in Pregnancies During the COVID-19 
Pandemic, JAMA Netw Open 3, e2030455 (2020).

47. C. Atyeo, K. M. Pullen, E. A. Bordt, S. Fischinger, J. Burke, A. Michell, M. D. Slein, C. Loos, L. L. Shook, A. A. Boatin, L. J. Yockey, D. Pepin, M.-C. Meinsohn, N. M. P. Nguyen, M. Chauvin, D. Roberts, I. T. Goldfarb, J. D. Matute, K. E. James, L. M. Yonker, L. M. Bebell, A. J. Kaimal, K. J. Gray, D. Lauffenburger, A. G. Edlow, G. Alter, Compromised SARS-CoV-2-specific placental antibody transfer, Cell 0 (2020), doi:10.1016/j.cell.2020.12.027.

48. I. T. Goldfarb, M. A. Clapp, M. D. Soffer, L. L. Shook, K. Rushfirth, A. G. Edlow, A. A. Boatin, A. J. Kaimal, W. H. Barth Jr, A. S. Bryant, Prevalence and Severity of Coronavirus Disease 2019 (COVID-19) Illness in Symptomatic Pregnant and Postpartum Women Stratified by Hispanic Ethnicity, Obstet. Gynecol. 136, 300-302 (2020).

49. R. L. Casazza, H. M. Lazear, J. J. Miner, Protective and Pathogenic Effects of Interferon Signaling During Pregnancy, Viral Immunol. 33, 3-11 (2020).

50. A. Bayer, N. J. Lennemann, Y. Ouyang, J. C. Bramley, S. Morosky, E. T. D. A. Marques Jr, S. Cherry, Y. Sadovsky, C. B. Coyne, Type III Interferons Produced by Human Placental Trophoblasts Confer Protection against Zika Virus Infection, Cell Host Microbe 19, 705-712 (2016).

51. M. H. Lehmann, L. E. Torres-Domínguez, P. J. R. Price, C. Brandmüller, C. J. Kirschning, G. Sutter, CCL2 expression is mediated by type I IFN receptor and recruits NK and T cells to the lung during MVA infection, J. Leukoc. Biol. 99, 1057-1064 (2016).

52. J. Bizzotto, P. Sanchis, M. Abbate, S. Lage-Vickers, R. Lavignolle, A. Toro, S. Olszevicki, A. Sabater, F. Cascardo, E. Vazquez, J. Cotignola, G. Gueron, SARS-CoV-2 Infection Boosts MX1 Antiviral Effector in COVID-19 Patients, iScience 23, 101585 (2020).

53. V. J. Costela-Ruiz, R. Illescas-Montes, J. M. Puerta-Puerta, C. Ruiz, L. Melguizo-Rodríguez, SARS-CoV-2 infection: The role of cytokines in COVID-19 disease, Cytokine Growth Factor Rev. 54, 62-75 (2020).

54. M. Z. Zulu, F. O. Martinez, S. Gordon, C. M. Gray, The Elusive Role of Placental Macrophages: The Hofbauer Cell, J. Innate Immun. 11, 447-456 (2019).

55. J. L. Hecht, B. Quade, V. Deshpande, M. Mino-Kenudson, D. T. Ting, N. Desai, B. Dygulska, T. Heyman, C. Salafia, D. Shen, S. V. Bates, D. J. Roberts, SARS-CoV-2 can infect the placenta and is not associated with specific placental histopathology: a series of 19 placentas from COVID-19-positive mothers, Mod. Pathol. 33, 2092-2103 (2020).

56. F. Facchetti, M. Bugatti, E. Drera, C. Tripodo, E. Sartori, V. Cancila, M. Papaccio, R. Castellani, S. Casola, M. B. Boniotti, P. Cavadini, A. Lavazza, SARS-CoV2 vertical transmission with adverse effects on the newborn revealed through integrated immunohistochemical, electron microscopy and molecular analyses of Placenta, EBioMedicine 59, 102951 (2020).

57. E. Ludwig, J. Harder, M. Lacorcia, Y. J. Honkpehedji, O. P. Nouatin, G. J. van Dam, P. L. A. M. Corstjens, E. Sartono, M. Esen, S. M. Lobmaier, A. A. Adegnika, C. Prazeres da Costa, Placental gene expression and antibody levels of mother-neonate pairs reveal an enhanced risk for inflammation in a helminth endemic country, Sci. Rep. 9, 15776 (2019).

58. F. M. Munoz, N. H. Bond, M. Maccato, P. Pinell, H. A. Hammill, G. K. Swamy, E. B. Walter, L. A. Jackson, J. A. Englund, M. S. Edwards, C. M. Healy, C. R. Petrie, J. Ferreira, J. B. Goll, C. J. Baker, Safety and immunogenicity of tetanus diphtheria and acellular pertussis (Tdap) immunization during pregnancy in mothers 
and infants: a randomized clinical trial, JAMA 311, 1760-1769 (2014).

59. G. Gonçalves, F. T. Cutts, M. Hills, H. Rebelo-Andrade, F. A. Trigo, H. Barros, Transplacental transfer of measles and total IgG, Epidemiol. Infect. 122, 273-279 (1999).

60. P. Palmeira, C. Quinello, A. L. Silveira-Lessa, C. A. Zago, M. Carneiro-Sampaio, IgG placental transfer in healthy and pathological pregnancies, Clin. Dev. Immunol. 2012, 985646 (2012).

61. M. C. Woodruff, R. P. Ramonell, D. C. Nguyen, K. S. Cashman, A. S. Saini, N. S. Haddad, A. M. Ley, S. Kyu, J. C. Howell, T. Ozturk, S. Lee, N. Suryadevara, J. B. Case, R. Bugrovsky, W. Chen, J. Estrada, A. Morrison-Porter, A. Derrico, F. A. Anam, M. Sharma, H. M. Wu, S. N. Le, S. A. Jenks, C. M. Tipton, B. Staitieh, J. L. Daiss, E. Ghosn, M. S. Diamond, R. H. Carnahan, J. E. Crowe Jr, W. T. Hu, F. E.-H. Lee, I. Sanz, Extrafollicular B cell responses correlate with neutralizing antibodies and morbidity in COVID-19, Nat. Immunol. 21, 1506-1516 (2020).

62. W. F. Garcia-Beltran, E. C. Lam, M. G. Astudillo, D. Yang, T. E. Miller, J. Feldman, B. M. Hauser, T. M. Caradonna, K. L. Clayton, A. D. Nitido, M. R. Murali, G. Alter, R. C. Charles, A. Dighe, J. A. Branda, J. K. Lennerz, D. Lingwood, A. G. Schmidt, A. J. Iafrate, A. B. Balazs, COVID-19-neutralizing antibodies predict disease severity and survival, Cell (2020), doi:10.1016/j.cell.2020.12.015.

63. D. C. Roopenian, S. Akilesh, FcRn: the neonatal Fc receptor comes of age, Nat. Rev. Immunol. 7, 715-725 (2007).

64. N. A. Lozano, A. Lozano, V. Marini, R. J. Saranz, R. S. Blumberg, K. Baker, M. F. Agresta, M. F. Ponzio, Expression of FcRn receptor in placental tissue and its relationship with IgG levels in term and preterm newborns, Am. J. Reprod. Immunol. 80, e12972 (2018).

65. V. Fonti, E. Belitser, Feature selection using lasso, VU Amsterdam Research Paper in Business Analytics 30, 1-25 (2017).

66. D. Rittirsch, M. A. Flierl, D. E. Day, B. A. Nadeau, F. S. Zetoune, J. V. Sarma, C. M. Werner, G. A. Wanner, H.-P. Simmen, M. S. Huber-Lang, P. A. Ward, Cross-talk between TLR4 and FcgammaReceptorIII (CD16) pathways, PLoS Pathog. 5, e1000464 (2009).

67. F. Nimmerjahn, J. V. Ravetch, Fcgamma receptors as regulators of immune responses, Nat. Rev. Immunol. 8, 34-47 (2008).

68. C. M. Petrilli, S. A. Jones, J. Yang, H. Rajagopalan, L. O’Donnell, Y. Chernyak, K. A. Tobin, R. J. Cerfolio, F. Francois, L. I. Horwitz, Factors associated with hospital admission and critical illness among 5279 people with coronavirus disease 2019 in New York City: prospective cohort study, BMJ 369, m1966 (2020).

69. B. B. Abate, A. M. Kassie, M. W. Kassaw, T. G. Aragie, S. A. Masresha, Sex difference in coronavirus disease (COVID-19): a systematic review and meta-analysis, BMJ Open 10, e040129 (2020).

70. H. Peckham, N. M. de Gruijter, C. Raine, A. Radziszewska, C. Ciurtin, L. R. Wedderburn, E. C. Rosser, K. Webb, C. T. Deakin, Male sex identified by global COVID-19 meta-analysis as a risk factor for death and ITU admission, Nat. Commun. 11, 6317 (2020).

71. N. Walker, P. Filis, U. Soffientini, M. Bellingham, P. J. O’Shaughnessy, P. A. Fowler, Placental transporter localization and expression in the Human: the importance of species, sex, and gestational age differences $\dagger$, Biol. Reprod. 96, 733-742 (2017).

72. S. Buckberry, T. Bianco-Miotto, C. T. Roberts, Imprinted and X-linked non-coding RNAs as potential 
regulators of human placental function, Epigenetics 9, 81-89 (2014).

73. S. Buckberry, T. Bianco-Miotto, S. J. Bent, G. A. Dekker, C. T. Roberts, Integrative transcriptome metaanalysis reveals widespread sex-biased gene expression at the human fetal-maternal interface, Mol. Hum. Reprod. 20, 810-819 (2014).

74. T. J. Stuart, K. O’Neill, D. Condon, I. Sasson, P. Sen, Y. Xia, R. A. Simmons, Diet-induced obesity alters the maternal metabolome and early placenta transcriptome and decreases placenta vascularity in the mouse, Biol. Reprod. 98, 795-809 (2018).

75. T. Sun, T. L. Gonzalez, N. Deng, R. DiPentino, E. L. Clark, B. Lee, J. Tang, Y. Wang, B. R. Stripp, C. Yao, H.-R. Tseng, S. A. Karumanchi, A. F. Koeppel, S. D. Turner, C. R. Farber, S. S. Rich, E. T. Wang, J. Williams, M. D. Pisarska, Sexually Dimorphic Crosstalk at the Maternal-Fetal Interface, J. Clin. Endocrinol. Metab. 105 (2020), doi:10.1210/clinem/dgaa503.

76. M.-J. Allard, A. Giraud, M. Segura, G. Sebire, Sex-specific maternofetal innate immune responses triggered by group B Streptococci, Sci. Rep. 9, 8587 (2019).

77. S. L. Bronson, T. L. Bale, Prenatal stress-induced increases in placental inflammation and offspring hyperactivity are male-specific and ameliorated by maternal antiinflammatory treatment, Endocrinology $\mathbf{1 5 5}$, 2635-2646 (2014).

78. R. L. Goldenberg, W. W. Andrews, O. M. Faye-Petersen, A. R. Goepfert, S. P. Cliver, J. C. Hauth, The Alabama Preterm Birth Study: intrauterine infection and placental histologic findings in preterm births of males and females less than 32 weeks, Am. J. Obstet. Gynecol. 195, 1533-1537 (2006).

79. T. L. Barke, K. M. Money, L. Du, A. Serezani, M. Gannon, K. Mirnics, D. M. Aronoff, Sex modifies placental gene expression in response to metabolic and inflammatory stress, Placenta 78, 1-9 (2019).

80. E. P. Scully, J. Haverfield, R. L. Ursin, C. Tannenbaum, S. L. Klein, Considering how biological sex impacts immune responses and COVID-19 outcomes, Nat. Rev. Immunol. 20, 442-447 (2020).

81. N. Vabret, G. J. Britton, C. Gruber, S. Hegde, J. Kim, M. Kuksin, R. Levantovsky, L. Malle, A. Moreira, M. D. Park, L. Pia, E. Risson, M. Saffern, B. Salomé, M. Esai Selvan, M. P. Spindler, J. Tan, V. van der Heide, J. K. Gregory, K. Alexandropoulos, N. Bhardwaj, B. D. Brown, B. Greenbaum, Z. H. Gümüş, D. Homann, A. Horowitz, A. O. Kamphorst, M. A. Curotto de Lafaille, S. Mehandru, M. Merad, R. M. Samstein, Sinai Immunology Review Project, Immunology of COVID-19: Current State of the Science, Immunity 52, 910-941 (2020).

82. A. E. Ades, A. Soriano-Arandes, A. Alarcon, F. Bonfante, C. Thorne, C. S. Peckham, C. Giaquinto, Vertical transmission of Zika virus and its outcomes: a Bayesian synthesis of prospective studies, Lancet Infect. Dis. (2020), doi:10.1016/S1473-3099(20)30432-1.

83. M. Zdravkovic, H. J. Knudsen, X. Liu, H. Hager, V. Zachar, G. Aboagye-Mathiesen, P. Ebbesen, High interferon alpha levels in placenta, maternal, and cord blood suggest a protective effect against intrauterine herpes simplex virus infection, J. Med. Virol. 51, 210-213 (1997).

84. B. W. Jagger, J. J. Miner, B. Cao, N. Arora, A. M. Smith, A. Kovacs, I. U. Mysorekar, C. B. Coyne, M. S. Diamond, Gestational Stage and IFN- $\lambda$ Signaling Regulate ZIKV Infection In Utero, Cell Host Microbe 22 , 366-376.e3 (2017).

85. K. J. Baines, A. M. Rampersaud, D. M. Hillier, M. J. Jeyarajah, G. K. Grafham, G. Eastabrook, J. C. 
Lacefield, S. J. Renaud, Antiviral Inflammation during Early Pregnancy Reduces Placental and Fetal Growth Trajectories, J. Immunol. 204, 694-706 (2020).

86. D. J. Dowling, O. Levy, Ontogeny of early life immunity, Trends Immunol. 35, 299-310 (2014).

87. M. J. Bunders, M. Altfeld, Implications of Sex Differences in Immunity for SARS-CoV-2 Pathogenesis and Design of Therapeutic Interventions, Immunity 53, 487-495 (2020).

88. C. Farquhar, R. Nduati, N. Haigwood, W. Sutton, D. Mbori-Ngacha, B. Richardson, G. John-Stewart, High maternal HIV-1 viral load during pregnancy is associated with reduced placental transfer of measles IgG antibody, J. Acquir. Immune Defic. Syndr. 40, 494-497 (2005).

89. J. E. Atwell, B. Thumar, L. J. Robinson, R. Tobby, P. Yambo, M. Ome-Kaius, P. M. Siba, H. W. Unger, S. J. Rogerson, C. L. King, R. A. Karron, Impact of Placental Malaria and Hypergammaglobulinemia on Transplacental Transfer of Respiratory Syncytial Virus Antibody in Papua New Guinea, J. Infect. Dis. 213, 423-431 (2016).

90. C. E. Jones, S. Naidoo, C. De Beer, M. Esser, B. Kampmann, A. C. Hesseling, Maternal HIV infection and antibody responses against vaccine-preventable diseases in uninfected infants, JAMA 305, 576-584 (2011).

91. A. M. Ciobanu, A. E. Dumitru, N. Gica, R. Botezatu, G. Peltecu, A. M. Panaitescu, Benefits and Risks of IgG Transplacental Transfer, Diagnostics (Basel) 10 (2020), doi:10.3390/diagnostics10080583.

92. C. L. Coe, H. R. Crispen, Social stress in pregnant squirrel monkeys (Saimiri boliviensis peruviensis) differentially affects placental transfer of maternal antibody to male and female infants, Health Psychol. 19, 554-559 (2000).

93. K. Maertens, T. M. P. Tran, N. Hens, P. Van Damme, E. Leuridan, Effect of Prepregnancy Pertussis Vaccination in Young Infants, J. Infect. Dis. 215, 1855-1861 (2017).

94. J. M. Kubiak, E. A. Murphy, J. Yee, K. Cagino, R. L. Friedlander, S. M. Glynn, K. C. Matthews, M. Jurkiewicz, A. C. Sukhu, Z. Zhao, M. Prabhu, L. Riley, Y. J. Yang, SARS-CoV-2 serology levels in pregnant women and their neonates, Am. J. Obstet. Gynecol. , doi:10.1016/j.ajog.2021.01.016.

95. C. Zhao, Y. Gao, N. Yu, T. Li, Y. Zhang, H. Zhang, G. Lu, Y. Gao, X. Guo, Unidirectional transport of IgG by neonatal $\mathrm{Fc}$ receptor in human thyrocytes varies across different IgG subclasses, Mol. Cell. Endocrinol. 477, 103-111 (2018).

96. K. D. Fairchild, R. G. Hudson, S. D. Douglas, S. E. McKenzie, R. A. Polin, Effect of gamma interferon on expression of Fc gamma receptors in monocytes of newborn infants and adults, Clin. Diagn. Lab. Immunol. 3, 464-469 (1996).

97. R. N. Pearse, R. Feinman, K. Shuai, J. E. Darnell Jr, J. V. Ravetch, Interferon gamma-induced transcription of the high-affinity Fc receptor for IgG requires assembly of a complex that includes the 91-kDa subunit of transcription factor ISGF3, Proc. Natl. Acad. Sci. U. S. A. 90, 4314-4318 (1993).

98. X. Liu, L. Ye, Y. Bai, H. Mojidi, N. E. Simister, X. Zhu, Activation of the JAK/STAT-1 signaling pathway by IFN-gamma can down-regulate functional expression of the MHC class I-related neonatal Fc receptor for IgG, J. Immunol. 181, 449-463 (2008).

99. Y. Li, P. Y. Lee, E. S. Kellner, M. Paulus, J. Switanek, Y. Xu, H. Zhuang, E. S. Sobel, M. S. Segal, M. Satoh, W. H. Reeves, Monocyte surface expression of Fcgamma receptor RI (CD64), a biomarker reflecting type-I interferon levels in systemic lupus erythematosus, Arthritis Res. Ther. 12, R90 (2010). 
100. E. Bischof, J. Wolfe, S. L. Klein, Clinical trials for COVID-19 should include sex as a variable, J. Clin. Invest. 130, 3350-3352 (2020).

101. COVID-19 Response Reporting (available at https://www.mass.gov/info-details/covid-19-responsereporting).

102. L. L. Shook, J. E. Shui, A. A. Boatin, S. Devane, N. Croul, L. M. Yonker, J. D. Matute, R. S. Lima, M. Schwinn, D. Cvrk, L. Gardner, R. Azevedo, S. Stanton, E. A. Bordt, L. J. Yockey, A. Fasano, J. Z. Li, X. G. Yu, A. J. Kaimal, P. H. Lerou, A. G. Edlow, Rapid establishment of a COVID-19 perinatal biorepository: early lessons from the first 100 women enrolled, BMC Med. Res. Methodol. 20, 215 (2020).

\section{Funding}

This work was supported by the National Institutes of Health, including NICHD (R01HD100022 and 3R01HD100022-02S20 to AGE and 1R01HD094937 to DJS), NIAID (1R21AI145071 to DJS, 3R37AI08028911S1, R01AI146785, U19AI42790-01, U19AI135995-02, U19AI42790-01, 1U01CA260476 - 01 to GA), NIMH (F32MH116604 to EAB), and NHLBI (5K08HL143183 to LMY, K08HL146963-02 and 3K08HL146963-02S1 to KJG). This material is based upon work supported by the National Science Foundation Graduate Research Fellowship under Grant No (\#1745302) to KMP. Additional support was provided by the Massachusetts General Hospital Department of Surgery, the Robert and Donna E. Landreth Family Fund, the Department of Pediatrics at Massachusetts General Hospital, The Regione Campania Italy (CUP G58D20000240002 - SURF 20004BP000000011), the Gates Foundation, the Ragon Institute of MGH and MIT, and the Massachusetts General Hospital and Brigham and Women's Hospital Departments of Obstetrics and Gynecology.

\section{Author Contributions}

Conceptualization and Methodology, E.A.B., L.L.S., G.A., A.G.E.; Investigation, E.A.B., L.L.S., C.A., K.M.P., R.M.D.G., M-C.M., M.C., S.F., L.J.Y., S.B., K.G., G.A., A.G.E; Formal Analysis, E.A.B., C.A., K.M.P., MC.M., K.J., D.J.R., D.L., G.A., A.G.E.; Writing - Original Draft, E.A.B., L.L.S., C.A., G.A., A.G.E. ; WritingReview and Editing and Supervision, E.A.B., L.L.S., C.A., K.M.P., R.M.D.G., M-C.M., M.C., S.F., L.J.Y., K.J., R.L., L.M.Y., A.F., S.B., L.M.B., D.J.R., D.P., J.R.H., S.D.B., J.Z.L., A.K., D.J.S., K.J.G., D.L., G.A., and A.G.E. 


\section{Competing interests}

K.J.G. has consulted for Illumina, BillionToOne, and Aetion outside the submitted work. A.F. reported serving as a cofounder and owning stock in Alba Therapeutics and serving on scientific advisory boards for NextCure and Viome outside the submitted work. G.A. reported serving as a founder of Systems Seromyx. J.Z.L. reported serving as a consultant for Abbvie and Jan Biotech. D.P. reported owning stock in Gilead Sciences, BioNano Genomics, Biogen, Bluebird Bio, ImmunoGen, Pfizer, and Bristol-Myers Squibb. D.J.R. reported receiving author royalties from UpToDate and Cambridge University Press outside the submitted work. Any opinion, findings, and conclusions or recommendation expressed in this material are those of the authors and do not necessarily reflect the views of the National Science Foundation. All others report no conflicts of interest.

\section{Data and materials availability}

All data associated with this study are present in the paper or the Supplementary Materials. 


\section{SUPPLEMENTARY MATERIALS}

\section{Sexually dimorphic placental responses to maternal SARS-CoV-2 infection}

Evan A Bordt*, Lydia L Shook*, Caroline Atyeo*, Krista M Pullen*, Rose M De Guzman, Marie-Charlotte Meinsohn, Maeva Chauvin, Stephanie Fischinger, Laura J. Yockey, Kaitlyn James, Rosiane Lima, Lael M Yonker, Alessio Fasano, Sara Brigida, Lisa M Bebell, Drucilla J Roberts, David Pépin, Jun R Huh, Staci D Bilbo, Jonathan Z Li, Anjali Kaimal, Danny Schust, Kathryn J Gray, Douglas Lauffenburger, Galit Alter, Andrea G Edlow

*These authors contributed equally to this work

\section{Address correspondence to:}

Andrea G Edlow

Vincent Center for Reproductive Biology

Massachusetts General Hospital

55 Fruit Street, Thier Research Building, 903b

$\mathrm{Ph}:$ 617-724-0654

Email: aedlow@mgh.harvard.edu

\section{This PDF file includes:}

Supplementary Materials and Methods

Fig. S1. Maternal SARS-CoV-2 infection does not impact placental expression of TNF, IL6, or CCL7.

Fig. S2. SARS-CoV-2 infected mothers with male fetuses demonstrate reduced placental transfer of SARSCoV-2 antibodies compared to those with female fetuses.

Fig. S3. Maternal and cord blood titers of HA and PTN in SARS-CoV-2 infected and non-infected mothers.

Fig. S4. SARS-CoV-2 infected mothers with male fetuses have lower plasma levels of SARS-CoV-2-specific antibodies.

Fig. S5. No effect of maternal SARS-CoV-2 infection on expression or localization of FC $\gamma$ R2.

Fig. S6. Effect of disease severity, time since infection, neonatal birthweight, and gestational age on gene expression and antibody transfer.

Table S1. Demographic and clinical characteristics of participants providing maternal and cord blood by fetal sex and maternal SARS-CoV-2 status.

Table S2. 2-way ANOVA analysis of inflammatory cytokine and interferon stimulated gene expression.

Table S3. 2-way ANOVA analysis of Fc receptor gene expression, immunoblots, and immunohistochemistry. Table S4. Taqman gene expression assays used for qPCR. 


\section{SUPPLEMENTARY MATERIALS AND METHODS}

\section{Maternal and cord blood collection and processing}

Sample collection protocols have been described in a previous publication (102) and are summarized below.

Blood from pregnant women was collected at delivery by venipuncture into EDTA tubes. Umbilical cord blood was collected immediately after delivery. The umbilical cord was wiped clean and blood was drawn directly from the vein using a syringe and transferred to EDTA vacutainer tubes. Blood was centrifuged at $1000 \mathrm{~g}$ for 10 min at room temperature. Plasma was aliquoted into cryogenic vials and stored at $-80^{\circ} \mathrm{C}$.

\section{Systems Serology}

A multiplexed Luminex assay was used to determine relative titer of antigen-specific isotypes, subclasses, and FcR binding, as previously described (45). The following antigens were used in this assay: SARS-CoV-2 RBD (Sino Biological), SARS-CoV-2 Spike (LakePharma), SARS-CoV-2 N (Aalto Bio Reagents). SARS-CoV-2 S1 (Sino Biological), SARS-CoV-2 S2 (Sino Biological), pertussis pertactin (List Reagents) and a mix of HA A/Michigan/45/2015 (H1N1), HA A/Singapore/INFIMH-16-0019/2016 (H3N2), B/Phuket/3073/2013

(Immunetech). Antigens were covalently linked to carboxyl-modified Magplex@ Luminex beads using SulfoNHS (N-hydroxysulfosuccinimide, Pierce) and ethyl dimethylaminopropyl carbodiimide hydrochloride (EDC). Antigen-coupled microspheres were blocked, washed, resuspended in PBS, and stored at $4^{\circ} \mathrm{C}$. Plasma (diluted 1:100 for IgG2/3, 1:500 for IgG1 and FcRn, 1:1000 for all other FcRs) was added to the antigen-coupled microspheres to form immune complexes, and plates were incubated overnight at $4^{\circ} \mathrm{C}$, shaking at $700 \mathrm{rpm}$. The next day, plates were washed with $0.1 \%$ BSA $0.02 \%$ Tween-20. Phycoerythrin (PE)-coupled mouse anti-human detection antibodies (Southern Biotech) were used to detect antigen-specific antibody binding. Avi-Tagged FcRs (Duke Human Vaccine Institute) were biotinylated using BirA500 kit (Avidity) per manufacturer's instructions in order to detect FcR binding. Biotinylated FcRs were tagged with PE and added to immune 
complexes. Fluorescence was acquired using an Intellicyt iQue. Relative antigen-specific antibody titer and FcR binding is reported as Median Fluorescence Intensity (MFI).

\section{Placental sampling and processing}

Fetal side biopsies ( 0.5 cubic centimeter per biopsy) were collected immediately after delivery from two separate locations at least $4 \mathrm{~cm}$ from the cord insertion avoiding surface vasculature, edges, and areas of gross pathology. Fetal membranes were dissected from the fetal surface and not included in the sample. Biopsies were then dissected in half, serially washed in DPBS and placed in RNAlater ${ }^{\circledR}$ (Invitrogen) and stored at least 24 hours at $4^{\circ} \mathrm{C}$. Excess RNAlater ${ }^{\circledR}$ was then removed by blotting on Kimwipes, and biopsies were subdivided into 50mg segments, placed into cryovials, flash frozen in liquid nitrogen and stored at $-80^{\circ} \mathrm{C}$. For histopathological examination, placentas were fixed in formalin, weighed, examined grossly, and sectioned/stained. Routine sections were taken for histopathologic diagnoses per the Amsterdam Consensus Criteria recommendations.

\section{RNA extraction}

Placental tissue was placed in Trizol $(100 \mathrm{uL} / 10 \mathrm{mg})$ and homogenized using a TissueTearor. The resulting suspension was then centrifuged at 12,000 $x \mathrm{~g}$ for $10 \mathrm{~min}$ after which the pellet was discarded. Chloroform was added to supernatant at a ratio of $100 \mathrm{uL}$ chloroform/50 mg tissue. Tubes were shaken vigorously for 15 seconds, allowed to stand at room temperature for $10 \mathrm{~min}$, and then centrifuged at 12,000 $x \mathrm{~g}$ for $15 \mathrm{~min}$. The aqueous phase was collected and the remainder of the RNA extraction procedure was performed using an RNeasy Mini Kit with on-column DNase I treatment (Qiagen) according to manufacturer instructions. RNA quantity and purity were assessed using a NanoDrop 2000 Spectrophotometer (ThermoFisher Scientific).

\section{cDNA synthesis and qPCR}


cDNA synthesis was performed using the iScript ${ }^{\mathrm{TM}} \mathrm{cDNA}$ Synthesis Kit (Bio-Rad) according to manufacturer instructions. Briefly, 800ng of RNA was mixed with iScript Reaction Mix, iScript Reverse Transcriptase, and nuclease-free water. No template control and No RT controls were prepared. All samples were primed at $25^{\circ} \mathrm{C}$ for $5 \mathrm{~min}$, heated to $46^{\circ} \mathrm{C}$ for $20 \mathrm{~min}$, and RT was inactivated at $95^{\circ} \mathrm{C}$ for $1 \mathrm{~min}$ using a MiniAmpTM Plus Thermal Cycler (ThermoFisher Scientific). Quantitative real-time polymerase chain reaction (qPCR) was then performed using Taqman gene expression assays on a QuantStudio 5 Real-Time PCR System (ThermoFisher Scientific). Gene expression assays used are listed in Supplemental Table 4. Gene expression was normalized to the placental reference gene Tyrosine 3-Monooxygenase/Tryptophan 5-Monooxygenase Activation Protein Zeta (YWHAZ) and expressed relative to female Covid-19 negative samples to yield a relative quantity value $\left(2^{-\mathrm{ddCt}}\right)$. All genes of interest were probed using gene expression assays with a dye of FAM-MGB, and $Y W H A Z$ was assessed using gene expression assays with a dye of VIC_PL. Two separate biopsies were each run in technical duplicate, and the average of biological replicates were then used to obtain final reported $2^{-\mathrm{ddCt}}$ values.

\section{Protein extraction and quantification}

Placental tissue was placed in RIPA Lysis and Extraction Buffer (ThermoFisher Scientific \#89901) containing Halt Protease and Phosphatase Inhibitor Cocktail (ThermoFisher Scientific \#78443) and homogenized using a TissueTearor. The resulting mixture was centrifuged at 10,000 rpm for $10 \mathrm{~min}$ at 4 degrees $\mathrm{C}$ and supernatant was kept for protein quantification. Protein was quantified using Pierce BCA Protein Assay Kit (ThermoFisher Scientific \#23225).

\section{Immunoblotting}

50 ug of protein was prepared in Protein Sample Loading Buffer (Li-Cor Biosciences) with 5 mM dithiothreitol (DTT), boiled for 10 min at 95 degree C, loaded on Mini-PROTEAN 4-20\% TGX Stain-Free Precast Gels (Bio$\mathrm{Rad}$ ), and run at $200 \mathrm{~V}$ for $30 \mathrm{~min}$, after which they were transferred onto low fluorescence PVDF membrane using a Trans-Blot Turbo Transfer System (Bio-Rad). Blots were then washed 3x 10 min in TBS (20x stock 
from ThermoFisher diluted 1:20 in $\mathrm{H} 2 \mathrm{O}$ ) followed by imaging of Stain Free total protein with a ChemiDoc MP System (Bio-Rad). After stain free imaging, blots were washed 3x $10 \mathrm{~min}$ in TBS, followed by blocking in Intercept (TBS) Blocking Buffer (Li-Cor Biosciences) for $1 \mathrm{hr}$. Primary antibodies were then incubated in Intercept T20 (TBS) Antibody Diluent (Li-Cor Biosciences) overnight at $4^{\circ} \mathrm{C}$. The next morning, membranes were washed 6x 10 min in TBS-T (20x stock from ThermoFisher was diluted 1:20 in H2O), followed by incubation with secondary antibodies at 1:15,000 dilution and hFAB Rhodamine Anti-Tubulin (Bio-Rad) at 1:4000 dilution for $1 \mathrm{hr}$ in Intercept T20 (TBS) Antibody Diluent (Li-Cor Biosciences). Finally, blots were washed 6x 10 min in TBS-T, after which they briefly rinsed in and then placed in TBS. Fluorescence was then imaged with a ChemiDoc MP System (Bio-Rad) and quantified using Image Lab Software (Bio-Rad). Data is presented as volume of bands for protein of interest relative to the volume of bands contained in the total protein stain-free image.

\section{Immunofluorescence}

For co-labeling immunofluoresence (IF) experiments, placenta tissue sections were rehydrated in an alcohol series after deparaffinization in xylene. Antigen retrieval was performed by boiling in $10 \mathrm{mM}$ sodium citrate ( $\mathrm{pH}$ 6.0) for 30min and cooled at room temperature before blocking for $15 \mathrm{~min}$ with background sniper (Biocare medical). Samples were then incubated in primary antibodies diluted in 5\% bovine serum albumin (BSA) for 1.5h at room temperature (Placental Alkaline Phosphatase (PLAP - ab212383) - 1:1000, Neonatal Fc Receptor $($ FcRn - ab193148) - 1:100, CD16 (CD16 - Leica NCL-L-CD16) - 1:100), CD32 (R\&D AF1330) - 10ug/ml, CD64 (Origene TA506331)- 1:100. The slides were washed in PBS Tween 0.1\% and incubated in fluorescently conjugated secondary antibodies (1:400 in 5\% BSA - Goat anti-Mouse IgG2a (A-21133), Goat anti-mouse IgG2b (A-21141), Goat anti-rabbit (ab150080), anti-mouse Igg1-(AF647 biolegend), donkey anti goat

(AA1056)). Finally, the slides were treated with Vector True View to eliminate red blood cells and background (Vector True View - SP8400-15 - Vector Laboratories), treated with DAPI (D13060) and cover-slipped with vectashield mounting medium (Vector Laboratories - H-1000). 
CellProfiler software (PMID:29969450) was used to quantify CD16/FcRn, CD32/FcRn, and CD64/FcRn

colocalization as well as their respective intensities. Briefly, RGB pictures were converted to gray and placental vilii selected to avoid measuring background. Following background removal, the pictures were filtered using the function CorrectIlluminationCalculate and aligned to evaluate colocalization. Finally, CD16, CD32 or CD64 and FcRn intensities in the placental vilii previously delimitated to quantify colocalization.

CellProlifer software was similarly used to quantify immunohistochemistry for ACE2 and CD163. Following isolation of each dye compound (DAB and Hematoxylin), the placental vilii were manually isolated and the mean intensity of DAB signal quantified.

\section{Multivariate Analyses}

All multivariate analyses were performed using R (version 4.0.0). Multivariate analyses included qPCR and Luminex antibody measurements. Missing data measurements were imputed using the k-nearest neighbor algorithm. Features were then centered and scaled to unit variance. Orthogonal partial least square discrimination analysis (O-PLSDA) was performed to classify data based on relative antibody transfer. Prior to building the O-PLSDA models, LASSO feature regularization and variable selection was performed, resulting in a reduced set of features that were consistently included in at least 80 out of 100 LASSO models. O- PLSDA models were built using the $\mathrm{R}$ 'ropls' Bioconductor package (orthI =1; PredI=1). Models were validated by evaluating the mean accuracy score after 100 trials of 5-fold CV. Accuracy scores for analogous models with permutated labels and random features were also reported for comparison.

\section{Statistical analyses}

Statistical tests used and statistical significance are reported in the Figure Legends. Statistical analyses were performed using GraphPad Prism 9 and R (version 4.0.0). Significant differences in participant characteristics were evaluated using Kruskal-Wallis tests for continuous variables and chi-square or Fisher's exact tests for categorical variables. Gene expression measurements, immunoblot measurements, and immunohistochemistry 
staining comparing maternal SARS-CoV-2 exposure status and fetal sex were evaluated by 2-way analysis of variance (2-way ANOVA) with Bonferroni’s post-hoc analysis. Kruskal-Wallis test followed by Dunn's posthoc test was used to determine significant differences between transfer ratios. Wilcoxon matched-pairs signed rank test was performed to determine significant differences between paired maternal-cord blood samples. All linear regression models were built in $\mathrm{R}$ (version 4.0.0) using the 'stats' package. False discovery rate (FDR) multiple comparisons correction was performed for Supplemental Fig. 6 using a corrected p-value of 0.05 as the cutoff for significance. 


\section{SUPPLEMENTARY FIGURES AND TABLES}

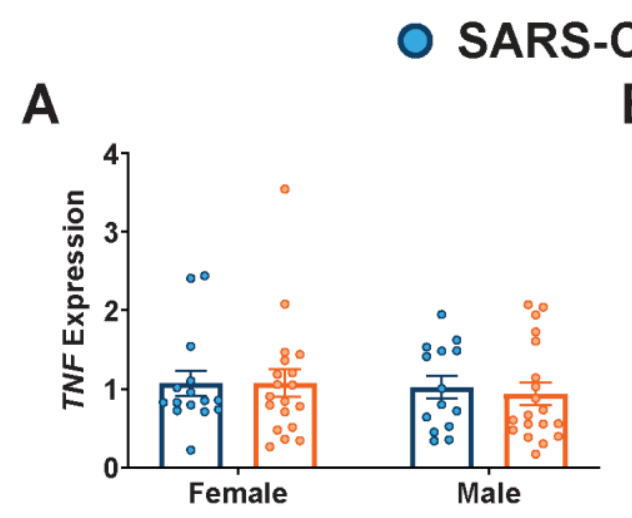

$B$

Supplementary Figure 1. Maternal SARS-CoV-2 infection does not impact placental expression of TNF, IL6, or CCL7.

(A-C) qPCR analyses of fetal male or fetal female expression of (A) TNF, (B) IL6, and (C) CCL7 in placental biopsies from SARS-CoV-2 negative (blue) or SARS-CoV-2 positive (orange) pregnancies. Two-way ANOVA followed by post-hoc analyses were performed to determine significance. Expression levels shown are relative to reference gene $Y W H A Z$. $* \mathrm{p}<0.05, * * \mathrm{p}<0.01$. 
A

Spike

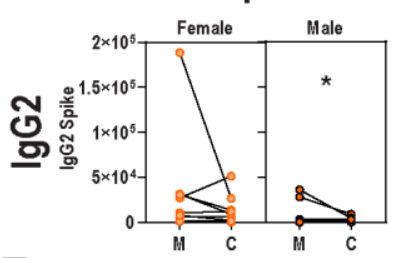

B

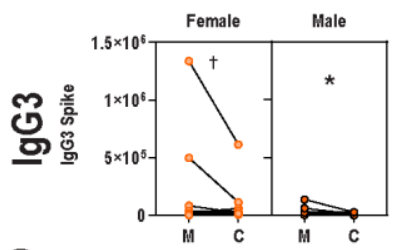

C

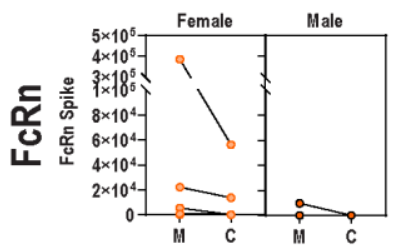

D

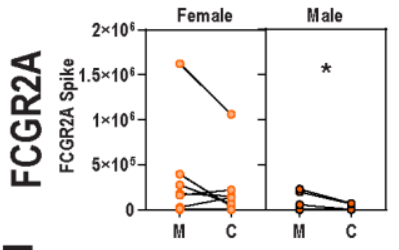

$\mathbf{E}$

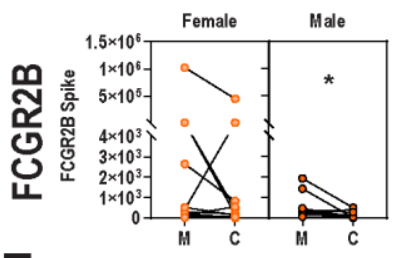

$\mathbf{F}$
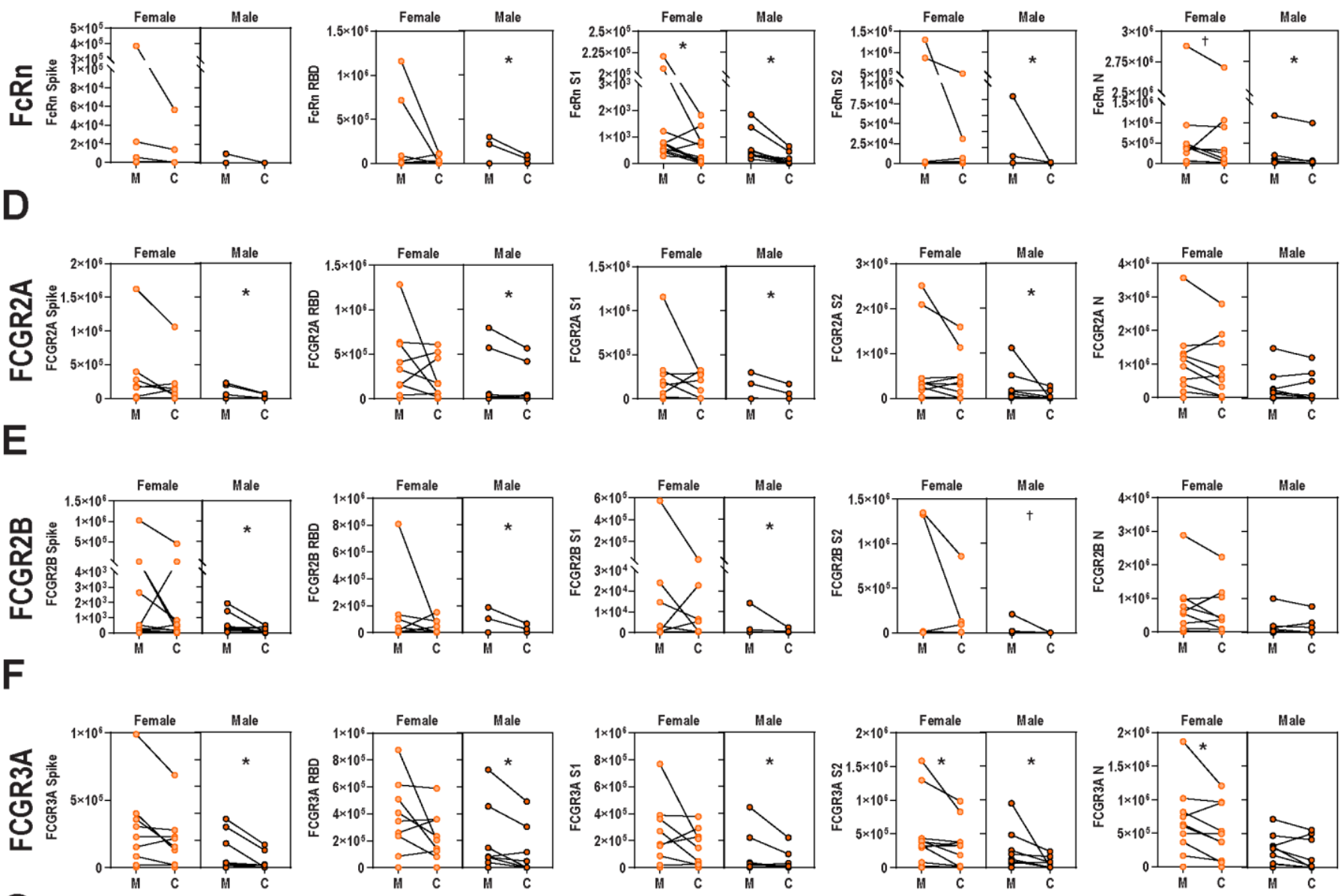

G
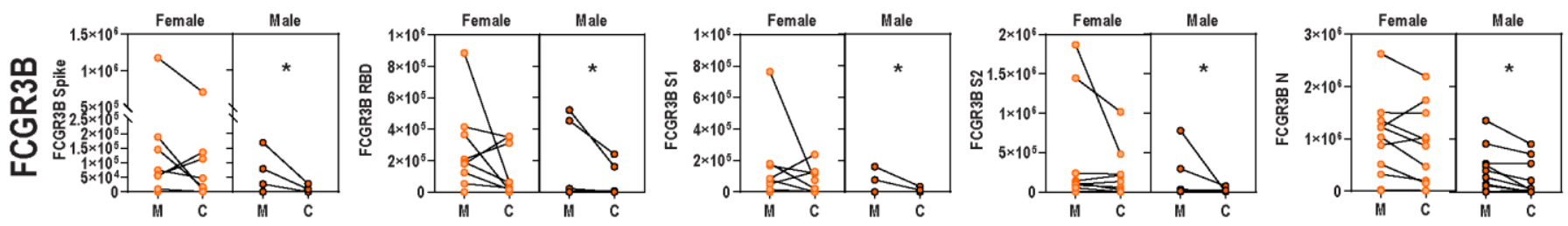

Supplementary Figure 2. SARS-CoV-2 infected mothers with male fetuses demonstrate reduced placental transfer of SARS-CoV-2 antibodies compared to those with female fetuses.

Dot plots showing relative Spike-, RBD-, S1-, S2-, and N-specific maternal blood (M) and cord blood (C) titers of (A) IgG2, (B), IgG3, (C) FcRn, (D) FCGR2A, (E) FCGR2B, (F) FCGR3A, and (G) FCGR3B. Females are 
shown in light orange while males are shown in dark orange with black border. Wilcoxon matched pairs signed rank test was performed to determine significance. ${ }^{*} \mathrm{p}<0.05, * * \mathrm{p}<0.01, * * * \mathrm{p}<0.0001$. 


\section{O Female SARS-CoV-2 - - Male SARS-CoV-2 -}

A

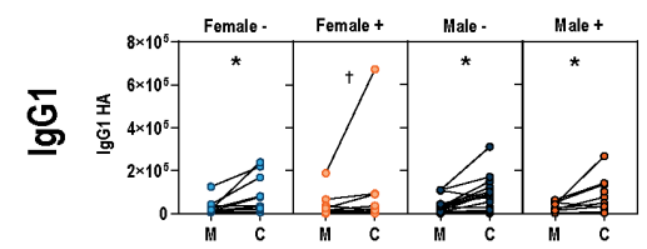

B

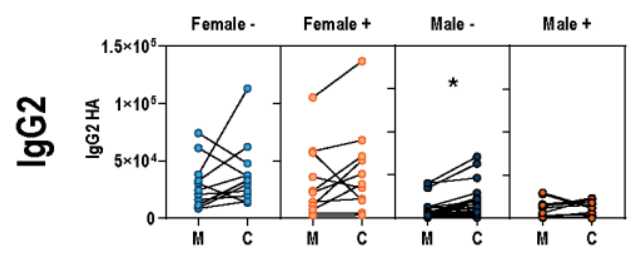

C

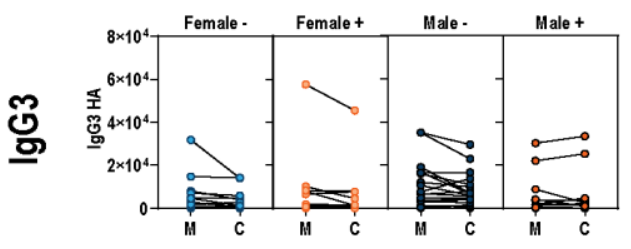

D

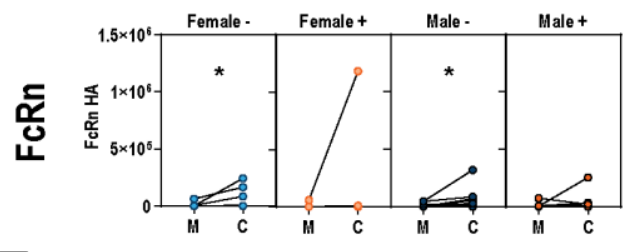

$\mathbf{E}$

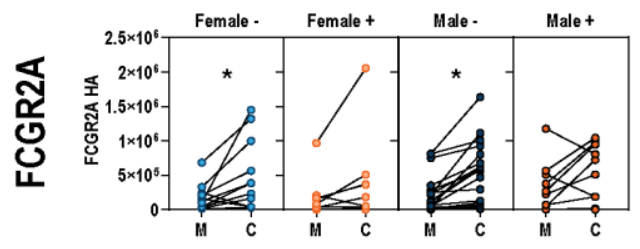

F

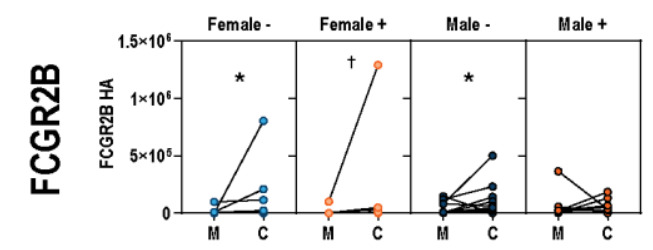

G

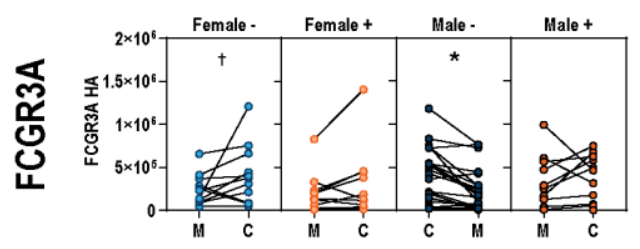

H

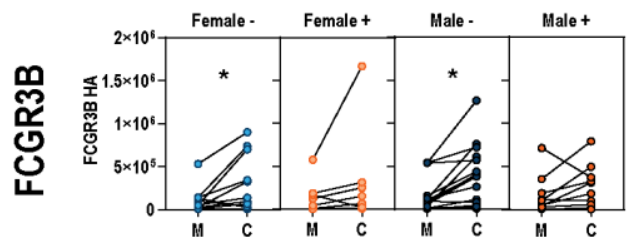

Female SARS-CoV-2 +

O Male SARS-CoV-2 +

\section{PTN}
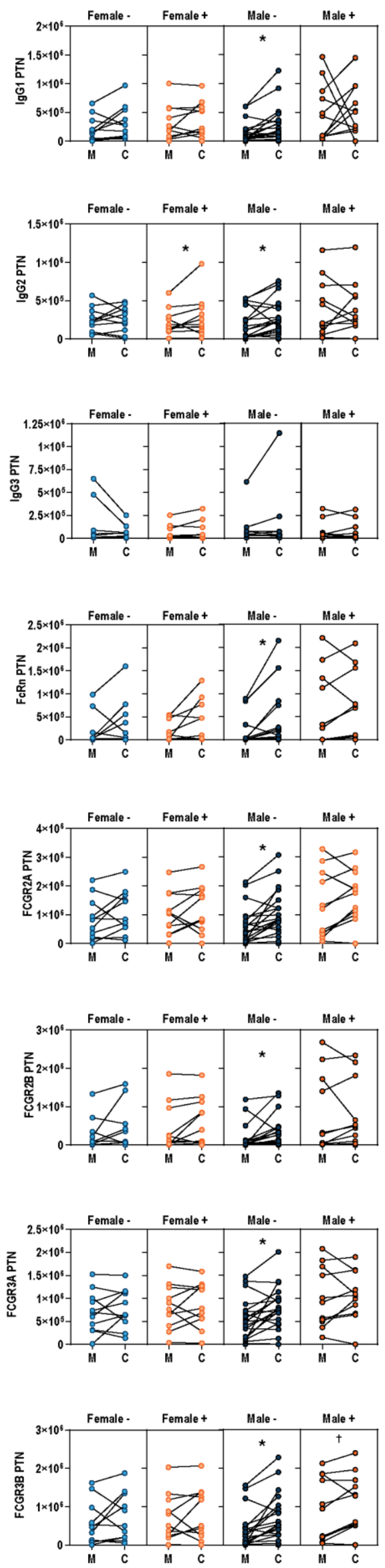


\section{Supplementary Figure 3. Maternal and cord blood titers of HA and PTN in SARS-CoV-2 infected and non-} infected mothers.

Dot plots showing relative hemagglutinin (HA)- and pertussis (PTN)-specific maternal blood (M) and cord blood (C) titers of (A) IgG1, (B) IgG2, (C) IgG3, (D) FcRn, (E) FCGR2A, (F) FCGR2B, (G) FCGR3A, and (H) FCGR3B. SARS-CoV-2 - females are shown in light blue, SARS-CoV-2 + females are shown in light orange, SARS-CoV-2 - males are shown in dark blue, and SARS-CoV-2 + males are shown in dark orange. Y-axis units for all plots are PBS-corrected mean fluorescence intensity (MFI). Wilcoxon matched-pairs signed rank test was performed to determine significance. ${ }^{*} \mathrm{p}<0.05, \dagger \mathrm{p}<0.10$. 


\section{SARS-CoV-2 -}

A

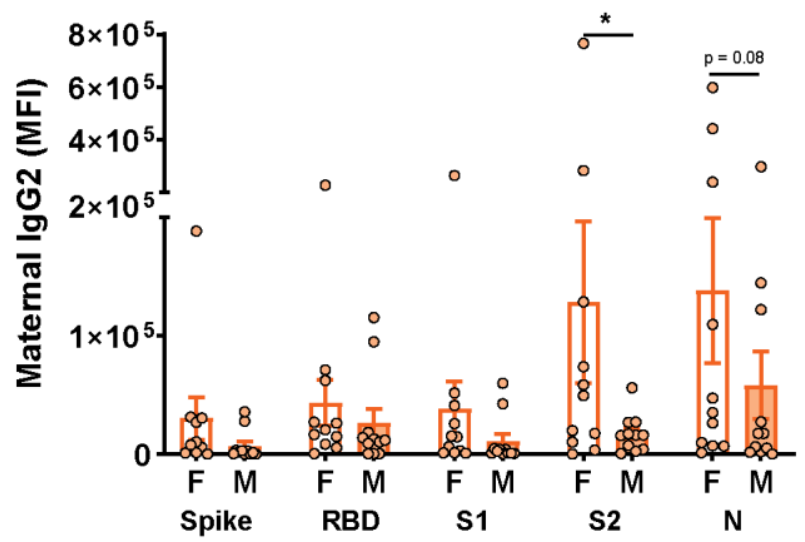

C

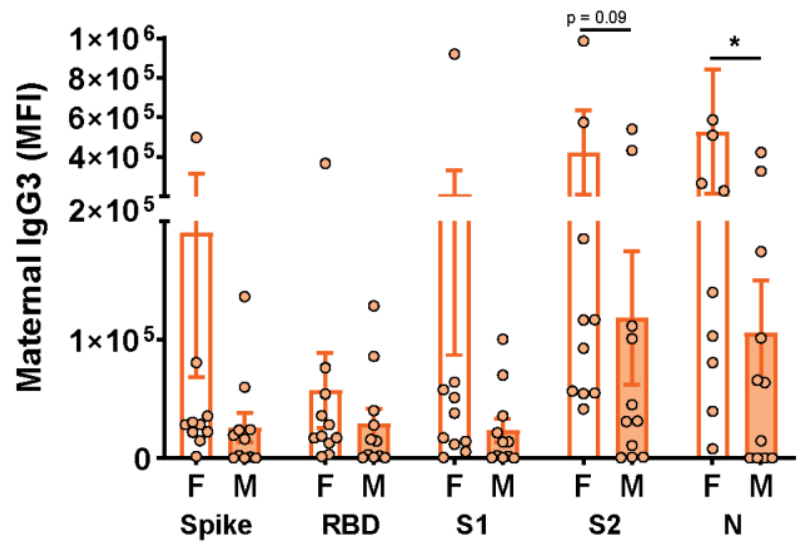

$\mathbf{E}$

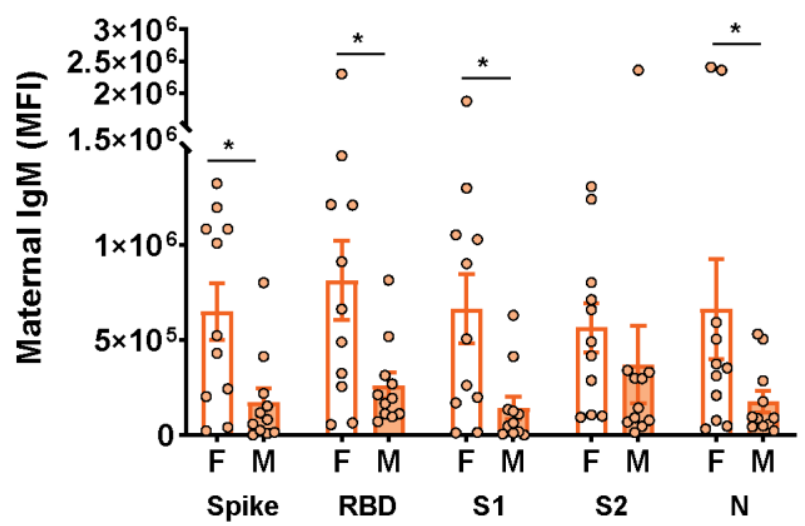

SARS-CoV-2 +

B

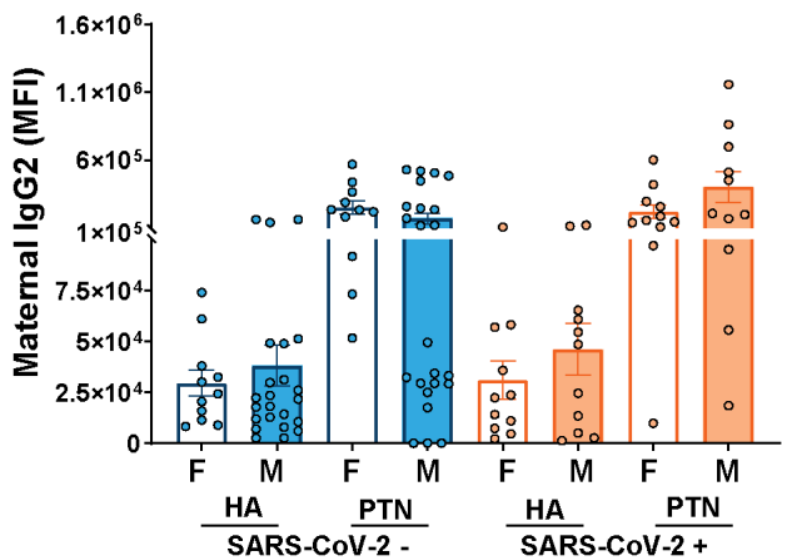

D

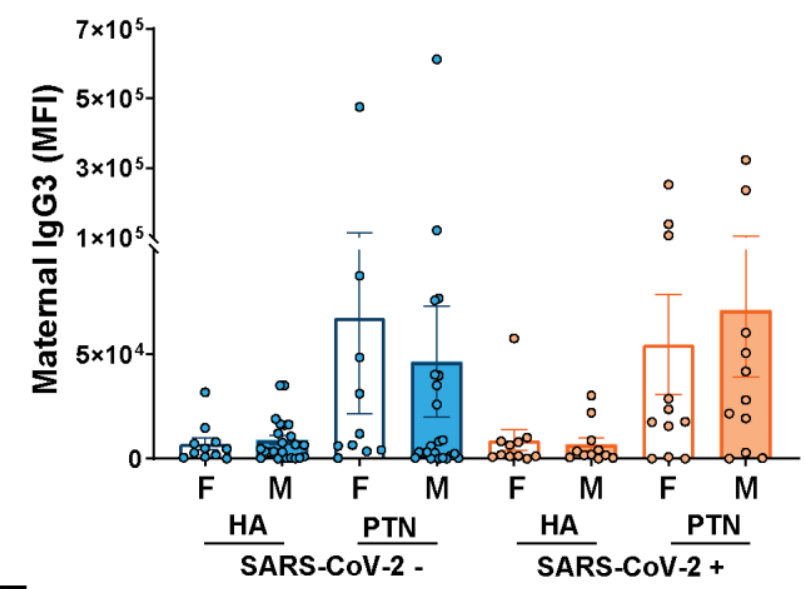

$\mathbf{F}$

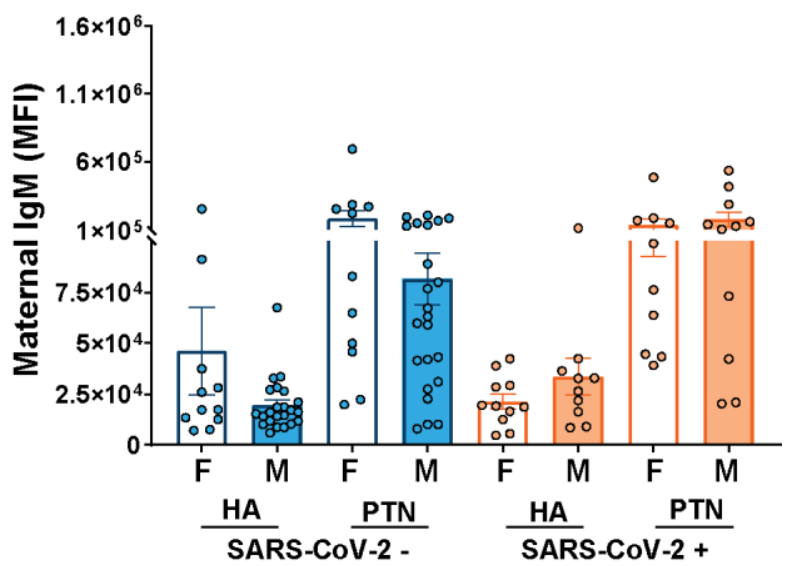

Supplementary Figure 4. SARS-CoV-2 infected mothers with male fetuses have lower plasma levels of SARS-CoV-2-specific antibodies.

A. Plots showing maternal Spike-, RBD-, S1-, S2-, and N-specific maternal blood IgG2 levels. Female neonates of mothers with SARS-CoV-2 are shown as white bars with an orange border while male neonates are shown as orange shaded bars with orange border. Two-way ANOVA followed by post-hoc analyses were performed to determine significance. There was a main effect of fetal/neonatal sex on maternal IgG1 levels $(p=0.003)$. $* \mathrm{p}<0.05$. 
B. Plots showing levels of IgG2 against HA and PTN in maternal plasma from either SARS-CoV-2 negative or SARS-CoV-2 positive mothers. Females born to SARS-CoV-2 - mothers are shown as white bars with blue border, females born to SARS-CoV-2 + mothers are shown as white bars with orange border. Males born to SARS-CoV-2 - mothers are shown as shaded blue bars with blue border, and males born to SARS-CoV-2 + mothers are shown as orange shaded bars with orange border. Two-way ANOVA revealed no significant effect of fetal sex.

C. Plots showing maternal Spike-, RBD-, S1-, S2-, and N-specific maternal blood IgG3 levels. Two-way ANOVA followed by post-hoc analyses were performed to determine significance. There was a main effect of fetal sex on maternal IgG3 levels $(\mathrm{p}=0.011)$. ${ }^{*} \mathrm{p}<0.05$.

D. Plots showing levels of IgG3 against HA and PTN in maternal plasma from either SARS-CoV-2 negative or SARS-CoV-2 positive pregnancies. Two-way ANOVA revealed no significant effect of fetal sex.

E. Plots showing maternal Spike-, RBD-, S1-, S2-, and N-specific maternal blood IgM3 levels. Two-way ANOVA followed by post-hoc analyses were performed to determine significance. There was a main effect of fetal sex on maternal IgM levels $(\mathrm{p}<0.0001)$. ${ }^{*} \mathrm{p}<0.05$.

F. Plots showing levels of IgM against HA and PTN in maternal plasma from either SARS-CoV-2 negative or SARS-CoV-2 positive pregnancies. Two-way ANOVA revealed no significant effect of fetal sex. 


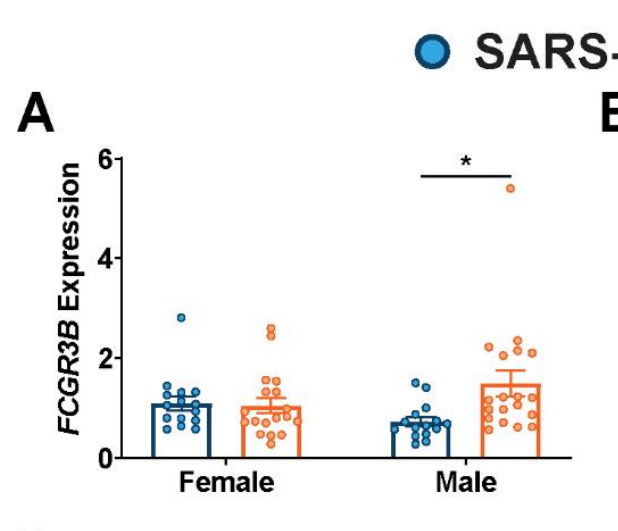

D
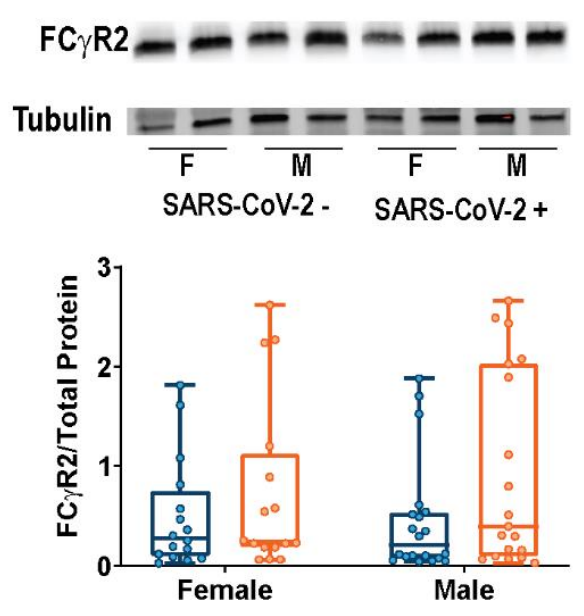

$\mathbf{F}$

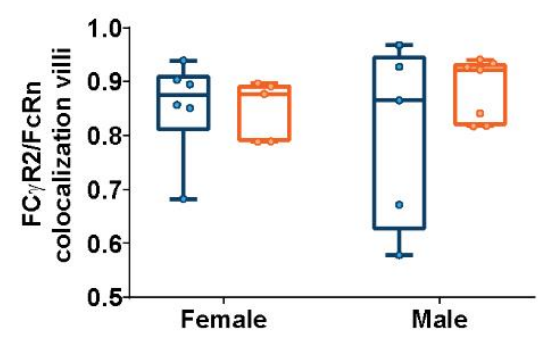

SARS-CoV-2 +

B

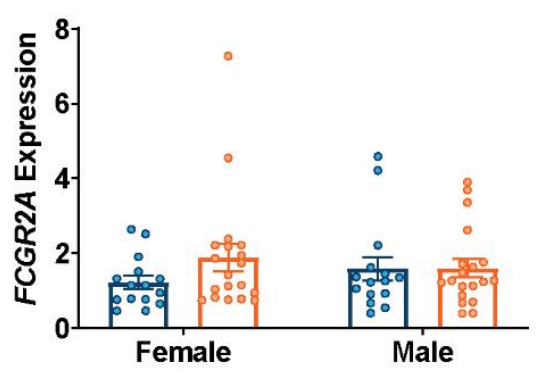

E
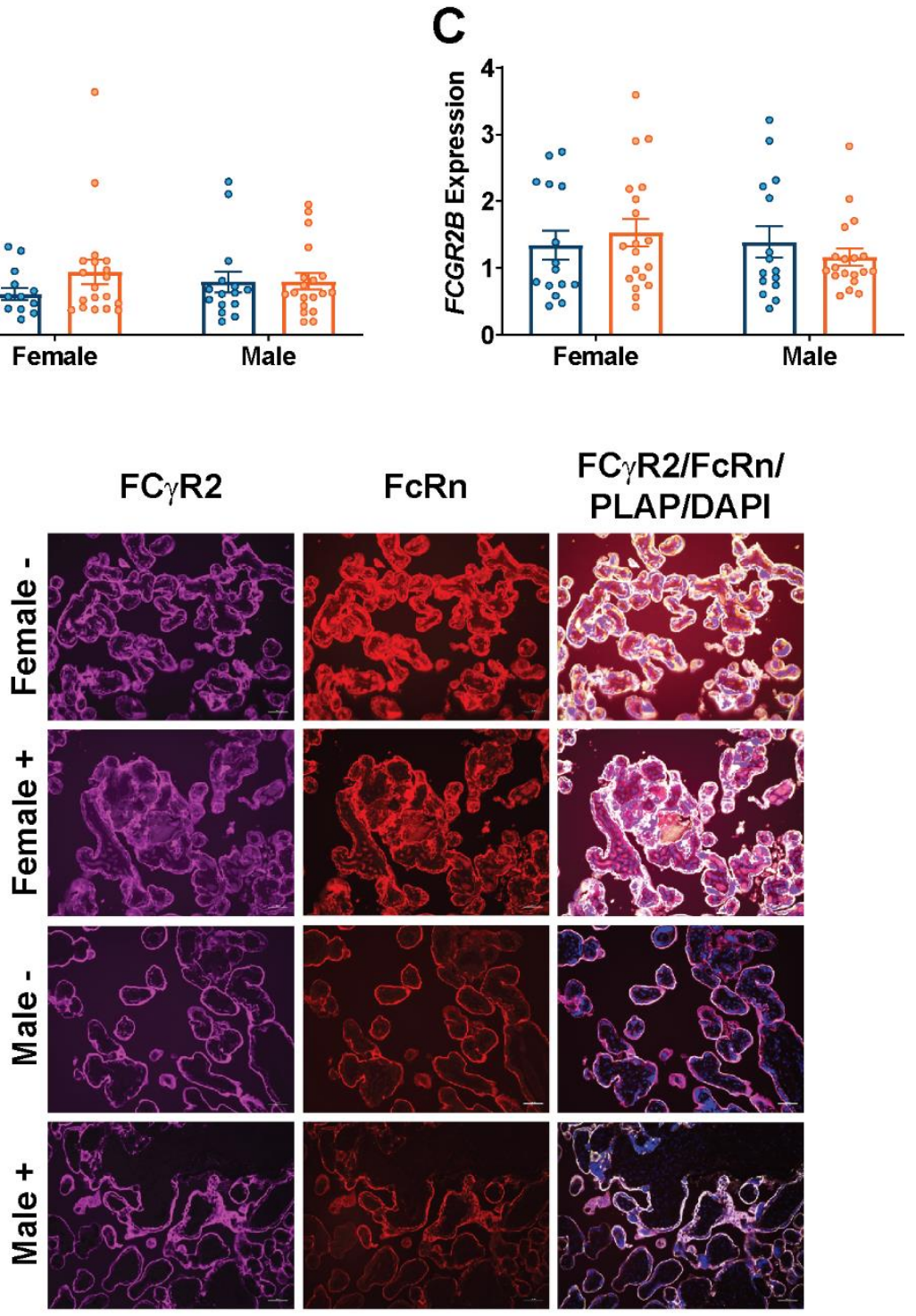

Supplementary Figure 5. No effect of maternal SARS-CoV-2 infection on expression or localization of FC $\gamma \mathbf{R} 2$.

(A-C) qPCR analyses of fetal male or fetal female expression of (A) FCGR3B, (B) FCGR2A, and (C) FCGR2B in placental biopsies from SARS-CoV-2 negative (blue) or SARS-CoV-2 positive (orange) pregnancies. Expression levels shown are relative to reference gene YWHAZ. (D) Representative immunoblots and quantification of $\mathrm{FC} \gamma \mathrm{R} 2$ in female or male placental biopsies from mothers testing negative (blue) or positive (orange) for SARS-CoV-2. (E) Placental tissue sections from SARS-CoV-2 + and SARS-CoV-2 - mothers were stained for FC $\gamma \mathrm{R} 2$ (purple), FcRn (red), and placental alkaline phosphatase (PLAP, green), a trophoblast marker, and DAPI (blue). (F) Box-and-whisker plots showing FC $\gamma \mathrm{R} 2 / \mathrm{FcRn}$ co-localization in placental villi. Two-way ANOVA followed by post-hoc analyses were performed to determine significance. ${ }^{*} p<0.05$. 
A

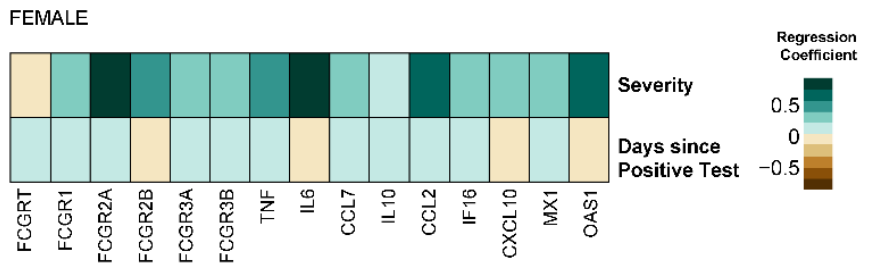

B
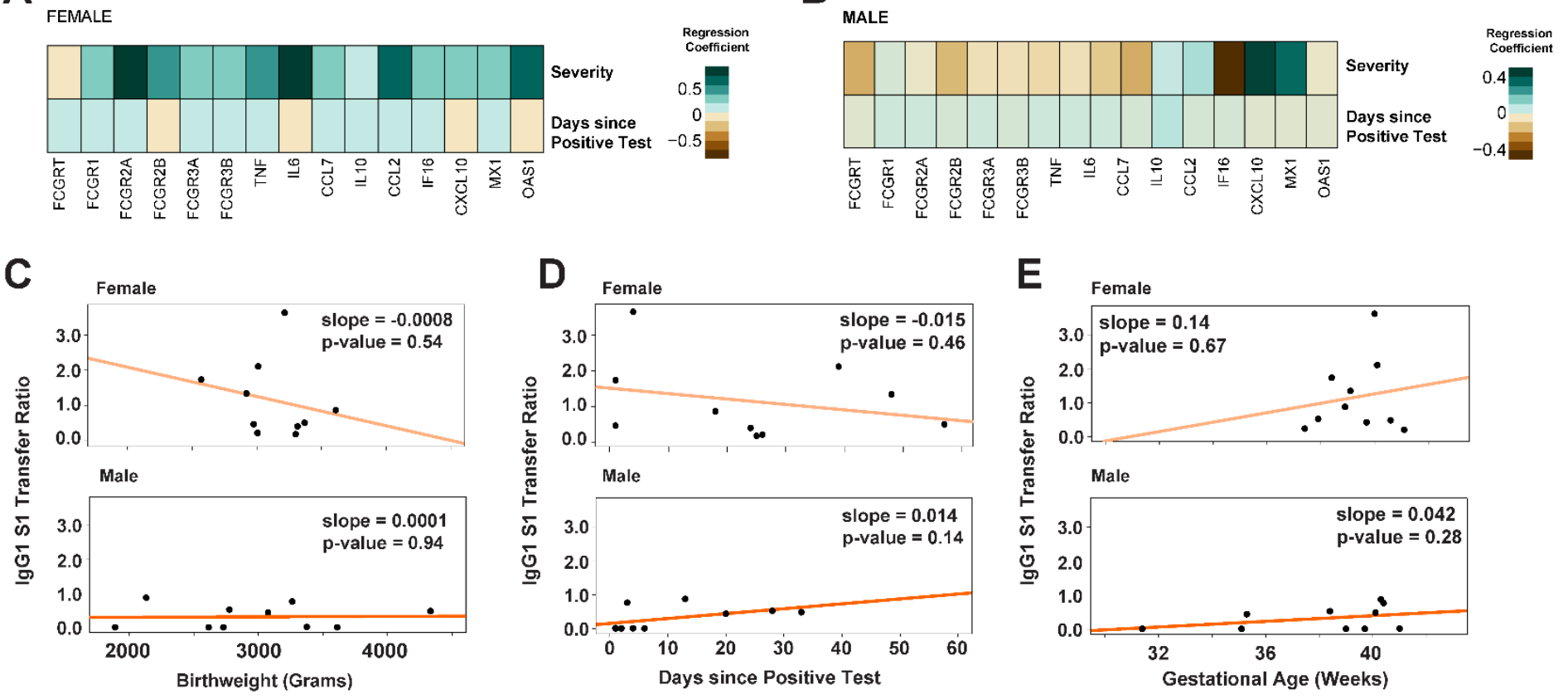

Supplementary Figure 6. Effect of disease severity, time since infection, neonatal birthweight, and gestational age on gene expression and antibody transfer.

(A) Heatmap depicting pairwise linear regressions between maternal disease severity (top), or time since positive test (bottom), and expression of each individual ISG or FcR for female placentas. None of the regression models had statistical significance after FDR multiple comparisons correction using a corrected pvalue of 0.05 as the cutoff. (B) Heatmap depicting pairwise linear regressions between maternal disease severity (top), or time since positive test (bottom), and expression of each individual ISG or FcR for male placentas. None of the regression models had statistical significance after FDR multiple comparisons correction using a corrected p-value of 0.05 as the cutoff. (C) Linear regression models were performed on female (top) and male (bottom) neonates separately to examine the effect of birthweight on placental transfer of S1-specific IgG1 (no significant effect). (D) Linear regression models were performed on pregnancies with a female fetus (top) and male fetus (bottom) separately to examine the effect of days since maternal infection on transplacental transfer of S1-specific IgG1 (no significant effect). (E) Linear regression models were performed on female (top) and male (bottom) neonates separately to examine the effect of gestational age at delivery on placental transfer of S1-specific IgG1 (no significant effect). 


\begin{tabular}{|c|c|c|c|c|c|c|}
\hline & \multirow{2}{*}{ All (55) } & \multicolumn{2}{|c|}{ Female } & \multicolumn{2}{|c|}{ Male } & \multirow[t]{2}{*}{$P^{b}$} \\
\hline & & $\begin{array}{l}\text { SARS-CoV-2 } \\
\text { negative } \\
\text { (11) }\end{array}$ & $\begin{array}{l}\text { SARS-CoV-2 } \\
\text { positive } \\
(11)^{a}\end{array}$ & $\begin{array}{l}\text { SARS-CoV-2 } \\
\text { negative } \\
(22)\end{array}$ & $\begin{array}{l}\text { SARS-CoV-2 } \\
\text { positive } \\
(11)^{\mathrm{a}}\end{array}$ & \\
\hline Maternal Age, years & 33 [29-38] & 34 [32-38] & $37[28-40]$ & $32[29-37]$ & $31[25-36]$ & 0.43 \\
\hline Parity, $n$ & $1[0-2]$ & $1[0-2]$ & $1[0-1]$ & $1[0-2]$ & $1[0-2]$ & 0.95 \\
\hline Race, $n(\%)$ & & & & & & 0.03 \\
\hline White & $36(65)$ & $8(73)$ & $5(45)$ & $18(82)$ & $5(45)$ & \\
\hline Black & $4(7)$ & $0(0)$ & $3(27)$ & $0(0)$ & $1(9)$ & \\
\hline Asian & $2(4)$ & $0(0)$ & $0(0)$ & $2(9)$ & $0(0)$ & \\
\hline Other & $8(15)$ & $3(27)$ & $2(18)$ & $1(5)$ & $2(18)$ & \\
\hline Not Reported & $5(9)$ & $0(0)$ & $1(9)$ & $1(5)$ & $3(27)$ & \\
\hline Ethnicity, $n(\%)$ & & & & & & 0.01 \\
\hline Hispanic & $19(35)$ & $3(27)$ & $4(36)$ & $3(14)$ & $9(82)$ & \\
\hline Non-Hispanic & $33(60)$ & $7(64)$ & $6(55)$ & $18(82)$ & $2(18)$ & \\
\hline Not Reported & $3(5)$ & $1(9)$ & $1(9)$ & $1(5)$ & $0(0)$ & \\
\hline $\begin{array}{l}\text { Chronic hypertension, } n \\
\text { (\%) }\end{array}$ & $1(2)$ & $0(0)$ & $0(0)$ & $1(5)$ & $0(0)$ & 0.68 \\
\hline DM/GDM, $n(\%)$ & $6(11)$ & $1(9)$ & $1(9)$ & $3(14)$ & $1(9)$ & 0.96 \\
\hline $\mathrm{BMI} \geq 30 \mathrm{~kg} / \mathrm{m}^{2}, n(\%)$ & $17(31)$ & $2(18)$ & $6(55)$ & $5(23)$ & $4(36)$ & 0.21 \\
\hline Pre-pregnancy BMI, $\mathrm{kg} / \mathrm{m}^{2}$ & $\begin{array}{l}27.0[21.6- \\
32.0]\end{array}$ & $27.0[22.6-29.8]$ & $\begin{array}{l}29.2[25.9- \\
36.3]\end{array}$ & $22.1[20.3-30.3]$ & $\begin{array}{l}29.5[22.5- \\
32.1]\end{array}$ & 0.16 \\
\hline GA at delivery, weeks & $39[38-40]$ & 39 [39-39] & $40[38-41]$ & 39 [38-41] & $39[35-40]$ & 0.86 \\
\hline Any labor, $n(\%)$ & $40(73)$ & $4(36)$ & $10(91)$ & $16(73)$ & $10(91)$ & 0.01 \\
\hline Neonatal birthweight, $g$ & $\begin{array}{l}3300[3005- \\
3630]\end{array}$ & $\begin{array}{l}3295[3060- \\
3590]\end{array}$ & $\begin{array}{l}3010[2920- \\
3315]\end{array}$ & $\begin{array}{c}3533[3254- \\
3784]\end{array}$ & $\begin{array}{c}3075[2615- \\
3610]\end{array}$ & 0.07 \\
\hline Multiple gestation, $\mathrm{n}$ & 1 & 0 & 0 & 1 & 0 & $\mathrm{~N} / \mathrm{A}$ \\
\hline $\begin{array}{l}\text { GA at positive SARS-CoV- } \\
2 \text { test, weeks }\end{array}$ & $\begin{array}{c}36.3[32.4- \\
38.8]\end{array}$ & $\mathrm{N} / \mathrm{A}$ & $36.3[32.4]$ & $\mathrm{N} / \mathrm{A}$ & $\begin{array}{l}35.4[32.4- \\
39.6]\end{array}$ & 0.81 \\
\hline $\begin{array}{l}\text { COVID-19 disease severity } \\
\text { at diagnosis }, n\end{array}$ & & & & & & 0.77 \\
\hline Asymptomatic & $5(23)$ & $\mathrm{N} / \mathrm{A}$ & $2(18)$ & $\mathrm{N} / \mathrm{A}$ & $3(27)$ & \\
\hline Mild/Moderate & $14(64)$ & $\mathrm{N} / \mathrm{A}$ & $7(64)$ & $\mathrm{N} / \mathrm{A}$ & $7(64)$ & \\
\hline Severe/Critical & $3(14)$ & $\mathrm{N} / \mathrm{A}$ & $2(18)$ & $\mathrm{N} / \mathrm{A}$ & $1(9)$ & \\
\hline $\begin{array}{l}\text { Time between SARS-CoV- } \\
2 \text { symptom onset and } \\
\text { delivery, days }\end{array}$ & 29 [9-44] & $N / A$ & $33[26-58]$ & $\mathrm{N} / \mathrm{A}$ & 29 [9-44] & 0.08 \\
\hline
\end{tabular}

Supplementary Table 1. Demographic and clinical characteristics of participants providing maternal and cord blood by fetal sex and maternal SARS-CoV-2 status.

Abbreviations: DM/GDM, diabetes mellitus/gestational diabetes mellitus; BMI, body mass index; GA, gestational age; N/A, not applicable.

${ }^{\text {a}} \mathrm{SARS}-\mathrm{CoV}-2$ positive and negative status determined by nasopharyngeal RT PCR at time of sample collection. If a participant was SARS-CoV-2 positive at any time in pregnancy she was included in "SARS-CoV-2 positive" category. ${ }^{b}$ Significant differences between groups were determined using chi-square test for categorical variables, and Kruskal-Wallis test for continuous variables presented as median [IQR]. ${ }^{\mathrm{c}}$ Severity determinations were made based on published criteria from the Society for Maternal-Fetal Medicine and the National Institutes of Health. 


\begin{tabular}{|c|c|c|c|c|c|c|c|}
\hline Gene & $\begin{array}{l}\text { Maternal } \\
\text { SARS- } \\
\text { CoV-2 } \\
\text { Status }\end{array}$ & Fetal Sex & Interaction & $\begin{array}{l}\text { Bonferroni } \\
\text { Female } \\
\text { Neg:Pos }\end{array}$ & $\begin{array}{l}\text { Bonferroni } \\
\text { Male } \\
\text { Neg:Pos }\end{array}$ & $\begin{array}{l}\text { Bonferroni } \\
\text { Neg } \\
\text { Female:Male }\end{array}$ & $\begin{array}{l}\text { Bonferroni } \\
\text { Pos } \\
\text { Female:Male }\end{array}$ \\
\hline$T N F$ & $\begin{array}{l}F_{(1,63)}= \\
0.061, p \\
=0.81\end{array}$ & $\begin{array}{c}F_{(1,63)}= \\
0.31, p= \\
0.58\end{array}$ & $\begin{array}{c}F_{(1,63)}= \\
0.076, p= \\
0.78\end{array}$ & $\mathrm{n} / \mathrm{a}$ & $\mathrm{n} / \mathrm{a}$ & $\mathrm{n} / \mathrm{a}$ & $\mathrm{n} / \mathrm{a}$ \\
\hline IL6 & $\begin{array}{c}F_{(1,64)}= \\
0.66, p= \\
0.42\end{array}$ & $\begin{array}{c}F_{(1,64)}= \\
0.017, p= \\
0.90\end{array}$ & $\begin{array}{c}\mathrm{F}_{(1,64)}= \\
2.3, p= \\
0.13\end{array}$ & $\mathrm{n} / \mathrm{a}$ & $\mathrm{n} / \mathrm{a}$ & $\mathrm{n} / \mathrm{a}$ & $\mathrm{n} / \mathrm{a}$ \\
\hline CCL7 & $\begin{array}{l}F_{(1,63)}= \\
0.0075, p \\
=0.93\end{array}$ & $\begin{array}{c}F_{(1,63)}= \\
0.57, p= \\
0.45\end{array}$ & $\begin{array}{c}F_{(1,63)}= \\
1.71, p= \\
0.20\end{array}$ & $\mathrm{n} / \mathrm{a}$ & $\mathrm{n} / \mathrm{a}$ & $\mathrm{n} / \mathrm{a}$ & $\mathrm{n} / \mathrm{a}$ \\
\hline IL10 & $\begin{array}{c}F_{(1,63)}= \\
3.58, p= \\
0.063\end{array}$ & $\begin{array}{c}F_{(1,63)}= \\
0.19, p= \\
0.66\end{array}$ & $\begin{array}{c}F_{(1,63)}= \\
7.72, p= \\
0.007\end{array}$ & $p>0.9999$ & $p=0.003$ & $p=0.068$ & $p=0.17$ \\
\hline CCL2 & $\begin{array}{c}F_{(1,64)}= \\
4.69, p= \\
0.03\end{array}$ & $\begin{array}{c}F_{(1,64)}= \\
0.85, p= \\
0.36\end{array}$ & $\begin{array}{c}\mathrm{F}_{(1,64)}= \\
1.25, p= \\
0.27\end{array}$ & $\mathrm{n} / \mathrm{a}$ & $\mathrm{n} / \mathrm{a}$ & $\mathrm{n} / \mathrm{a}$ & $\mathrm{n} / \mathrm{a}$ \\
\hline IFI6 & $\begin{array}{c}F_{(1,64)}= \\
0.25, p= \\
0.62\end{array}$ & $\begin{array}{c}F_{(1,64)}= \\
0.17, p= \\
0.68\end{array}$ & $\begin{array}{c}F_{(1,64)}= \\
7.74, p= \\
0.007\end{array}$ & $p=0.22$ & $p=0.047$ & $p=0.24$ & $p=0.038$ \\
\hline CXCL10 & $\begin{array}{c}F_{(1,62)}= \\
3.049, p= \\
0.086\end{array}$ & $\begin{array}{c}F_{(1,62)}= \\
0.17, p= \\
0.68\end{array}$ & $\begin{array}{c}F_{(1,62)}= \\
12.36, p= \\
0.0008\end{array}$ & $p=0.42$ & $p=0.001$ & $p=0.022$ & $p=0.045$ \\
\hline$M X 1$ & $\begin{array}{c}F_{(1,63)}= \\
4.46, p= \\
0.039\end{array}$ & $\begin{array}{c}F_{(1,63)}= \\
0.12, p= \\
0.74\end{array}$ & $\begin{array}{c}F_{(1,63)}= \\
1.038, p= \\
0.31\end{array}$ & $\mathrm{n} / \mathrm{a}$ & $\mathrm{n} / \mathrm{a}$ & $\mathrm{n} / \mathrm{a}$ & $\mathrm{n} / \mathrm{a}$ \\
\hline OAS1 & $\begin{array}{c}F_{(1,63)}= \\
0.74, p= \\
0.39\end{array}$ & $\begin{array}{c}F_{(1,63)}= \\
0.039, p= \\
0.85\end{array}$ & $\begin{array}{c}F_{(1,63)}= \\
5.99, p= \\
0.017\end{array}$ & $p=0.54$ & $p=0.044$ & $p=0.27$ & $p=0.11$ \\
\hline
\end{tabular}

Supplementary Table 2. 2-way ANOVA analysis of inflammatory cytokine and interferon stimulated gene expression. Two-way ANOVA followed by Bonferroni's post-hoc analyses (when interaction term was significant) were performed to determine significance. All main and interaction effects for genes of interest are represented for both male and female placentas in addition to all post-hoc analyses performed. Significant effects are indicated by bolded statistics. N/A: not applicable, indicates post-hoc testing not performed due to lack of significant interaction term. 


\begin{tabular}{|c|c|c|c|c|c|c|c|}
\hline Gene & $\begin{array}{c}\text { Maternal } \\
\text { SARS-CoV-2 } \\
\text { Status } \\
\end{array}$ & $\begin{array}{l}\text { Fetal } \\
\text { Sex }\end{array}$ & Interaction & $\begin{array}{c}\text { Bonferroni } \\
\text { Female } \\
\text { Neg:Pos }\end{array}$ & $\begin{array}{l}\text { Bonferroni } \\
\text { Male } \\
\text { Neg:Pos }\end{array}$ & $\begin{array}{c}\text { Bonferroni } \\
\text { Neg } \\
\text { Female:Male }\end{array}$ & $\begin{array}{l}\text { Bonferroni } \\
\text { Pos } \\
\text { Female:Male } \\
\end{array}$ \\
\hline FCGRT & $\begin{array}{c}F_{(1,63)}= \\
0.052, p= \\
0.82\end{array}$ & $\begin{array}{l}F_{(1,63)}= \\
0.0037 \\
p=0.95\end{array}$ & $\begin{array}{c}F_{(1,63)}=6.91 \\
p=0.011\end{array}$ & $p=0.19$ & $p=0.09$ & $p=0.18$ & $p=0.098$ \\
\hline FCGR1 & $\begin{array}{c}F_{(1,64)}=2.01 \\
p=0.16\end{array}$ & $\begin{array}{l}F_{(1,64)}= \\
0.33, p \\
=0.57\end{array}$ & $\begin{array}{c}F_{(1,64)}=5.64 \\
p=0.021\end{array}$ & $p>0.99$ & $p=0.019$ & $p=0.46$ & $p=0.060$ \\
\hline FCGR2A & $\begin{array}{c}F_{(1,64)}=1.33 \\
p=0.25\end{array}$ & $\begin{array}{l}F_{(1,64)}= \\
0.017, p \\
=0.90\end{array}$ & $\begin{array}{c}F_{(1,64)}=1.21 \\
p=0.28\end{array}$ & $n / a$ & $\mathrm{n} / \mathrm{a}$ & $\mathrm{n} / \mathrm{a}$ & $n / a$ \\
\hline FCGR2B & $\begin{array}{c}F_{(1,64)}=0.012 \\
p=0.91\end{array}$ & $\begin{array}{l}F_{(1,64)}= \\
0.69, p \\
=0.41\end{array}$ & $\begin{array}{c}F_{(1,64)}=1.15 \\
p=0.29\end{array}$ & $n / a$ & $\mathrm{n} / \mathrm{a}$ & $\mathrm{n} / \mathrm{a}$ & $n / a$ \\
\hline FCGR3A & $\begin{array}{c}F_{(1,64)}=0.43 \\
p=0.51\end{array}$ & $\begin{array}{l}F_{(1,64)}= \\
0.24, p \\
=0.63\end{array}$ & $\begin{array}{c}F_{(1,64)}=5.24 \\
p=0.025\end{array}$ & $p=0.51$ & $p=0.042$ & $p=0.14$ & $p=0.36$ \\
\hline FCGR3B & $\begin{array}{c}F_{(1,63)}=3.69 \\
p=0.059\end{array}$ & $\begin{array}{l}F_{(1,63)}= \\
0.031, p \\
=0.86\end{array}$ & $\begin{array}{c}F_{(1,63)}=4.81, \\
p=0.032\end{array}$ & $p>0.99$ & $p=0.009$ & $p=0.36$ & $p=0.16$ \\
\hline Protein & $\begin{array}{c}\text { Maternal } \\
\text { SARS-CoV-2 } \\
\text { Status } \\
\end{array}$ & $\begin{array}{l}\text { Fetal } \\
\text { Sex }\end{array}$ & Interaction & $\begin{array}{c}\text { Bonferroni } \\
\text { Female } \\
\text { Neg:Pos }\end{array}$ & $\begin{array}{c}\text { Bonferroni } \\
\text { Male } \\
\text { Neg:Pos }\end{array}$ & $\begin{array}{c}\text { Bonferroni } \\
\text { Neg } \\
\text { Female:Male }\end{array}$ & $\begin{array}{l}\text { Bonferroni } \\
\text { Pos } \\
\text { Female:Male } \\
\end{array}$ \\
\hline FcRn & $\begin{array}{c}F_{(1,78)}=0.74 \\
p=0.39\end{array}$ & $\begin{array}{l}F_{(1,78)}= \\
2.006, p \\
=0.16\end{array}$ & $\begin{array}{c}F_{(1,78)}=5.51 \\
p=0.021\end{array}$ & $p=0.61$ & $p=0.046$ & $p>0.99$ & $p=0.022$ \\
\hline $\mathrm{FC} \gamma \mathrm{R} 1$ & $\begin{array}{c}F_{(1,76)}=0.28 \\
p=0.60\end{array}$ & $\begin{array}{l}F_{(1,76)}= \\
0.67, p \\
=0.42\end{array}$ & $\begin{array}{c}F_{(1,76)}=1.76 \\
p=0.19\end{array}$ & $\mathrm{n} / \mathrm{a}$ & $\mathrm{n} / \mathrm{a}$ & $\mathrm{n} / \mathrm{a}$ & $\mathrm{n} / \mathrm{a}$ \\
\hline $\mathrm{FC} \gamma \mathrm{R} 2$ & $\begin{array}{c}F_{(1,67)}=3.79 \\
p=0.056\end{array}$ & $\begin{array}{l}F_{(1,67)}= \\
0.15, p \\
=0.70\end{array}$ & $\begin{array}{c}F_{(1,67)}=0.41 \\
p=0.52\end{array}$ & $n / a$ & $\mathrm{n} / \mathrm{a}$ & $\mathrm{n} / \mathrm{a}$ & $\mathrm{n} / \mathrm{a}$ \\
\hline $\mathrm{FC} \gamma \mathrm{R} 3$ & $\begin{array}{c}F_{(1,74)}=3.035 \\
p=0.086\end{array}$ & $\begin{array}{l}F_{(1,74)}= \\
2.22, p \\
=0.14\end{array}$ & $\begin{array}{c}F_{(1,74)}=4.86 \\
p=0.031\end{array}$ & $p>0.99$ & $p=0.011$ & $p>0.99$ & $p=0.028$ \\
\hline $\begin{array}{c}\text { Co- } \\
\text { localization }\end{array}$ & $\begin{array}{c}\text { Maternal } \\
\text { SARS-CoV-2 } \\
\text { Status } \\
\end{array}$ & $\begin{array}{l}\text { Fetal } \\
\text { Sex }\end{array}$ & Interaction & $\begin{array}{c}\text { Bonferroni } \\
\text { Female } \\
\text { Neg:Pos }\end{array}$ & $\begin{array}{c}\text { Bonferroni } \\
\text { Male } \\
\text { Neg:Pos }\end{array}$ & $\begin{array}{c}\text { Bonferroni } \\
\text { Neg } \\
\text { Female:Male }\end{array}$ & $\begin{array}{l}\text { Bonferroni } \\
\text { Pos } \\
\text { Female:Male }\end{array}$ \\
\hline FC $\gamma R 3 / F c R n$ & $\begin{array}{c}F_{(1,17)}=2.27 \\
p=0.15\end{array}$ & $\begin{array}{l}F_{(1,17)}= \\
0.67, p \\
=0.42\end{array}$ & $\begin{array}{c}F_{(1,17)}= \\
14.01, p= \\
0.002\end{array}$ & $p=0.24$ & $p=0.004$ & $p=0.016$ & $p=0.078$ \\
\hline $\mathrm{FC} \gamma \mathrm{R} 2 / \mathrm{FcRn}$ & $\begin{array}{c}F_{(1,19)}=0.86 \\
p=0.37\end{array}$ & $\begin{array}{c}F_{(1,19)}= \\
0.034, p \\
=0.86\end{array}$ & $\begin{array}{c}F_{(1,19)}=1.15 \\
p=0.30\end{array}$ & n/a & $\mathrm{n} / \mathrm{a}$ & $\mathrm{n} / \mathrm{a}$ & $\mathrm{n} / \mathrm{a}$ \\
\hline FC $\gamma R 1 / F c R n$ & $\begin{array}{c}F_{(1,19)}= \\
0.0004, p= \\
0.99\end{array}$ & $\begin{array}{l}F_{(1,19)}= \\
0.59, p \\
=0.45\end{array}$ & $\begin{array}{c}F_{(1,19)}= \\
0.017, p= \\
0.90\end{array}$ & $n / a$ & $\mathrm{n} / \mathrm{a}$ & $\mathrm{n} / \mathrm{a}$ & $n / a$ \\
\hline
\end{tabular}

Supplementary Table 3. 2-way ANOVA analysis of Fc receptor gene expression, immunoblots, and immunohistochemistry. Two-way ANOVA followed by Bonferroni's post-hoc analyses (when interaction 
term was significant) were performed to determine significance. All main and interaction effects for genes and proteins of interest are represented for both male and female placentas in addition to all post-hoc analyses performed. Significant effects are indicated by bolded statistics. N/A: not applicable, indicates post-hoc testing not performed due to lack of significant interaction term. 


\begin{tabular}{|c|c|c|}
\hline Assay ID & Gene Symbol & Dye Label \\
\hline Hs00237047_m1 & $Y W H A Z$ & VIC_PL \\
\hline Hs00175415_m1 & FCGRT & FAM-MGB \\
\hline Hs00174081_m1 & FCGR1A & FAM-MGB \\
\hline Hs00234969_m1 & FCGR2A & FAM-MGB \\
\hline Hs00269610_m1 & FCGR2B & FAM-MGB \\
\hline $\mathrm{Hs} 02388314 \mathrm{~m} 1$ & FCGR3A & FAM-MGB \\
\hline $\mathrm{Hs} 04334165 \mathrm{~m} 1$ & FCGR3B & FAM-MGB \\
\hline Hs00234140_m1 & CCL2 & FAM-MGB \\
\hline Hs00174131_m1 & IL6 & FAM-MGB \\
\hline Hs00174128_m1 & TNF & FAM-MGB \\
\hline Hs00171147_m1 & CCL7 & FAM-MGB \\
\hline Hs00242571_m1 & IFI6 & FAM-MGB \\
\hline $\mathrm{Hs} 00171042 \mathrm{~m} 1$ & CXCL10 & FAM-MGB \\
\hline Hs00895608_m1 & $M X 1$ & FAM-MGB \\
\hline $\mathrm{Hs} 00961622 \mathrm{~m} 1$ & IL 10 & FAM-MGB \\
\hline Hs00242943_m1 & OAS1 & FAM-MGB \\
\hline
\end{tabular}

\section{Supplementary Table 4. Taqman gene expression assays used for RTqPCR.}

ThermoFisher Scientific Assay ID, Gene symbol, and color dye for each gene expression assay used. 